\title{
La communication
}

littéraire et ses outils : écrits publics, écrits privés

\section{Bernadette Cabouret (dir.)}

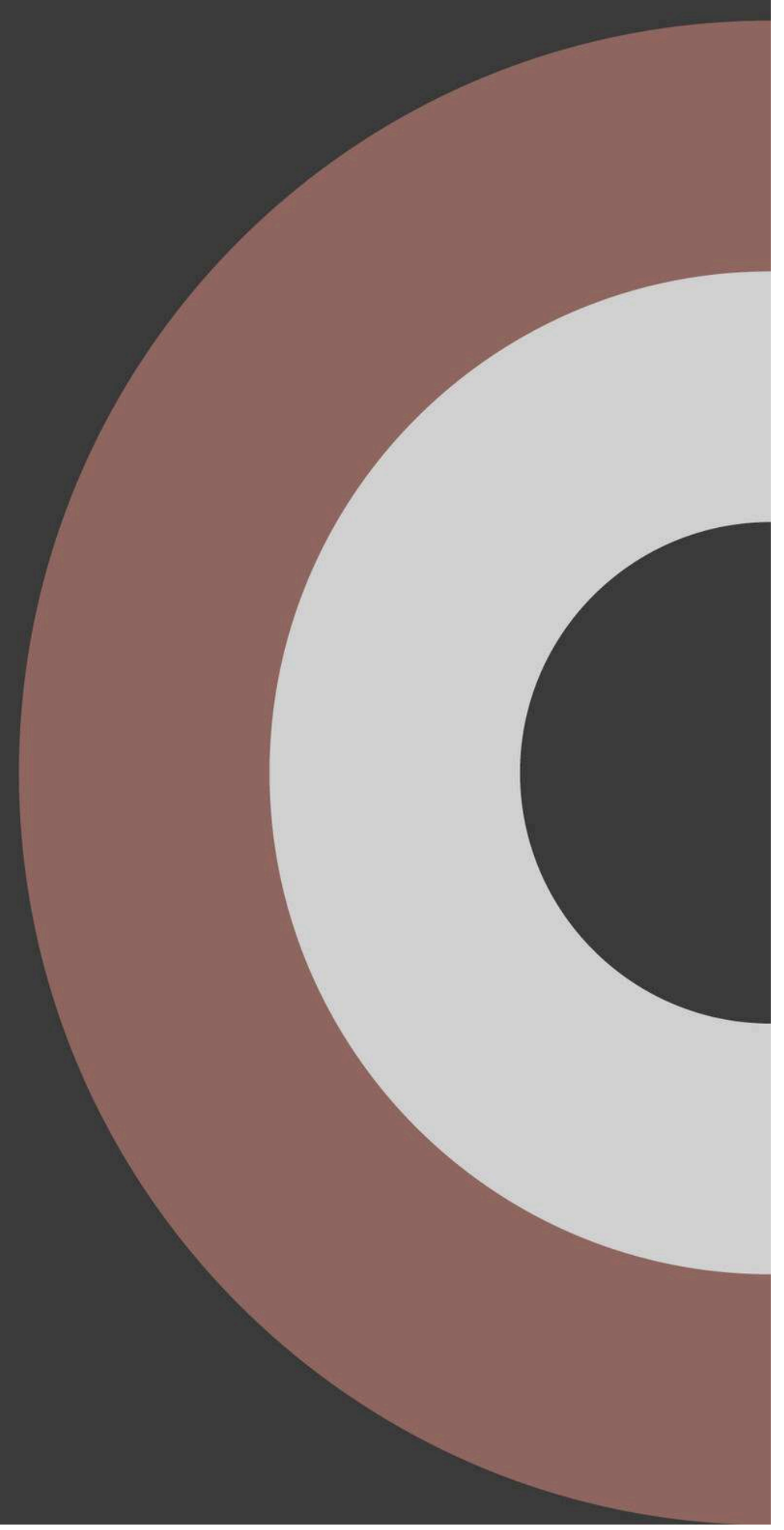




\section{La communication littéraire et ses outils : écrits publics, écrits privés}

\section{Bernadette Cabouret (dir.)}

DOI : $10.4000 /$ books.cths.3605

Éditeur : Éditions du Comité des travaux historiques et scientifiques

Lieu d'édition : Paris

Année d'édition : 2018

Date de mise en ligne : 27 novembre 2018

Collection : Actes des congrès nationaux des sociétés historiques et scientifiques

EAN électronique : 9782735508631

\section{OpenEdition}

Books

https://books.openedition.org

Édition imprimée

Nombre de pages : 141

Référence électronique

CABOURET, Bernadette (dir.). La communication littéraire et ses outils : écrits publics, écrits privés.

Nouvelle édition [en ligne]. Paris : Éditions du Comité des travaux historiques et scientifiques, 2018

(généré le 17 mars 2022). Disponible sur Internet : <http://books.openedition.org/cths/3605>. ISBN :

9782735508631. DOI : https://doi.org/10.4000/books.cths.3605.

(c) Éditions du Comité des travaux historiques et scientifiques, 2018

Conditions d'utilisation :

http://www.openedition.org/6540 


\section{RÉSUMÉS}

À partir d'exemples portant sur divers types d'écrits (dictionnaire, journal, roman, correspondance), cet ouvrage interroge les formes de la communication littéraire dans les sphères publique et privée.

Le Congrès national des sociétés historiques et scientifiques rassemble chaque année universitaires, membres de sociétés savantes et jeunes chercheurs. Ce recueil est issu de travaux présentés lors du $139^{\mathrm{e}}$ Congrès sur le thème « Langages et communication ».

\section{BERNADETTE CABOURET (DIR.)}

Professeur d'histoire romaine à l'université Jean-Moulin - Lyon III.

\section{NOTE DE L'ÉDITEUR}

Les articles de cet ouvrage ont été validés par le comité de lecture des Éditions du Comité des travaux historiques et scientifiques dans le cadre de la publication des actes du $139^{e}$ Congrès national des sociétés historiques et scientifiques tenu à Nîmes en 2014. 
La communication littéraire et ses outils : écrits publics, écrits privés

Sous la direction de

Bernadette Cabouret

Éditions DU CTHS

2018 
Ministère de l'Éducation nationale, de l'Enseignement supérieur et de la Recherche

Congrès national des sociétés historiques et scientifiques 139e, Nîmes, 2014

Collection Actes des congrès nationaux des sociétés historiques et scientifiques Version électronique ISSN 1764-7355 


\section{Introduction}

Bernadette Cabouret

Professeur d'histoire romaine à l'université Jean-Moulin - Lyon III Membre du laboratoire Histoire et sources des mondes antiques (HISOMA, UMR 5189)

Co-responsable du master Patrimoine et musées

Extrait de : CABOURET Bernadette (dir.), La communication littéraire et ses outils : écrits publics, écrits privés, éd. électronique, Paris, Éd. du Comité des travaux historiques et scientifiques (Actes des congrès nationaux des sociétés historiques et scientifiques), 2018.

Quel rapport la littérature, qui est création, expression personnelle, bref qui est une forme d'art, peut-elle entretenir avec la communication ? On s'interrogera, dans cette section du très riche congrès de Nîmes, sur les formes spécifiques que peuvent prendre les langages littéraires et sur la communication qu'ils instaurent. Cela pose la question de l'émetteur du message que suppose toute communication, mais aussi et surtout des récepteurs. La communication littéraire entend-elle transmettre une information ou simplement témoigner de l'expérience, de la sensibilité de son auteur, et cette transmission n'altère-telle pas l'authenticité du témoignage?

L'ensemble des articles ici rassemblés portera sur deux types d'écrits produits en direction du public... ou non : d'une part ceux qui appartiennent au genre romanesque ou lexicographique (dictionnaires), d'autre part des écrits de nature privée, en l'occurrence la correspondance. Ce dernier genre développe un langage propre et répond à des exigences codifiées. Il est l'expression la plus aboutie de la communication qui s'établit à distance, sous forme écrite. L'approche ici proposée porte autant sur le contenu et l'utilisation de la correspondance que sur la forme épistolaire elle-même.

Un des articles porte sur un dictionnaire, un autre sur un journal (le « canard»). Pierrette Bérengier présente l'entreprise de mise à jour du dictionnaire provençal-français de Frédéric Mistral dans une version numérisée, qui enregistre les néologismes (désinences féminines de noms de métiers, qui étaient tous masculins du temps du félibrige...) et surtout fournit une restitution de la prononciation des mots. Ainsi le provençal peut rester une langue vivante et son lexique être sans cesse enrichi pour le plus grand profit des littéraires spécialisés, des linguistes mais aussi des amateurs et amoureux de la langue. L'auteur détaille les difficultés, mais aussi les richesses de l'entreprise. 
Philippe Nieto étudie une forme de communication de type journalistique et qui reste vivace jusqu'au début du xxe siècle, le «canard» (le nom même interroge), feuille d'information non périodique et illustrée. Ce sont les faits divers qui alimentent ces feuilles au style éclectique, comportant notamment ce que l'on appelle des « complaintes », qui mettent le récit du crime en vers.

Restons dans l'univers du crime. L'étude de Louis Bergès aborde un lexique très particulier, celui de la langue verte, en l'occurrence l'argot employé par les personnages de Balzac. Le choix du « réalisme » langagier avait déjà interpellé l'auteur de La Comédie humaine: comment faire entrer en littérature le langage familier de la pègre et de la misère ? L'écrivain en fait certes un marqueur social, dans une peinture crue des réalités de la société, mais aussi un mode d'expression poétique, la poésie «noire » de l'univers du vice et du mal.

Roger Klotz étudie un érudit local du XIXe siècle, qui fut critique musical au sein du Journal des débats et peut apparaitre comme un précurseur du Félibrige ; cette production prouve que la littérature provençale fait bien partie de la littérature française.

Si l'on passe à la correspondance, on s'attache à une forme de communication privée parfois confidentielle - ou semi-privée. Le problème tient cependant au caractère tronqué de cette communication: on ne possède pas toujours les réponses du correspondant, ce qui interroge sur l'apport historique de ce type d'écrit et sur sa valeur informative. Les correspondances étudiées dans cette section sont de différentes natures: les communications ne sont pas seulement informatives, mais aussi affectives et symboliques.

À la fin du XVIII ${ }^{e}$ siècle, la famille Fabre, étudiée par Danièle Bertrand-Fabre, montre sa profonde solidarité par tout un échange de lettres où l'abbé Fabre, curé et romancier occitan, sert la cause de son neveu, Favre de Saint-Castor; il le nourrit de conseils et intervient pour lui auprès des supérieurs du jeune homme. Mais la correspondance dissimule aussi (des détails occultés se révèlent à la faveur d'une étude approfondie), et donc se pose la question de la transparence de la communication épistolaire. C'est bien un genre éminemment complexe.

La correspondance entre deux humanistes et prélats, Georges de Selve, ambassadeur à Rome en 1537-1538, et Georges d'Armagnac, illustre la communication diplomatique (Nicole Lemaitre). C'est le souci de comprendre la complexité des situations et d'essayer 
d'en rendre compte qui anime l'épistolier : le « négocier » permanent semble être en effet le souci premier de l'ambassadeur. Il sait observer et s'informer dans tous les camps : or ces lettres ont été conservées quand s'est constituée l'administration des Affaires étrangères, ce qui dit assez la valeur de communication historique que revêt cette correspondance!

C'est sur des événements historiques tout aussi cruciaux que porte la correspondance de Nicolas de Fontenay, député du tiers état en 1789, écrivant à sa femme restée en Normandie ; les nouvelles politiques côtoient les affaires familiales, évoquant tour à tour les réformes religieuses qui marquent l'œuvre de la Constituante, celles touchant à l'armée ou encore les réformes civiles (Anne Mézin). Ce membre d'une riche famille d'industriels normands s'enthousiasmait à l'idée de participer à la construction d'un monde nouveau. Sa correspondance - privée - saisit ses réactions sur le vif et ne travaille pas le style en vue d'une « publication ». La force de ce témoignage tient dès lors au point de vue personnel donné sur les événements.

Enfin Isabelle Ortega étudie les relations épistolaires qui se nouent entre nobles italiens installés en Morée au XIII siècle et les membres de leur lignage restés en Italie: les échanges, qui portent sur des sujets variés (nouvelles familiales, ambitions politiques, loisirs aristocratiques), créent ainsi un réseau solidaire, mais sans aller jusqu'à faire oublier les tensions. Ainsi les lettres envoyées et reçues constituent-elles une précieuse photographie de la communication interpersonnelle et des moyens adoptés pour faire partager à son correspondant ses sentiments et opinions, comme dans une conversation à distance. Sans le souci de la publicité donnée à son propos, renforcée par toute la force persuasive qu'imprime l'écrit, la correspondance est une forme de communication privilégiée, objet d'étude dont les historiens comme les littéraires peuvent se saisir. 



\title{
$D^{\prime}$ hier à demain : la mise à jour du dictionnaire provençal-français de Frédéric Mistral
}

\author{
Pierrette Bérengier \\ Docteur ès lettres, professeur de mathématiques \\ Majoral du Félibrige (Languedoc), membre du Conseil de l'écrit mistralien \\ Secrétaire générale de l'Association pour les langues et cultures européennes menacées
}

\begin{abstract}
Extrait de : CABOURET Bernadette (dir.), La communication littéraire et ses outils : écrits publics, écrits privés, éd. électronique, Paris, Éd. du Comité des travaux historiques et scientifiques (Actes des congrès nationaux des sociétés historiques et scientifiques), 2018.

Cet article a été validé par le comité de lecture des Éditions du Comité des travaux historiques et scientifiques dans le cadre de la publication des actes du 139 e Congrès national des sociétés historiques et scientifiques tenu à Nîmes en 2014.
\end{abstract}

Jean-Marie Le Clézio, prix Nobel de littérature comme Mistral, parlait de l'impuissance de la parole pour dire notre vie quotidienne. Les mots que nous avons sont incapables de tout dire, et nous n'en aurons jamais assez... Il en est du provençal comme de toutes les langues. C'est pourquoi, voici bientôt huit ans, à l'initiative du majoral Bernard Giély, des Provençaux réunis dans la salle des états généraux de Provence, à Aix, ont créé sous l'égide du Félibrige un Counsèu de l'escrit mistralen (Conseil de l'écrit mistralien : CEM) dans le but premier d'effectuer une mise à jour, une révision et une modernisation $d u$ dictionnaire de Frédéric Mistral, le Tresor dóu Felibrige (TdF), cela afin de pouvoir continuer à employer notre langue dans la vie quotidienne actuelle. Cette décision a été entérinée par le bureau du Félibrige et par le consistoire en date du 25 novembre 2006.

C'est ainsi que le CEM, nouvel organe du Félibrige, avec le soutien du Col'oc (Centre de l'oralité en langue d'oc, à Aix-en-Provence) et pendant un temps du Ciel d'oc (le Centre international de l'écrit en langue d'oc), a pu commencer son travail et se réunir une fois par mois à l'Oustau de Prouvènço, à Aix-en-Provence. Le CEM se veut une sorte d'académie, un conseil culturel, une autorité en matière linguistique pour tous les mistraliens. Il est en liaison permanente, pour le soutien logistique, avec le bureau du Félibrige, support de ce conseil. Le Counsèu de l'Escrit Mistralen peut créer des commissions spécialisées sur des thèmes précis et s'associer à des personnes extérieures. 
Le CEM s'était à l'origine fixé trois objectifs :

- principalement, la numérisation du dictionnaire provençal-français ;

- l'ajout des néologismes validés par le Conseil de l'écrit mistralien (depuis 1884, il n’y avait pas eu de mise à jour - cela fait 133 ans - et aucun apport nouveau, alors que cela se fait pour tous les dictionnaires) ;

- l'enregistrement oral de chaque entrée du TdF et des néologismes.

Il s'agissait de créer un dictionnaire informatique, dans le but de sauvegarder la graphie mistralienne, de conserver sa modernité et de mettre à jour de façon permanente le Tresor dóu Felibrige, en associant ceux que j'ose appeler les «savants » (grammairiens, écrivains, linguistes) à ceux qui pratiquent réellement et quotidiennement la langue. Mais il est très vite apparu que cela ne suffisait pas. En effet, nous nous sommes aperçus que le $T d F$ devait lui-même être corrigé, ce qui s'est ajouté à nos objectifs.

Nous avons prévu d'éditer une version papier du dictionnaire original (simplement expurgée de quelques coquilles ou fautes d'impression) et une édition du Tresor dóu Felibrige modernisé, à jour des néologismes validés par le Conseil de l'écrit mistralien. Le but final est de réaliser une nouvelle édition numérique complétée du Tresor dóu Felibrige, avec un moteur de recherche permettant de trouver les mots, de les lire et de les écouter s'il en est besoin.

\section{La numérisation}

Concrètement, le premier travail fut la numérisation du TdF. Ce travail est aujourd'hui terminé. Le texte numérisé est bien sûr lu et relu par les membres du CEM, qui doivent corriger le texte obtenu, souvent mal reconnu par le scanner. Il faut mettre des majuscules à la place de minuscules et vice-versa, corriger les sauts de ligne manquants ou en trop, corriger les lettres et accents erronés. Pour cela, le travail est réparti par équipes.

\section{La création de mots nouveaux}

Le CEM a essuyé une averse incroyable de reproches lors de sa naissance : réflexions des mécontents et réactions négatives en tous genres. La critique ressassait que le provençal n'a pas besoin de mots nouveaux, qui ne servent à rien et que l'on n'emploie jamais. À croire que les Provençaux n'ont pas besoin des mots du vocabulaire international, ne voyagent pas, n'utilisent pas Internet, vivent dans une sorte de Provence musée, isolée de 
toute influence moderne. Il est pourtant nécessaire de nommer une réalité ou un concept nouveau comme télévision, ordinateur, hélicoptère, scooter ou d'autres réalités scientifiques ou médicales, par exemple.

La terminologie scientifique ne peut guère s'accommoder de désignations populaires. Nous devons remplacer cette façon de dire par des termes formés sur le grec ou le latin. Il est difficile d'employer le même mot, boufigo par exemple, pour une ampoule de médicament, une ampoule derrière le talon, un phlyctène, un aphte, un bourgeon, un abcès, un furoncle, etc.

On doit également admettre que la langue n'est pas seulement fonctionnelle : la vie n'est pas faite que d'utile, il y a aussi le besoin intérieur, personnel, le plaisir. Notre langue doit permettre à chacun de s'exprimer dans n'importe quelle situation s'il le désire, en famille, entre amis, etc. N'oublions pas non plus les écrivains, qui peuvent avoir besoin des termes les plus nouveaux pour leurs romans, les articles de journaux et autres essais.

Parmi les mécontents, il y avait aussi - et il y a sans doute toujours - , ceux qui se disent les «vrais mistraliens », pour qui Frédéric Mistral est un prophète et pour qui les mots qu'il nous a légués suffisent. Nous continuerions donc de nous promener en vélocipède et nous ignorerions les avions - que Mistral connaissait pourtant déjà, puisqu'un aviateur était allé le saluer en atterrissant à Maillane !

Le provençal, comme toutes les langues vivantes, s'enrichit sans cesse de nouveaux termes. Il faut voir là sa capacité à s'adapter à l'évolution de la société, des techniques et de la technologie. En réalité, les termes se créent dans toutes sortes de domaines de la vie quotidienne pour répondre aux besoins du monde actuel. Le dictionnaire s'enrichit pour nommer et désigner de nouvelles réalités.

Ces créations lexicales se font de maintes façons, comme pour toutes les langues :

- par dérivation ;

- par composition ;

- par raccourcissement ou abréviation ;

- à partir de sigles ;

- par emprunt à d'autres langues. 


\section{La dérivation}

Pour former un mot nouveau par dérivation, on ajoute un préfixe ou un suffixe à un mot ou un radical déjà attesté dans le $T d F$.

Par exemple : loucau >loucalisa > loucalisacioun $>$ desloucalisacioun.

Mistral a souvent donné un ou plusieurs mots d'une série, sans noter de façon exhaustive tous les dérivés. Nous les ajoutons, mais on ne peut pas toujours parler de vrais néologismes. Il s'agit, dans ce cas, simplement de mots manquants mais qui devaient exister à l'époque de Mistral, ou qui existent depuis longtemps dans la langue parlée.

\section{La composition}

La composition est une forme de création lexicale très employée dans les langages techniques et scientifiques, mais aussi dans la vie de tous les jours. On associe des éléments qui représentent une unité de sens (souvent d'origine grecque ou latine) entre eux ou avec un mot déjà existant.

- ludo- (jeu) + -tèco (réceptacle) > ludoutèco (service de prêt de jeux).

- giga- (multiplié par 109) + óutet > gigaóutet (unité de capacité de mémoire en informatique de 1 milliard d'octets).

Les mots-valises, comme Internèt + astrounaute > internaute, se forment en provençal comme en français, seule la prononciation différant.

\section{Le raccourcissement}

Le raccourcissement est une façon de créer un mot nouveau en supprimant une ou plusieurs syllabes d'un mot trop long - à ne pas confondre avec les abréviations, qui se lisent comme si le mot était écrit entier.

- un aristoucrato $>$ un aristò.

- un autoubus $>$ un bus.

- Madamisello > Damisello.

- cinematougrafe > cinema > ciné.

\section{La création à partir de sigles}

De plus en plus de sigles passent dans le langage actuel. Ils sont formés par la première lettre de chacun des mots ou bien des éléments qui composent l'expression.

- lou TGV (trin à grando vitesso), reste le même en provençal. 
- la BD (bando dessinado), etc.

Des sigles et acronymes peuvent servir de base, comme en français, à la formation d'autres mots par dérivation :

- RMI > eremisto (vo Rmisto).

$-\mathrm{BD}>$ bedefilo.

\section{L'emprunt à d'autres langues}

Le provençal, comme toutes les langues, emprunte des mots nouveaux à des langues étrangères. De nos jours, les emprunts viennent surtout de l'anglais. Certains sont utiles, d'autres non. Le jogging, qui est simplement de la marche ou de la course à pied, est inutile. Nous avons les mots nécessaires. En revanche, pour le vêtement, nous sommes bien obligés de dire «jogging », qu'on peut orthographier joguin ou jouguin pour mieux l'adapter à la phonétique provençale. Un «zoom » ne se rapproche guère de notre façon d'écrire, mais le mot se prononce [zum] et on peut valider zoum ou zoume en provençal. Au contraire, le français «building » se traduit facilement par grato-cèu; nous n'avons pas besoin de créer un «monstre ». On sait aussi qu'il y a des mots qui ne font que passer et changent avec la mode. «Dancing " signifie "discothèque », mais on a besoin du mot si l'on ne veut pas faire d'anachronisme dans un récit.

Le plus amusant a trait à des mots que nous avions oubliés et qui reviennent maintenant avec une identité anglaise. Lou bóuget, la bóugeto, un petit sac ou une petite bourse. Ce mot serait parti d'Aquitaine au temps de l'occupation anglaise pour devenir budget de l'autre côté de la Manche et nous revenir dans le TdF de Mistral en buget. Et maintenant nous l'avons comme base des néologismes bugeta, bugetàri, bugetisa, bugetisacioun et bugetivore.

Par la force des choses, le français est pour nous la référence en matière de néologismes. Nous sommes pratiquement obligés de nous aligner sur la façon de parler française. Nous l'avons vu, par exemple, pour l'ordinateur. Le provençal a le verbe coumputa. Il est clair que le computer américain aurait pu se dire coumputaire ou coumputadou, mais on a dû coller au français avec ourdinatour formé sur « ordinateur ». Le mot était déjà socialisé, le CEM l'a validé.

Les emprunts ne sont pas nouveaux : il y a déjà longtemps que les mots arabes azzahr, sukkar, kharrô̂ba avaient donné l'asard, lou sucre, lou carròbi, etc. Aujourd'hui, les 
circulations étant facilitées, des emprunts se font dans des langues plus lointaines. Le japonais nous fournit par exemple kimonò, aïkidò ou judò, facilement « provençalisables ».

Bien sûr, tant que faire se peut, nous évitons les emprunts, surtout les anglicismes qui nous envahissent, et nous les remplaçons par des termes plus provençaux.

L'ouvrage français de référence est le Grand Robert de la langue française (version en ligne). Les membres du CEM, chargés à chaque fois d'une tranche de vingt pages du TdF, les comparent avec le Grand Robert pour recenser les termes qui manquent. Ils proposent une création, parfois un choix et nous renvoient les résultats de leur travail. Nous sommes deux à superviser, à accepter ou rejeter ce qui nous paraît de toute évidence mal formé, à compléter ce qui a pu être oublié, à rectifier et homogénéiser la présentation. Pour cela nous nous basons aussi sur des dictionnaires français-langue d'oc comme Piat ${ }^{1}$, Xavier de Fourvières $^{2}$, Jules Coupier ${ }^{3}$ etc., puis nous regardons la façon dont les autres langues romanes ont formé les mêmes mots, en particulier le catalan, mais aussi l'italien, l'espagnol ou le portugais.

Lorsque tout est au point, nous l'envoyons à tous les membres pour vérification. Nous récoltons alors des remarques, que nous centralisons. Là encore, nous en acceptons ou rejetons certaines, et une fois par mois nous présentons le résultat à l'équipe réunie à Aixen-Provence pour une dernière discussion et une validation définitive. Désormais les collaborateurs du CEM ont pris l'habitude des méthodes de travail et se conforment mieux à la présentation demandée, mais nous devons toujours corriger, compléter, et malgré tout, le jour de la réunion, nous nous apercevons qu'il y a encore quelques fautes ou erreurs qui ont échappé à la relecture. Nous avons fini de valider les néologismes et les ajouts de mots dérivés des 1196 pages du tome 1 du Tresor dóu Felibrige et nous en sommes à la lettre $\mathrm{J}$ du tome 2 . Nous en validons des centaines à chaque réunion.

\section{L'enregistrement oral}

Outre le texte du dictionnaire, la version informatisée donnera le son des mots. En cliquant sur le mot, on entendra la façon dont il doit être prononcé.

\footnotetext{
${ }^{1}$ L. Piat, Dictionnaire français-occitanien.

${ }^{2} \mathrm{X}$. de Fourvières, Lou pichot tresor : dictionnaire provençal.

${ }^{3}$ J. Coupier, Dictionnaire français-provençal.
} 
L'enregistrement est fait au Col'Oc, à Aix-en-Provence, en collaboration avec le Cep d'Oc. Chaque semaine, on y lit des centaines de mots devant un micro avec une technicienne qui fait tous les réglages. Chaque mot est dit par une voix de femme puis par une voix d'homme.

\section{La modernisation du corpus de Frédéric Mistral}

Nous nous sommes heurtés à certains problèmes de graphie dans le Tresor dóu Felibrige, et le CEM s'est donc proposé d'améliorer quelques usages graphiques, trop souvent gênants pour les écoliers et les étudiants d'aujourd'hui qui n'entendent pas la langue chez eux.

Nous avons aussi rencontré différents problèmes: erreurs, oublis, etc. Par exemple, Mistral donnait souvent la définition d'un mot sans en indiquer l'équivalent français. Nous devons ajouter cet équivalent afin de rendre possible une prochaine recherche informatique. Mistral vivait avec son temps et souvent les mots (en particulier ceux désignant un métier, mais pas seulement) n'apparaissent qu'au masculin. Nous devons donc ajouter les désinences féminines. Le Tresor dóu Felibrige comportait aussi des erreurs de genre, des oublis, des fautes d'impression et les séries à compléter.

Si le CEM garde pour but essentiel de fixer les règles qui concernent la façon d'écrire notre langue en graphie mistralienne, c'est-à-dire de valider ou de créer des mots nouveaux adaptés au monde d'aujourd'hui et de faciliter la langue parlée en employant cette graphie, au fur et à mesure d'autres objectifs se sont imposés. Comme vous avez pu le constater, c'est bien le Tresor dóu Felibrige de Mistral qui reste le centre de nos préoccupations. Nous ne modifions rien, sinon quelques erreurs manifestes, nous n'ôtons rien ; et tout ce que nous ajoutons est bien sûr clairement signalé. Notre souhait est que ce travail donne à tous l'idée d'une langue vivante, moderne et en perpétuelle évolution, telle que la considérait déjà Frédéric Mistral.

\section{Bibliographie}

COUPIER Jules, Dictionnaire français-provençal, Aix-en-Provence, association Dictionnaire provençal-français, 1995. 
FOURVIÈRES Xavier de, Lou pichot tresor : dictionnaire provençal, Raphèles-les-Arles, CPM, 1987 (1902).

MiSTRAL Frédéric, Tresor dóu Felibrige ou Dictionnaire provençal-français embrassant les divers dialectes de la langue d'oc moderne, Aix-en-Provence, Ramondet-Aubin, 2 vol., 18781886.

PIAT Louis, Dictionnaire français-occitanien donnant l'équivalent des mots français dans tous les dialectes de la langue d'oc moderne, Aix-en-Provence, Edicioun Ramoun Berenguié, 1970 (1893).

\footnotetext{
Résumé

Depuis sept ans, le Conseil de l'écrit mistralien (CEM), sous l'égide du Félibrige, l'association créée par Frédéric Mistral, travaille à la mise à jour du Tresor dóu Felibrige, le dictionnaire provençal-français publié par Frédéric Mistral en 1879. Il s'agissait, au départ, de créer et d'ajouter des néologismes au dictionnaire ; mais bien vite il apparut qu'il fallait aussi ajouter certains mots plus anciens et cependant absents du Tresor dóu Felibrige, compléter certaines familles de mots par les dérivés, corriger des approximations et des erreurs. Le manque d'homogénéité de certaines transcriptions graphiques a aussi obligé à réfléchir sur certaines règles, quitte à devoir les modifier ou les compléter. Il s'agit donc d'un travail de longue haleine. Le but du CEM est d'élaborer une nouvelle version imprimée du Tresor dóu Felibrige, mais surtout une version numérique en ligne permettant à tous, en particulier aux étudiants et autres apprenants, de l'utiliser aussi comme un dictionnaire français-provençal et d'écouter la prononciation de chaque mot.
} 


\section{L'éclectisme du style dans le « canard » au XIX” siècle}

Philippe Nieto

Conservateur aux Archives nationales

Extrait de : CABOURET Bernadette (dir.), La communication littéraire et ses outils : écrits publics, écrits privés, éd. électronique, Paris, Éd. du Comité des travaux historiques et scientifiques (Actes des congrès nationaux des sociétés historiques et scientifiques), 2018.

Cet article a été validé par le comité de lecture des Éditions du Comité des travaux historiques et scientifiques dans le cadre de la publication des actes du 139 e Congrès national des sociétés historiques et scientifiques tenu à Nîmes en 2014.

L'intérêt de l'imprimé pour la diffusion de «nouvelles » est apparu très tôt. Le premier recensé pourrait être un feuillet vendu en 1488, relatant la prise de Fougères par les troupes françaises, très peu de temps après l'événement lui-même ${ }^{1}$. Très tôt, également, les informations à caractère politique, comme les batailles, les couronnements, les entrées de ville, etc., doivent laisser une place grandissante à ce que l'on appellera plus tard en France des «faits divers »: catastrophes, accidents spectaculaires, crimes, phénomènes fabuleux, naissance de monstres...

Ces feuilles imprimées, tirées à l'occasion d'un événement, ont été tardivement appelées «occasionnels ». C'est un terme générique relevant plutôt de la langue savante et du vocabulaire propre aux historiens du livre, ou plus exactement «de l'écrit »; car ces occasionnels ne sont généralement pas des «livres». Leur aspect matériel ${ }^{2}$ les fait ressembler aux livrets de colportage, desquels ils ne se distinguent pas toujours. Quant à leur nom, il prend tout son sens rapporté à une autre catégorie d'imprimés d'information, les «périodiques", publiés, comme leur nom l'indique, avec une certaine régularité. Dans le courant du XIXe siècle, ces occasionnels sont plutôt appelés des « canards ».

Contre toute attente, le canard a peu intéressé les historiens. Beaucoup moins que la littérature de colportage, souvent appelée «bibliothèque bleue», en référence aux

\footnotetext{
${ }^{1} \mathrm{~J}$.-P. Seguin, Nouvelles à sensation, canards du XIXe siècle, p. 9.

2 Ibid., n. p. : «Jusqu'en 1631, leur format conserve les dimensions moyennes de $10 \times 16,5 \mathrm{~cm}$; les brochures ont de six à seize pages. Après 1631, la plupart adoptent le format petit in-4 $4^{\circ}$ des gazettes; le nombre des pages imprimées varie alors entre deux et quatre. »
} 
impressions troyennes. Dans le domaine français, on ne peut guère citer que deux noms d'historiens : Jean-Pierre Seguin et Maurice Lever.

L'abondante production de Jean-Pierre Seguin se distingue par l'exhaustivité et la qualité de ses recensements d'occasionnels. Ses ouvrages et articles font encore référence ; mais il faut reconnaître que ce sont finalement davantage des œuvres d'érudition ${ }^{3}$, de bibliophilie, ou des publications de sources ${ }^{4}$ que des analyses historiques poussées. Quant à Maurice Lever, son seul et unique ouvrage sur la question est une anthologie d'occasionnels particulièrement bien choisis, augmentée d'une préface remarquable, mais qui ne fait qu'introduire le sujet ${ }^{5}$. Pour le XIXe siècle français, la seule véritable étude historique complète sur la question des occasionnels est celle de Thomas Cragin, professeur associé au Muhlenberg College, en Pennsylvanie ${ }^{6}$.

\section{À l'affût du canard}

Sont plutôt appelés «canards » les occasionnels du XIXe siècle. Mais cette convention est elle-même bousculée par Jean-Pierre Seguin, qui sous-titre l'un de ses ouvrages: « 517 canards imprimés entre 1529 et $1631^{7}$ ». Nous avons choisi de présenter le canard sous sa forme tardive, celle qui s'impose à partir des années 1810, en effectuant quelques plongées dans les époques antérieures pour mettre en relief ruptures et continuités de style : feuille unique de moyen ou grand format, tantôt imprimée sur le seul recto, tantôt recto-verso, parfois pliée, l'illustration occupant une place importante; diffusion principalement urbaine. Par ces caractéristiques, notre «canard» se distingue de la production imprimée diffusée ordinairement par le colportage : feuilles pliées en cahiers aboutissant à des livrets de formats plus petits, pagination plus importante, place réduite de l'illustration.

Sur l'origine du terme même de «canard» pour désigner ce type d'occasionnel, certainement issu de l'argot des imprimeurs, les propositions de Balzac, Nerval et

\footnotetext{
3 J.-P. Seguin, L'information en France de Louis XII à Henri II, et : L'information en France avant le périodique.

${ }^{4} \mathrm{~J}$.-P. Seguin, Nouvelles à sensation, et : Canards du siècle passé.

${ }^{5} \mathrm{M}$. Lever, Canards sanglants : naissance $d u$ fait divers.

${ }^{6} \mathrm{~T}$. Cragin, Murder in Parisian streets : manufacturing crime an justice in the popular press.

7 J.-P. Seguin, L'information en France avant le périodique.
} 
d'autres, rapportées par Jean-Pierre Seguin, se révèlent plutôt floues ${ }^{8}$. Elles concordent sur un point: un certain mépris pour le contenu des informations, traitées de « racontars», «billevesées", de «fait qui a l'air d'être vrai mais qu'on invente pour relever les faits-Paris ${ }^{9}$ quand ils sont pâles », de "nouvelle quelquefois vraie, toujours exagérée, souvent fausse $\mathrm{e}^{10}$ ». Nous retrouvons presque mot pour mot l'appréciation de Pierre de L'Estoile, grand amateur d'occasionnels et de placards, occasionnels qu'il égratigne pourtant en les qualifiant de «balivernes", «fadezes", «fables", « sornettes ${ }^{11} » \ldots$

Mais c'est surtout l'objet désigné par ce terme qui reste plutôt imprécis. Le canard est-il la nouvelle elle-même? L'imprimé qui rapporte cette information? Le personnage qui la vend dans la rue, en criant, ou plutôt caquetant «comme un canard»? Sans être dépourvu d'ambiguïtés, l'exposé le plus clair à ce sujet se trouve dans les Français peints par eux-mêmes ${ }^{12}$. Le terme y désigne à la fois la feuille, imprimée par un «canardier », et le crieur lui-même. Selon cette source, en 1841, le nombre de lieux de production de canards est limité à deux cents pour Paris, et « on ne peut en créer de nouveau sans extinction ou démission du titulaire de la charge ${ }^{13} »$. Le canardier est responsable de sa publication ; il porte son manuscrit au visa de la préfecture de police, section des mœurs, et reçoit son permis d'imprimer. Les crieurs lui achètent les canards et se chargent de les vendre. Ils sont achetés à la centaine, au prix de 1,50 F, et revendus 5 centimes l'exemplaire. Un bon crieur peut en placer ainsi mille par jour ${ }^{14}$.

Comme on le voit, la diffusion du canard est considérable jusqu'à la fin du siècle, en dépit de la concurrence croissante du périodique, en particulier du «journal à 5 sous », créé dans le sillage du Petit Journal fondé en 1863 par Polydore Millaud. Cette ténacité de l'occasionnel a sans doute été mal jugée par certains historiens, comme Jean-Pierre Seguin ou Michelle Perrot qui écrit, à propos de l'affaire Troppmann, fin 1869, qu'elle «suscite

\footnotetext{
8 J.-P. Seguin, Nouvelles à sensation, p. 23-26.

9 « Faits-Paris » : nous dirions aujourd'hui : faits divers.

${ }^{10} \mathrm{G}$. de Nerval, Histoire véridique du canard et autres textes, p. 118.

${ }^{11}$ P. de L'Estoile, Registre-journal du règne de Henri III (1575-1589).

${ }^{12} \mathrm{G}$. Delmas, Les Français peints par eux-mêmes, t. 3, p. 44 sq.

${ }^{13}$ Ibid., p. 49.

14 Ibid., p. 47.
} 
une ultime gerbe de canards ${ }^{15} »$. La vitalité de ce type d'imprimé est encore attestée tard dans le siècle, et le canard ne meurt vraiment qu'à partir du premier quart du XXe siècle. On en trouve encore en 1938, publiés à l'occasion de l'affaire Weidmann ${ }^{16}$, une affaire qui, pour employer un cliché très parlant, « défraie la chronique ».

Gaëtan Delmas, dans Les Français peints par eux-mêmes, distingue trois sortes de canards : politique, criminel et scandaleux. La troisième catégorie apparaît un peu mystérieuse : Delmas suggère qu'elle plaît particulièrement aux femmes. Peut être s'agit-il d'une forme ancienne de ce que nous placerions aujourd'hui dans la presse «pipole ». La politique en 1841 est un sujet éminemment délicat. Reste la dernière catégorie, la plus intéressante en termes de tirage puisque, à en croire l'auteur :

«Le canard criminel fait les délices du peuple parisien, qui le gobe avec un plaisir toujours nouveau; aussi le crieur le met-il à toutes les sauces. Cependant, depuis quelques années, les amateurs se montrent plus difficiles, il leur faut un bon crime avec circonstances aggravantes, un crime bien conditionné, un crime $n^{0} 1$, sans cela, bouillon complet ${ }^{17}$. »

Nous prendrons donc comme objet d'analyse le «canard criminel», qui offre deux atouts: un contenu plutôt homogène, voire répétitif, un corpus encore suffisamment abondant, en dépit de pertes considérables dues au manque d'intérêt manifesté pour les conserver.

Prenons deux exemples de canards : le premier, d'un grand format très courant, imprimé sur le seul recto, issu de l'imprimerie Gambin, à Paris, daté de la fin de 1835 (fig. 1) ; le second, plus tardif - dépôt légal 1876 -, sur une feuille recto-verso, imprimé par Claverie et Baudet (fig. 2).

Ces deux pièces sont composées de la même manière, avec un titre en gros caractères, surmontant une image occupant presque la moitié de la feuille, sous laquelle figurent un texte qui développe le titre, et une complainte. La quasi-totalité des canards se présentent selon cette formule. Il faut maintenant procéder à l'« autopsie » du corps de l'animal, en le démembrant de la tête aux palmes.

\footnotetext{
${ }^{15}$ M. Perrot, Les ombres de l'histoire, p. 292-293.

16 « Le crime du monstre », Paris, L. Cotté éd.

17 G. Delmas, Les Français peints par eux-mêmes, t. 3, p. 49. Les italiques sont de l'auteur.
} 


\section{Autopsie du canard : le titre}

Nous désignerons sous le nom de «titre » un ensemble de mots placés en chef du ou des feuillets, composés dans un corps de caractères plus grand, en regroupant titre proprement dit et sous-titre, quand il existe.

Le canard de chez Gambin (fig. 1) montre parfaitement la structure d'un en-tête de canard du milieu du XIX siècle : un titre en lettres capitales, qui attire le regard et attise l'appétit du lecteur - «Condamnation et exécution »-, une suite du titre apportant des bribes de détails destinés à susciter sa gourmandise.

Dans l'exemplaire recto-verso plus tardif (fig. 2), le lecteur est également happé par un titre plein de promesses, qui joue moins sur le registre de l'horreur que sur celui de l'énigme et de la révélation - «crime mystérieux »-, le reste de la phrase étant rejeté en caractères maigres. Un déterminant, «le », place ce « crime mystérieux » dans la catégorie des grands mystères dont tout le monde parle; un qualificatif de lieu est destiné non seulement à situer et nommer ce crime, mais également à le placer dans la proximité du lecteur, comme pour dire : «C'est arrivé près de chez vous ».

Un en-tête composé dans deux corps de caractères différents - titre, suite de titre - est typique des imprimés occasionnels. Dans les plus anciens, il s'agit d'un texte assez long, purement descriptif, amorcé par un ou plusieurs mots mis en relief (fig. 3 et 4). Mais on voit apparaître progressivement, sur certaines feuilles (fig.5), un vocabulaire plus accrocheur - «misérable », « remarquable »-, assorti d'un grossissement du titre encore plus appuyé.

Le canard du XIXe siècle sait admirablement décliner une échelle de corps de caractères et de graisses, et parfaitement épingler des termes frappants et intrigants pour construire des titres attractifs (fig. 6). Le canardier puise dans un lexique très codé et très attendu par le lectorat. Dans ce lexique se côtoient des mots destinés à provoquer le frisson « horrible assassinat», "crime affreux», «tortures effroyables», "femme coupée en morceaux », «suites funestes ", « le petit martyr alsacien »... - et des termes frisant la démesure - «événement extraordinaire » (fig. 6), «aventure singulière »... La suite du titre, loin de résumer avec honnêteté et brièveté l'affaire traitée par l'occasionnel, est surtout prétexte à allécher le chaland en lui promettant une succession de détails 
« curieux », « intéressants » (fig. 6), « horribles » (fig. 10), « affreux», « épouvantables », « exacts » ou « circonstanciés »...

Dans les canards les plus tardifs, la combinaison titre - sous-titre évolue. On choisit un titre plus personnalisé, moins passe-partout, moins interchangeable, qui gagne au final en expressivité (fig. 2). C'est à l'illustration, plus vivante, plus descriptive, que revient le rôle de sous-titre, qui attire le regard vers les « détails » qui seront développés dans le texte.

\section{Autopsie du canard : l'image}

L'illustration est l'un des éléments apparemment les plus indispensables au canard. Pourtant, son apparition est tardive, et beaucoup d'occasionnels ne sont pas vraiment illustrés avant le début du XIXe siècle. Si l'importance de l'image dans l'impact de l'occasionnel sur le public a très tôt été perçue, son utilisation semble avoir été freinée par des considérations techniques et économiques. Graver une planche à partir d'un dessin est un long et délicat travail, qui coûte cher. Il est difficile d'associer deux éléments essentiels : rapidité d'exécution et d'impression, prix de vente plutôt bas.

C'est ce qui explique l'utilisation très courante de bois de réemploi, surtout quand il ne $\mathrm{s}^{\prime}$ agissait pas de grandes affaires criminelles pour lesquelles une commande spécifique auprès d'un graveur pouvait être rentable. Jusqu'à l'aube du XIXe siècle, quand les occasionnels sont illustrés, c'est le plus souvent avec des images passe-partout, inlassablement réutilisées, parfois découpées et combinées, pour répondre à peu près au déroulé de l'affaire citée. Quoi de plus anonyme qu'une scène montrant un supplicié roué vif (fig. 4 et 5)? L'image stéréotypée du châtiment est parfois combinée avec une évocation très approximative du crime lui-même, à partir de bois susceptibles d'illustrer un peu n'importe quoi (fig. 4).

La technique paresseuse et peu coûteuse du réemploi est utilisée encore au XIXe siècle, même tardivement. Les images sont parfois totalement fantaisistes, comme en témoigne ce canard, que l'on peut dater des années 1830 ou 1840, sobrement titré «Nouvelles du jour »-sans que l'on précise lequel... (fig. 7). Le choix des vignettes qui figurent sur cette feuille paraît plutôt mystérieux; deux décapitations sont visiblement tirées de vies de saints, une autre semble montrer un roi endormi... Toutes, en dehors des trois petits personnages en haut à gauche, sont plutôt anciennes et gravées au XVIe siècle, ou retaillées à partir de modèles du XVIe siècle. Il est intéressant de noter que la scène de 
décapitation d'une sainte, en haut à droite, a déjà été repérée par nous sur la couverture en papier bleu d'un livret de colportage intitulé Histoire de la vie et du procès du fameux Louis-Dominique Cartouche, imprimé chez Charles-Louis Baudot ${ }^{18}$, qui fut actif entre 1830 et 1848 à Troyes.

Le plus souvent, le canardier est plus subtil, et le réemploi ne peut être mis en évidence qu'en comparant plusieurs feuilles entre elles (fig. 8). L'utilisation de bois de réemploi n'était pas toujours facile car plusieurs mois, voire plusieurs années pouvaient séparer deux impressions, et les occasionnels avaient une espérance de vie plutôt brève puisque peu de lecteurs les conservaient après lecture - comme les journaux et les tracts publicitaires d'aujourd'hui.

Ces pratiques astucieuses de certains canardiers se font ensuite de plus en plus rares. Les lecteurs sont plus nombreux, plus exigeants, moins crédules, la concurrence plus farouche entre les imprimeurs, la menace des journaux illustrés plus redoutable. Si l'on ajoute les progrès des techniques de gravure et d'impression et une répartition des coûts de fabrication sur un plus grand nombre d'exemplaires, on comprend pourquoi l'image dans les canards gagne progressivement en qualité informationnelle, décrivant un fait divers précis et devenant une illustration à usage unique, non réemployable.

L'analyse des illustrations d'occasionnels sur le long terme montre que s'effectue un déplacement du sujet représenté : le supplice cède la place à l'image du crime, une image choisie avec soin, à la fois pour résumer et pour intriguer - le moment-clé, celui où tout bascule, ramassé en une seule image (fig. 6, 9, 10); décomposition en épisodes scabreux (fig. 1), procédé que la presse illustrée transposera plus tard en véritable bande dessinée ; découverte du cadavre. Mais on trouve également des illustrations à mi-chemin entre ces deux styles, l'étape intermédiaire étant l'image de l'échafaud comme horizon final du crime (fig. $8 \mathrm{~b}$ et $8 \mathrm{c}$ ).

Cette évolution est également lisible dans le titre lui-même (fig. 1, 6 et 2). Les plus anciens titres mentionnent toujours la peine subie par le criminel, avec des détails; les plus récents donnent plutôt les faits eux-mêmes - également avec des détails.

${ }^{18}$ Voir P. Nieto, «La question de l'image dans le fait divers criminel », p. 203, fig 2. 
L'illustrateur doit donc camper le crime, les protagonistes et le lieu des événements en fonction des informations contenues dans le texte. Pour les portraits, le plus souvent des assassins, parfois de la victime, le procédé généralement utilisé est celui des vignettes entourant la scène du meurtre (fig. 9 et 10), réalisées vraisemblablement à partir des photos de l'identité judiciaire ou de dessins d'audience. Cette disposition de portraits des acteurs du drame associés à la représentation de l'acte criminel va devenir une habile convention, y compris dans la presse périodique illustrée, et ce jusqu'à nos jours.

Certains illustrateurs ajoutent des éléments informatifs supplémentaires, un plan des lieux - procédé que l'on retrouve à la même époque dans le roman judiciaire, notamment chez Gaboriau - ou la « maison du crime » (fig. 10).

À partir du moment où l'image décrit le fait divers, au lieu de simplement l'évoquer, on ouvre la possibilité de transférer les informations contenues dans les longs sous-titres des anciens occasionnels vers l'illustration. L'image fait office de bandeau d'appel incitant à lire le texte ; le titre se réduit à ses éléments expressifs, des mots-clés en caractères gras destinés à attirer le lecteur, et à des données de localisation et de personnalisation exigées par la clientèle : lieu du crime, nom des assassins...

\section{Autopsie du canard: le texte narratif}

Le texte est censé raconter le fait divers et répondre aux promesses figurant dans le titre, le sous-titre ou l'image, laquelle, comme toute image, a besoin d'une légende pour être tout à fait comprise. La disparition du sous-titre, qui faisait office de table des matières, conduit parfois à insérer dans le texte des intertitres, dont la formulation attrayante en rappelle les termes (fig. 2).

Si les feuilles diffusées aux XVII et XVIII siècles à l'occasion d'exécutions, et sans doute la plupart du temps sur les lieux mêmes de l'exécution (fig. 3, 4 et 5), portaient une date précise, beaucoup d'autres occasionnels avaient la fâcheuse habitude de situer les faits rapportés dans un temps flou; ce qui permettait de réimprimer le même texte à plusieurs mois d'écart en le faisant passer pour une nouveauté. Cette pratique est encore présente dans les canards du XIXe siècle. Certains se placent hors du temps (fig. 7), d'autres ne mentionnent pas l'année. De même que pour le titre et l'illustration, l'évolution du canard tend à dater précisément les faits divers représentés. 
Le texte suit une évolution parallèle à celle du titre et du sujet de l'illustration. Dans les occasionnels les plus anciens, la description détaillée du supplice domine (fig. 3 et 4). Dans le canard du XIXe siècle, c'est le récit du crime qui occupe la place la plus importante, la condamnation et l'exécution n'étant souvent mentionnées que comme des suites logiques de l'acte criminel, voire totalement passées sous silence. Le style du texte adopte un ton fréquemment proche du récit romanesque - vif, dialogué, détaillé sur des points mineurs... - rappelant le roman judiciaire : goût du mystère, du rebondissement, parfois détails de l'enquête.

\section{Autopsie du canard : la complainte}

Dernier élément récurrent du canard au XIXe siècle, la « complainte ». La complainte est un mode de communication très ancien, antérieur même à l'invention de l'imprimerie. Il s'agit d'un texte en vers assez long mais formé de courtes strophes et, surtout, destiné à être chanté. Ils existait avant la Révolution des chanteurs publics, certains spécialisés dans la complainte criminelle. La profession était réglementée ; à Paris, ils officiaient généralement au Pont-Neuf ${ }^{19}$.

Pour qu'elles puissent être chantées immédiatement, souvent au moment même de l'événement - par exemple l'exécution d'un criminel - ces complaintes ne sont que rarement, et en principe jamais, des créations musicales. Elles sont chantées sur des airs connus du chanteur et des auditeurs, on dirait aujourd'hui des standards musicaux. Le plus répandu, au XIXe siècle, est le fameux «air de Fualdès » (fig. 2 et 9), du nom d'une affaire emblématique de 1817, le meurtre d'un ancien magistrat à Rodez, qui a donné lieu à un engouement de spéculations plus ou moins fantaisistes et de rumeurs sur un prétendu complot royaliste.

La complainte présente une structure tripartite. Elle commence par une formule d'appel (fig. 1) :
«Ecoutez le triste récit
Du plus affreux de tous les crimes
Commis par un lâche bandit
Sur ses frères, faibles victimes,

${ }^{19}$ J. Le Floc'h, « Les complaintes judiciaires », p. 94. 
Vraiment on frémit d'horreur,

Quand on pense à ce fratricide ;

On est plongé dans la douleur

En voyant cet homme perfide. »

Suit la narration détaillée des méfaits de l'odieux criminel. La complainte se termine par une brève morale :

«Trembles [sic], scélérat, car pour toi

Il n'est plus d'espoir sur la terre.

Ton cœur qui palpite d'effroi,

Te fait prévoir ton heure dernière.

Couché au fond d'un noir cachot,

$\mathrm{Tu}$ vois l'image des victimes

Que tu fis descendre au tombeau

Et qui te reprochent tes crimes. »

La complainte est, à l'évidence, le témoignage d'une époque lointaine où la communication orale était prépondérante en matière d'information. On aurait pu s'attendre à ce que cet archaïsme s'efface progressivement de la forme finale de l'occasionnel, le canard du XIXe siècle. Or non seulement ce genre ne disparaît pas, mais il reste vif et répandu jusqu'aux premières années du XXe siècle, et on trouve encore des complaintes dans les années $1930^{20}$. Notons que certaines complaintes font l'objet d'impression spécifiques, généralement sur une feuille recto, souvent sans illustration, et ce même tard dans la période concernée, ce qui atteste encore de leur vitalité.

Pour donner un indice de l'importance de la complainte dans la structure du canard, il suffit de renvoyer à l'emplacement choisi dans de nombreux cas par l'imprimeur: encadrant l'image (fig. 9), au recto d'une impression recto-verso, avant le texte narratif lui-même (fig. 2), etc. Dans les publications mentionnant plusieurs affaires distinctes, il arrive fréquemment que l'on prenne soin de rédiger scrupuleusement une complainte par affaire.

${ }^{20}$ Sur la permanence du genre, voir T. Cragin, Murder in Parisian streets ; J.-F. Heintzen, «Le canard était toujours vivant !». 


\section{Ruptures et continuité}

La leçon à tirer d'une étude menée sur ce qui reste aujourd'hui de la production des canards du XIXe siècle est claire: contre toute attente, le périodique ne tue pas l'occasionnel. Le journal à grand tirage, qui publie chaque dimanche un supplément illustré, est certes un redoutable concurrent, s'adressant au même lectorat et captant la même matière à « faits divers ». Alors comment expliquer la vigueur du canard ?

La réponse est complexe et fait appel à plusieurs registres. Techniquement, il est indéniable que le canard, s'il n'est pas, au sens propre, un périodique, n'est pas non plus si occasionnel; il n'existe pas d'étude quantitative sur la production des canards au XIXe siècle et au tournant du XXe siècle, mais les éléments dont nous disposons suggèrent des impressions régulières, des imprimeurs connus; le périodique n'a pas vraiment d'intérêt pour la relation de faits divers, faisant partie par définition d'un ensemble discontinu.

Culturellement, ensuite, le lien entre publications occasionnelles et fait divers paraît solidement ancré dans les esprits. Comme nous l'avons vu, ce type d'imprimé conserve encore dans sa forme même les traces de ses formes passées, la mémoire des nouvelles chantées, sous la forme de complaintes, un lexique de mots récurrents connus, reconnus, répétitifs, qui parlent immédiatement aux imaginations et proposent une sorte d'éclectisme rassurant. Le terme nous parait d'autant mieux choisi qu'il correspond à une tendance propre au XIXe siècle à habiller avec des formes anciennes les innovations techniques et artistiques, à dissimuler les poutrelles de fonte sous des placages néogothiques, néo-byzantins, néo-baroques, ou sous un joyeux tintamarre de tous les styles qui les ont précédées.

Thomas Cragin va plus loin encore en supposant une structure mentale «populaire» attachée à un système de pensée séculaire qui voit le crime comme la pure manifestation du Mal, dans une interprétation totalement sourde aux développements de la science criminologique du XIXe siècle :

«La représentation de la criminalité dans le canard au XIXe siècle illustre un rejet des idées nouvelles à propos du crime et privilégie les anciennes conceptions. $S^{\prime}$ inspirant en partie des 
croyances catholiques et des théories classiques, le genre explique le crime comme l'acte froidement calculé d'un être mauvais ${ }^{21}$. »

Pour Cragin, le canard livre au peuple les faits divers qu'il réclame depuis le XVIe siècle22. À l'inverse d'une opposition schématique entre une approche archaïque du crime (l'occasionnel) et une approche résolument neuve (le périodique illustré bon marché), ne faudrait-il pas plutôt examiner les influences du premier sur ce dernier ? Formellement, les journaux illustrés se distinguent-ils radicalement des canards ? La vision du crime et du criminel qui habite les périodiques est-elle fondamentalement différente de celle des occasionnels?

Ce que permet le périodique, c'est de suivre une enquête, de coller à l'actualité d'une affaire. Mais ce n'est vraiment intéressant que pour les «grandes » affaires, fertiles en rebondissements. Même sur ce créneau, le canard et l'imagerie «populaire » parviennent à résister, comme en témoigne l'affaire Troppmann, qui du 22 septembre 1869 à fin janvier 1870 tient la France en haleine, décuple les tirages du Petit Journal, mais suscite également un nombre important d'occasionnels, de complaintes, etc.

La supériorité du périodique, c'est de pouvoir diffuser des feuilletons, qu'il s'agisse de fiction ou d'un fait divers à rallonge. La différence ne saute d'ailleurs pas aux yeux pour le lecteur.

«En somme, l'affaire Troppmann apparaît comme une sorte de "feuilleton vrai", qui vient en contrepoint du feuilleton romanesque situé dans la partie basse de la première page des journaux populaires, que l'on appelle, dans le jargon de la presse, le "rez-de-chaussée". Pendant cinq mois, Le Petit Journal vit sur un petit nuage, partageant sa une entre un feuilleton fictionnel et un compte-rendu, parfois très romancé, des rebondissements de ce fait divers exceptionnel, intitulé d'abord "le Crime de Pantin", puis "l’Affaire Troppmann", brouillant les frontières entre réalité et fiction ${ }^{23}$. »

\footnotetext{
${ }^{21}$ T. Cragin, Murder in Parisian streets, p. 218 : «The canard's despictions of criminality illustrate its maker's rejection of the century's new ideas about crime in favor of older ones. Drawing incompletely from Catholic belief and classical theory, the genre explained crime as the cold calculated act of an evil being. »

${ }^{22} \mathrm{Ibid}$. : "Troughout the century, the canards gave the public the faits divers they had been demanding since the sixteenth century. »

${ }^{23}$ P. Nieto, « Troppmann, portraits d'un monstre criminel », p. 301.
} 
Pendant cinq longs mois, Le Petit Journal propose chaque jour une première page coupée en deux : la partie basse, le rez-de-chaussée en termes techniques, étant occupée par un feuilleton romanesque, la partie haute étant consacrée à l'autre feuilleton, l'affaire Troppmann, dite également $\mathrm{du}$ « crime de Pantin ».

Mais pour la plupart des faits divers, les faits banalement divers, la périodicité n'apporte rien. De fait, il va se développer, au tournant du siècle, un nombre considérable de journaux, souvent hebdomadaires, explicitement orientés vers le fait divers: Le Crime illustré, Les faits divers illustrés, le fameux CEil de la police... qui viennent s'ajouter aux suppléments hebdomadaires des grands journaux parisiens et provinciaux. Ces types de publications ne diffèrent vraiment des occasionnels que sur un point: ce que l'on appellerait aujourd'hui une "signature graphique » et un nom de "marque», qui les distinguent de la masse des autres publications et suscitent à la longue une attente d'un lectorat fidélisé, si le nouveau titre est parvenu à séduire.

Ce sont plutôt ces publications-là qui vont faire disparaître, à terme, les canards criminels, non pas en les démodant, en les « ringardisant », mais plutôt en s'en inspirant pour une part, en les vampirisant, en jouant également sur deux registres réellement nouveaux: une force de frappe financière supérieure et l'insertion dans un nouveau modèle commercial, celui de la marque, que l'on appelle un «titre » dans le monde de l'imprimé et de la presse. 


\section{Condamnation et Execution}

Du fratricide Courvoisier, convaincu d'ayoir assassiné son frère, de lavoir coupé par morceaux, de les avoir cachés dans son jardín, ensuite de Ies avoir déposés dans un four abandonné où ils furent découverts et dètails sur ce fils dénaturé que la férocité de son caractère porta à mutiler le cadarre de son père. Cour dassises du Merbihan, siance du 14 soptembire 1855.

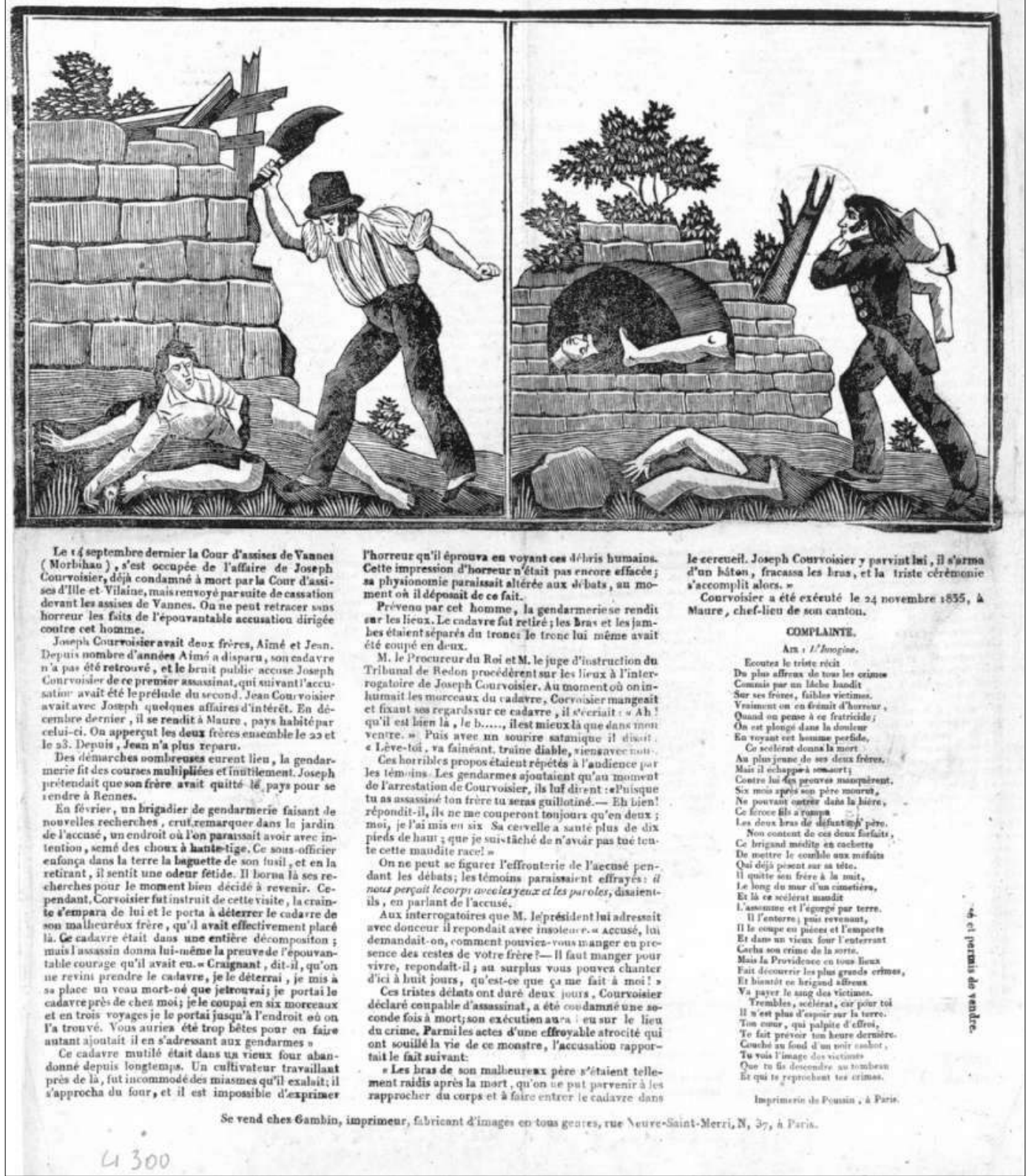

Fig. 1. - Un canard de 1835 : « Se vend chez Gambin, imprimeur fabricant d'images », Paris. Coll. P. Nieto. 

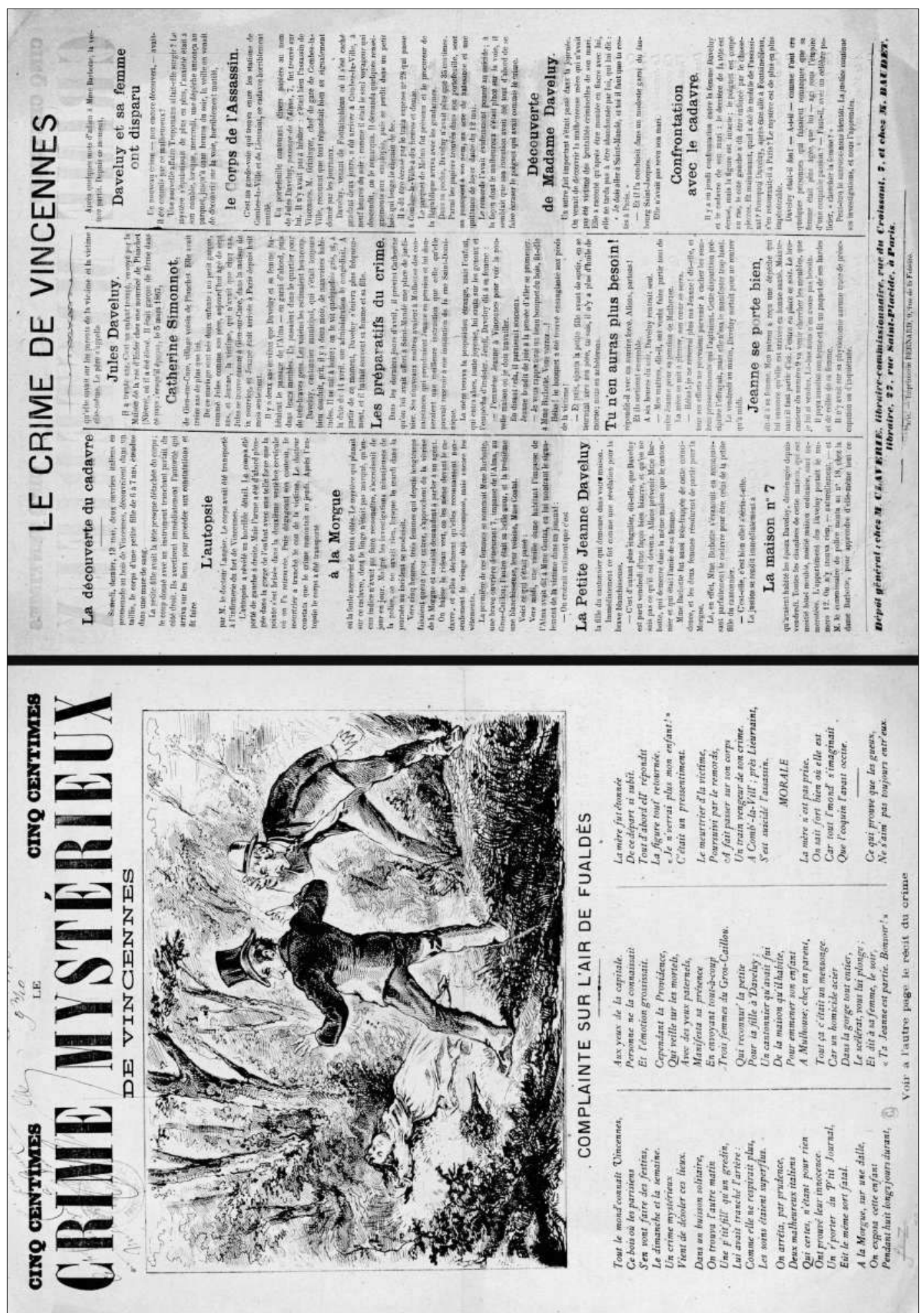

Fig. 2. - Un canard de 1876, « Dépôt général : chez M. Claverie : imprimeur-commissionnaire [...] et M. Baudet : imprimeur », Paris.

Coll. P. Nieto. 


\section{8}

EXECUTION veritable d'un affa J Inat par deux enfans qui ont tué leur Pere, condamnés par J U G EM EN T à faire amende honorable dervant $l$ E Elife Nôtre Dame, enfuite à a voir le poing compé, d̀ estre traifné fur la Claye, à eftre rompu vif, Emblemfuite jette all feu.

T Njeune hommede Torigni proche Rouen âgè de 25 ans, fit complotavec fon frere, voyant quils ne pouvoient obtenir ce qu'il defiroient deleur pere, prirent l'abominable réfolution de le tuer, afin d'cetre les maiftres de fon bien a prés fa mort, ce pernicieux but les fic entreprendre cette horrible action, qu'ils executerent pendant Ia nuit, \& après avoir pris,tout ce qu'ils fouhsitoient, ils fe fauvertent dans un eadroit ou ils crurent être bien cachez, l'un des deux cependant fe méfiant de la fureté de cet endroit fe fauva ailleurs, fon frere qui étoit refté fut découvert quelques jours après, \& ne tarda gueres à éprouver qu'on ne peur fe cacher de Dieu, en quelqu'endroit qu'on fe retire; Ce malheureux fut conduit les fers aux preds \& aux mains dans les Prifons de Rouen, quelque jours aprés il fur appliqué à la queftion ordinaire \& extraordinaire dans la ghênne de la torture, il declara que fon frere étoit complice avec lui, \& avoua fon crime \& le fujet qu'il y avoit porté; fur fa déclararion il fut condam. né à faire amende honorable devant l'Eglife de NotreDame de Rouen a avoir le poing coupé, enfuite d'eftre trainé fur le claye aux vieux marché pout y être rompu vif \& jetré dans le feu, ce qui fut executé le même jour. lon eft à la pourfuice de fon frere qui aura le même fort que lui.

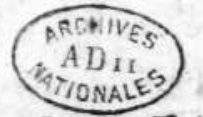

Permes d'imprimer o Colporter le 25. Juin 1728. H ER A U LT.

De linprimarie fo Luis Colgand, ruede la vieille Boucleries

Fig. 3. - Un occasionnel de 1728, « De l'imprimerie Loüis Coignard », permis d'imprimer et de colporter dans l'Héraut.

Coll. P. Nieto. 


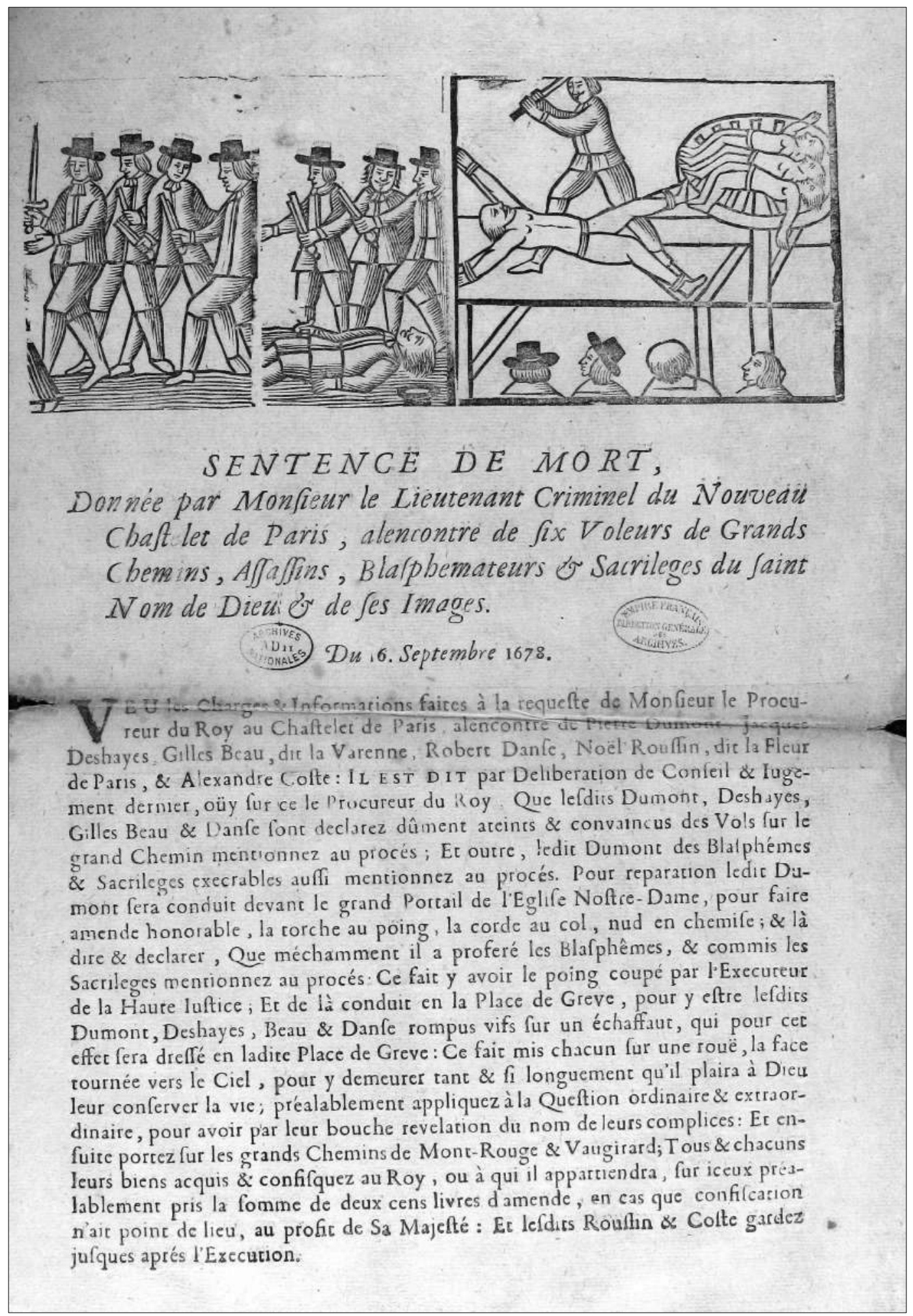

Fig. 4. - Un occasionnel de 1678, s. 1.

Coll. P. Nieto. 


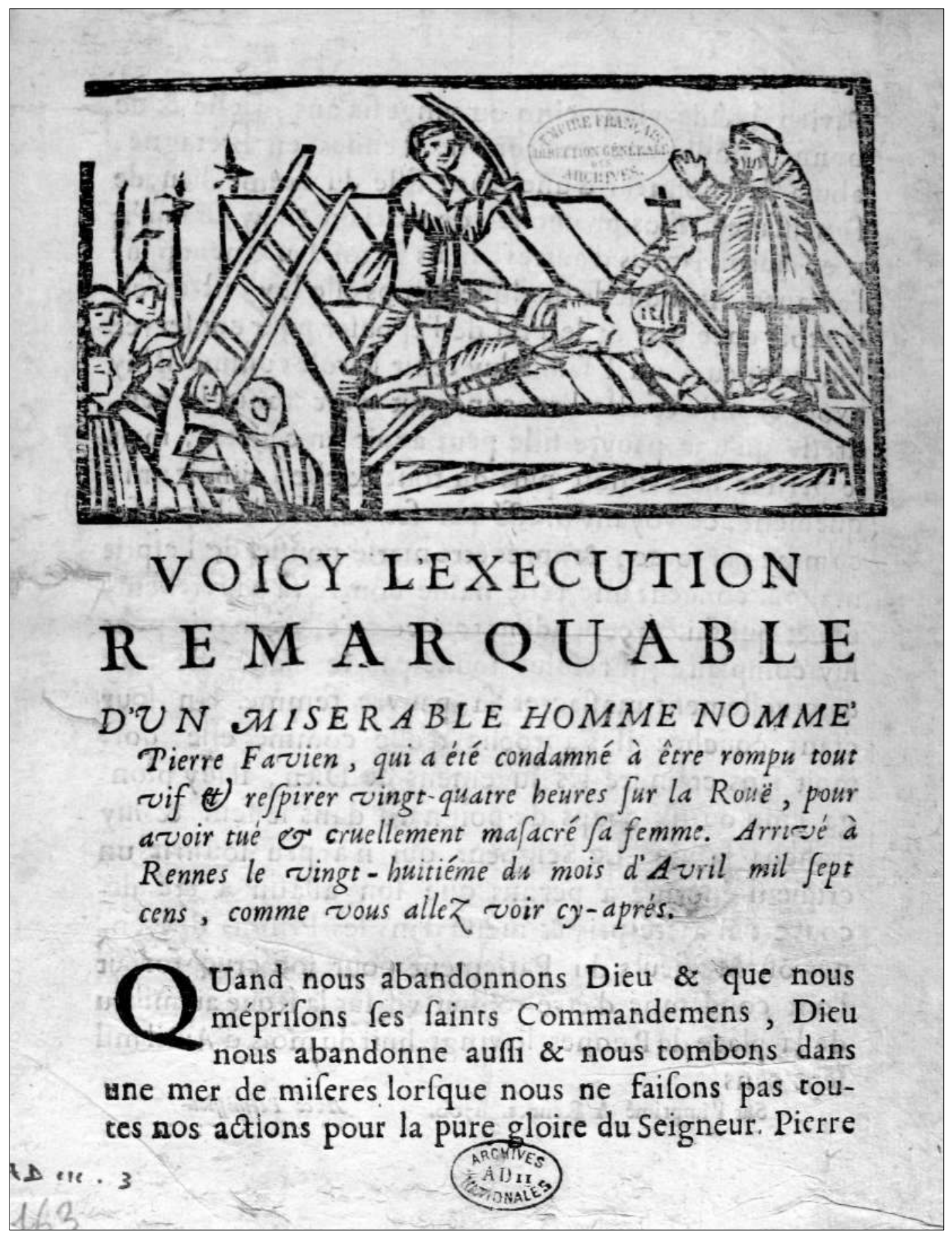

Fig. 5. - Un occasionnel de 1700, « Sur l'imprimé à Rennes ».

Coll. P. Nieto. 


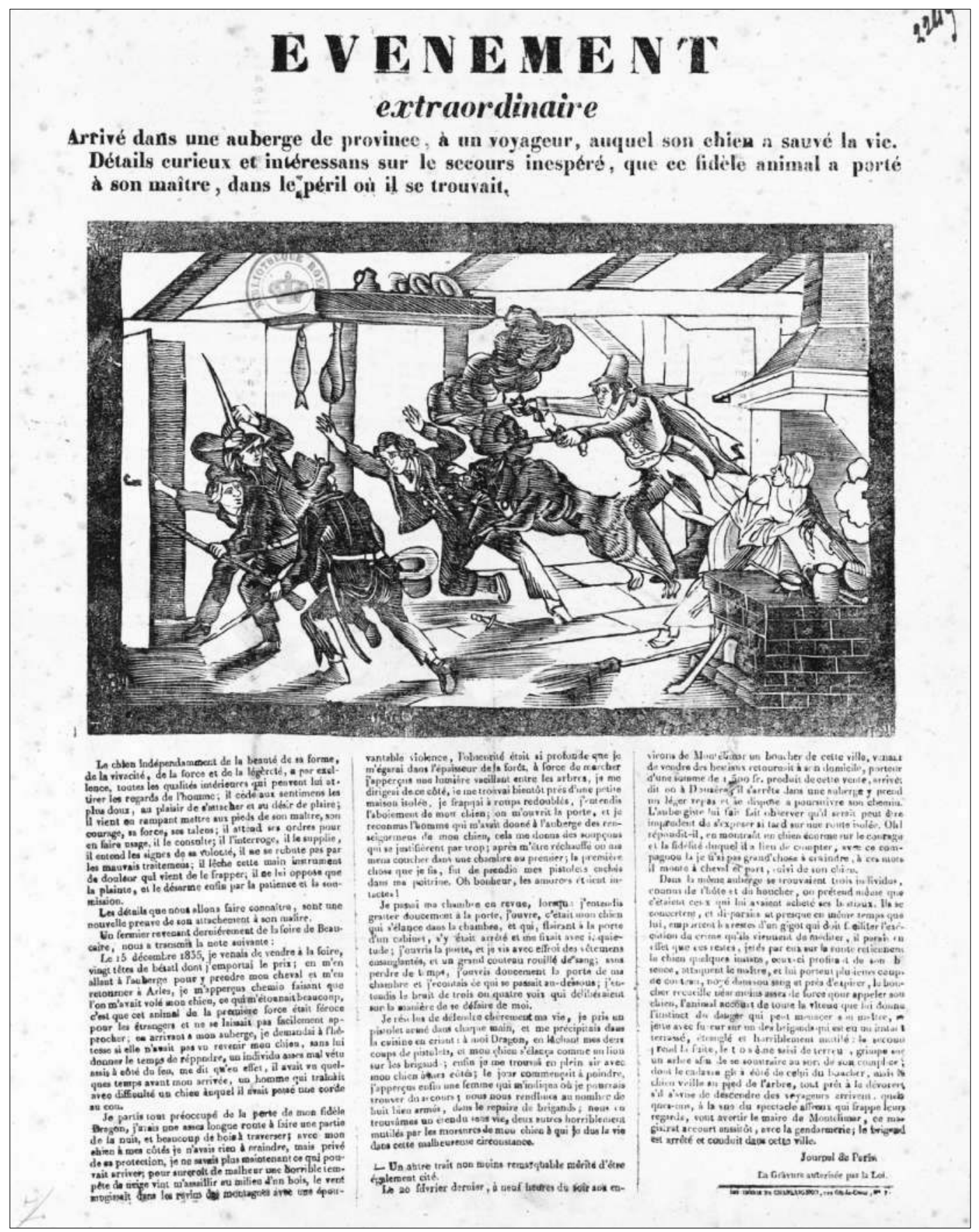

Fig. 6. - Un canard de 1836, Chassaignon, Paris.

Coll. P. Nieto. 


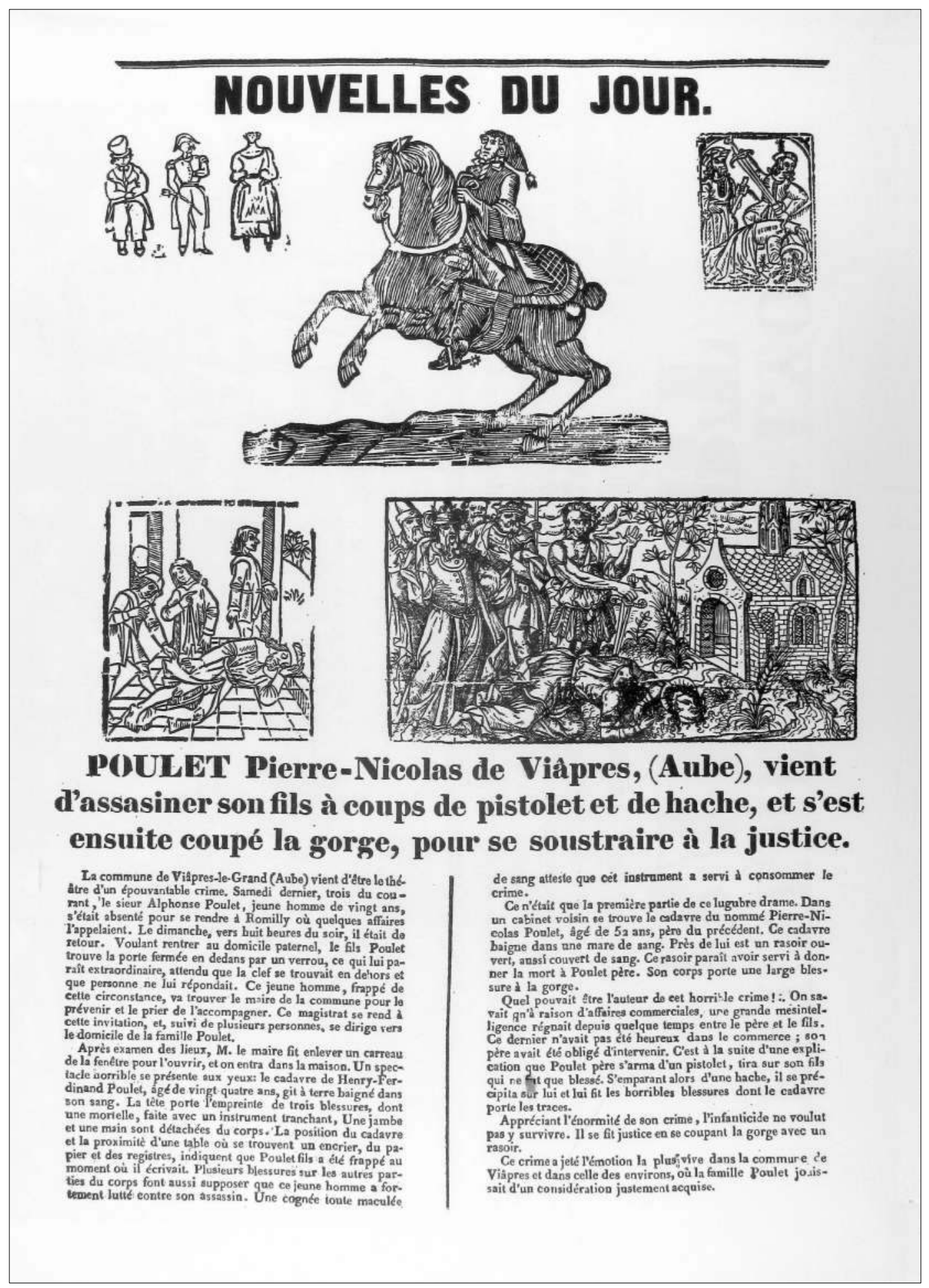

Fig. 7. Un canard non daté et non signé (années 1830 ou 1840 ?).

Coll. P. Nieto. 


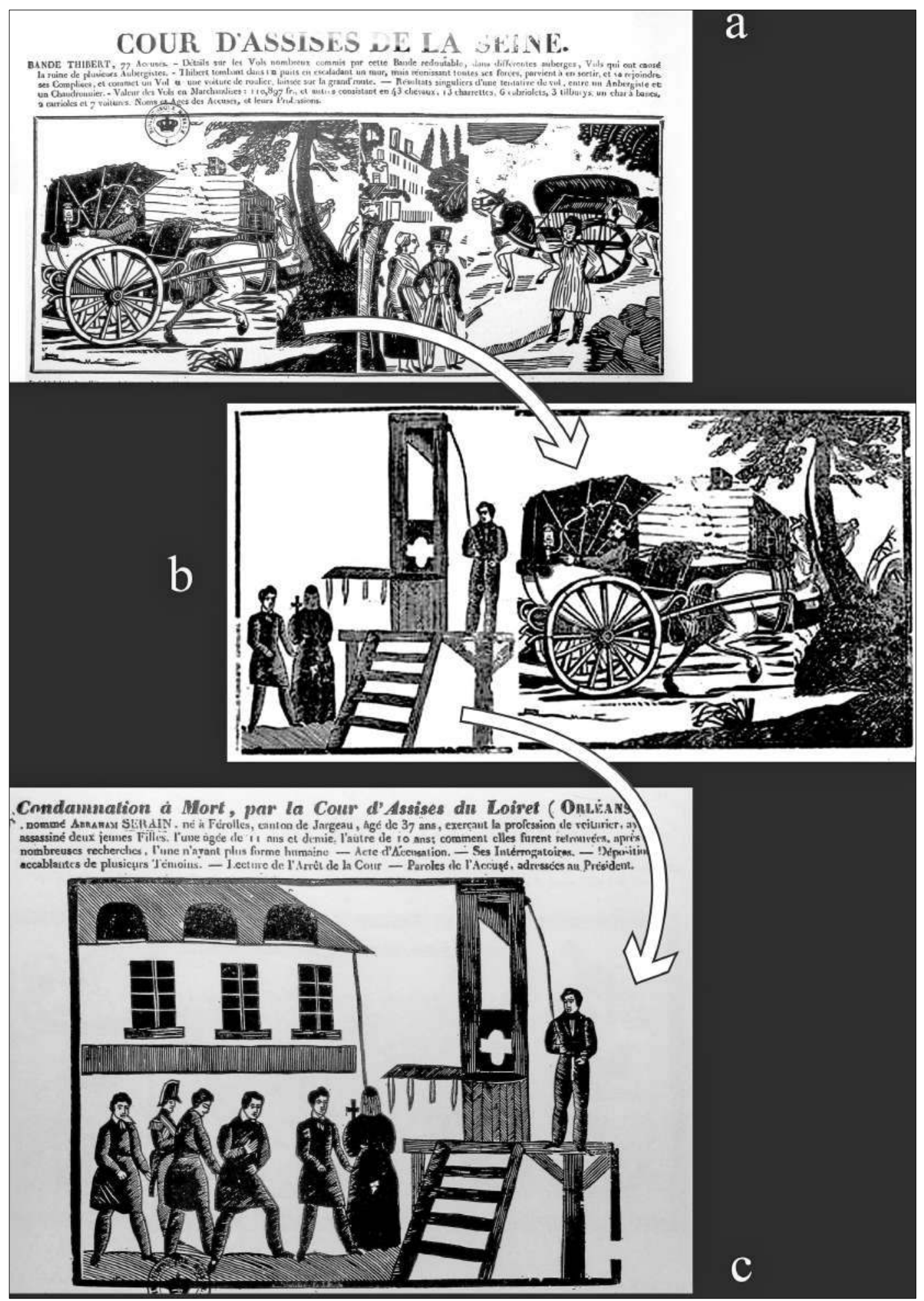

Fig. 8. Un exemple de réemploi de bois gravés, Chassaignon à Paris.

(a) Cour d'assises de la Seine, procès de la « bande Thibert », 1847 ;

(b) Cour d'assises de la Seine-et-Oise, s. d. ;

(c) Cour d'assises du Loiret, 1842.

Coll. P. Nieto. 


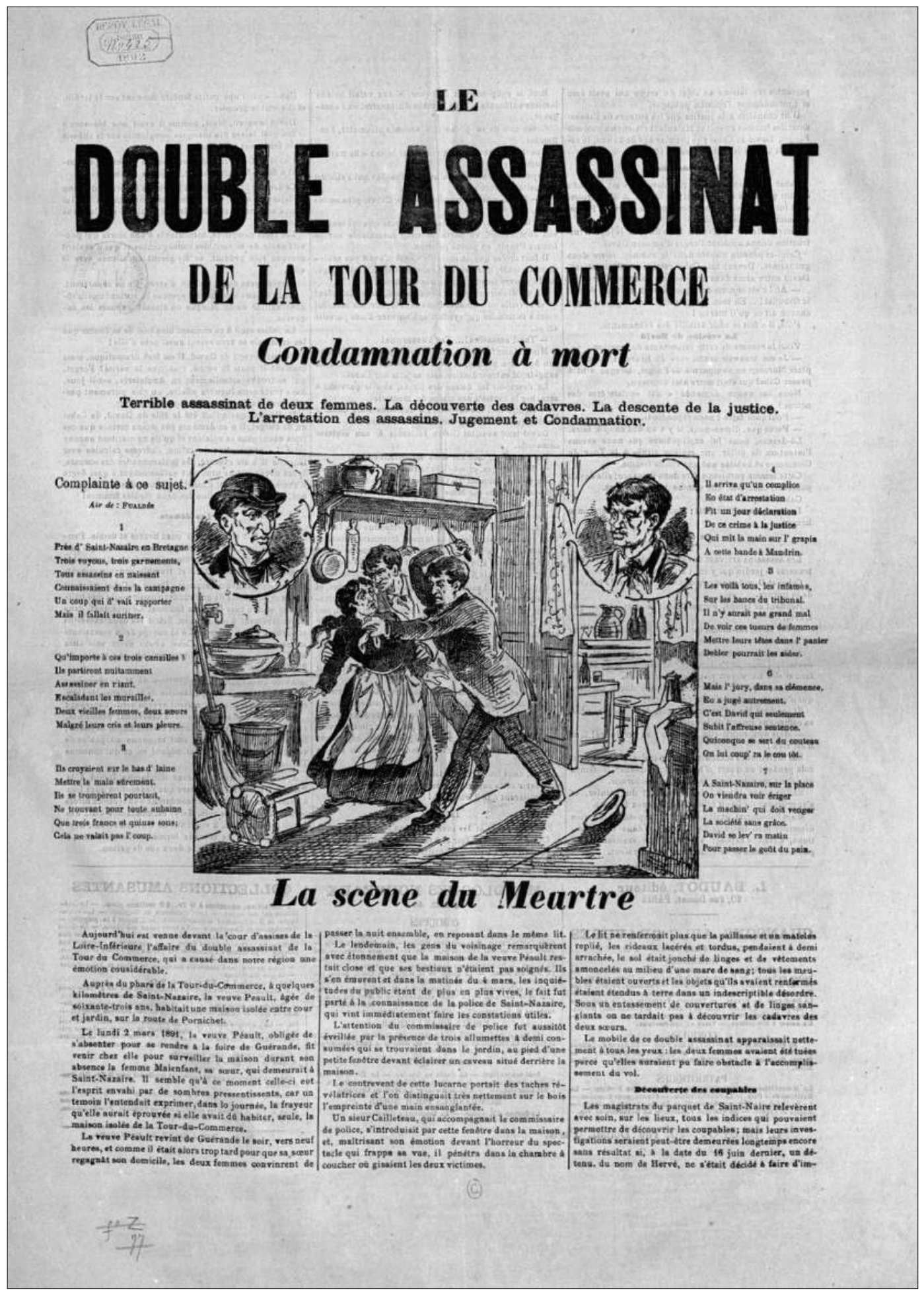

Fig. 9. Un canard de 1892, L. Baudot, Paris.

Coll. P. Nieto. 


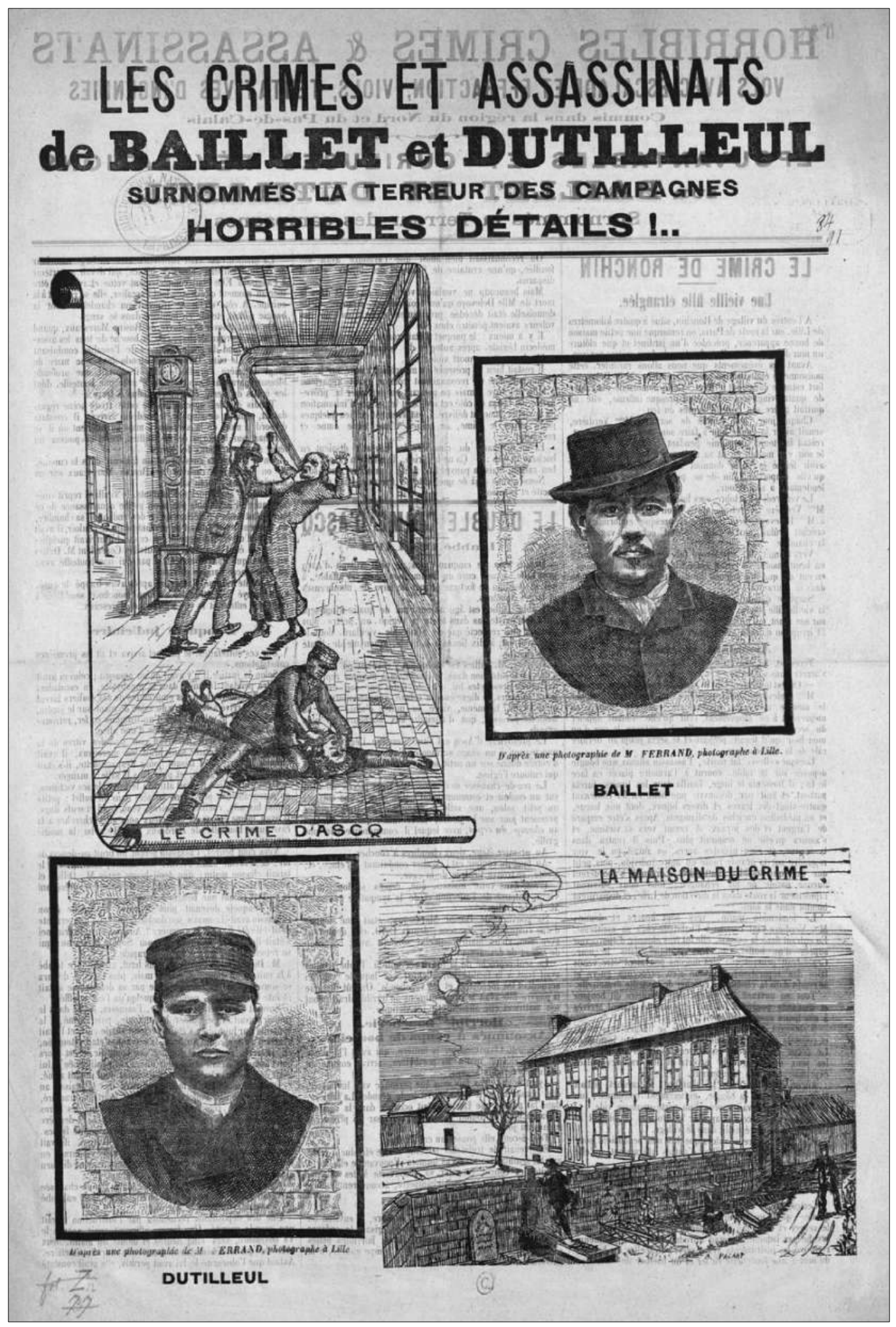

Fig. 10. Un canard de 1891, L. Bayard, Lille. Coll. P. Nieto. 


\section{Bibliographie}

CRAGIN Thomas, Murder in Parisian streets. Manufacturing crime and justice in the popular press, 1830-1900, Cranbury, Lewisburg Bucknell University Press, 2006, 273 p.

DELMAS Gaëtan, «Le canard», dans L. Curmer, Les Français peints par eux-mêmes, vol. 3, Paris, Curmer, 1841, p. 43-56, 2 pl. h.t.

HeINTZEN Jean-François «Maxou », «Le canard était toujours vivant ! De Troppmann à Weidmann, la fin des complaintes criminelles, 1870-1939 », http://criminocorpus.revues.org/2562.

LE FLOC'H Joseph, «Les complaintes judiciaires », dans Histoire et justice : panorama de la recherche, hors-série de Revue d'histoire de l'enfance « irrégulière », 2001, p. 93-103.

LEVER Maurice, Canards sanglants. Naissance du fait divers, Paris, Fayard, 1993, 517 p.

Nerval Gérard de, Histoire véridique du canard et autres textes, éd. Jean-Luc Steinmetz, Pantin, Castor Astral (Les Inattendus), 2008, 227 p. (rééd. de l'édition de 1844).

NIETO Philippe, «La question de l'image dans le fait divers criminel», dans M. Corbier et G. Sauron (dir.), Langages et communication : écrits, images, sons, Paris, Éditions du CTHS (Actes des congrès des sociétés historiques et scientifiques, édition électronique), 2017, p. 201-212.

NiETO Philippe, «Troppmann, portraits d'un monstre criminel », dans A. Milano (dir.), Generali e mendicati, attori e sovrani. Ritratti nelle stampe a larga diffusione dal XVII al XX secolo / Generals and beggars, actors and sovereigns. Portraits in widely circulating prints from XVII to XX Century, Bassano del Grappa, Tassotti, 2013, p. 299-315.

PERROT Michelle, «L'affaire Troppmann (1869)», dans M. Perrot, Les ombres de l'histoire. Crime et châtiment au XIXe siècle, Paris : Flammarion, 2001, p. 283-298 (rééd d'un art. paru dans L'Histoire, no 30, 1981).

SEGUIN Jean-Pierre, Nouvelles à sensation. Canards du XIXe siècle, Paris, Armand Colin, 1959, $226 \mathrm{p}$.

SEGUIN Jean-Pierre, L'information en France de Louis XII à Henri II, Genève, Droz, 1961, $133 \mathrm{p}$. 
SEGUIN Jean-Pierre, L'information en France avant le périodique: 517 canards entre 1529 et 1631, Paris, Maisonneuve et Larose, 1964, 129 p.

SEGUIN Jean-Pierre, Canards du siècle passé, Paris, Pierre Horay, 1969, 80 p.

\begin{abstract}
Résumé
On appelle «canards» au XIXe siècle les feuilles d'information non périodiques, dernière forme des occasionnels des siècles passés. Le canard se présente à nos yeux dans un style éclectique combinant des éléments apparemment archaïques : titre, image et texte évoluent progressivement vers une plus grande expressivité et une personnalisation croissante, accolés à une complainte dont la forme paraît immuable. Contrairement aux idées reçues, cette forme de publication reste plutôt vivace jusqu'au seuil du xxe siècle, en dépit de la concurrence des périodiques à bon marché, qui se placent sur le même segment commercial : le fait divers. En fait, c'est sans doute moins le supplément illustré du journal qui tuera le canard que l'apparition d'une presse spécialisée, qui va y puiser des éléments narratifs en les combinant avec une force de frappe supérieure et une logique de marque, ou plutôt de titre.
\end{abstract}





\title{
Balzac et l'argot : enjeux littéraires autour du roman populaire
}

\author{
Louis Bergès \\ Conservateur général du patrimoine \\ Membre du Comité des travaux historiques et scientifiques, \\ section Histoire du monde moderne, de la Révolution française et des révolutions
}

La «langue des Grecs, des filous, des voleurs et des assassins » est-elle disponible pour l'écrivain? Dans son essai sur l'argot'1, Balzac met en lumière le problème posé par l'entrée en littérature d'un langage familier au milieu de la pègre et des pauvres : l'argot. Il reste ici ancré sur l'origine du mot au XVIIe siècle, qui désigne la «langue verte », celle du monde des mendiants et de la misère.

Au moment où Balzac franchit les portes du succès littéraire, l'argot fait déjà l'objet d'une réelle production lexicographique : dès 1827 paraît le Dictionnaire de l'argot ou guide des gens du monde; avec le Vidocq dévoilé, Raban et Marco Saint-Hilaire publient en 1828 le premier glossaire de l'argot, qui sera suivi par les Mémoires de Vidocq lui-même. Au même moment paraît Les omnibus du langage de David Lévi Alvarès, qui recensent $a$ contrario toutes les formes et locutions « vicieuses » qui corrompent la langue française.

Au-delà du cliché habituel sur la littérature romantique censée s'ouvrir sur le monde réel, c'est-à-dire sur les injustices du monde et la cruauté sociale, par opposition à l'univers fermé propre aux écrivains classiques, il va s'agir ici de s'interroger sur les enjeux de la naissance d'une nouvelle inspiration romanesque, au cœur de laquelle on retrouve naturellement l'auteur de La Comédie humaine.

\footnotetext{
1 «Essai philosophique, linguistique et littéraire sur l'argot, les filles et les voleurs », chapitre VII de La dernière incarnation de Vautrin, publié en 1847.
} 
Les jugements des contemporains, puis ceux du siècle suivant, n'ont pas peu contribué à faire de l'argot une sorte de marque de fabrique du style balzacien. Obscurité lexicale, brutalité linguistique au service du roman, inintelligibilité, étrangeté déroutante, fascination du laid, exotisme à la Fenimore Cooper², les qualificatifs n'ont pas manqué pour attaquer les pages sombres de Splendeurs et misères des courtisanes, où évolue le bagnard Vautrin. Police du langage et respect des normes ont continué ainsi à figurer comme objectifs premiers des critiques littéraires comme des écrivains eux-mêmes, qui n'ont eu de cesse de commenter les créations de leurs prédécesseurs ou contemporains.

Ce n'est pas un hasard si la fonction argotique se trouve au centre de ce que François Mauriac a appelé dans ses Mémoires intérieurs le point culminant de la géographie romanesque balzacienne ${ }^{3}$, la relation parisienne Jacques Collin - Lucien de Rubempré, au cœur du roman précédemment cité.

Dans Contre Sainte-Beuve, Marcel Proust souligne la vulgarité intrinsèque du langage de Balzac, «si profonde qu'elle va jusqu'à corrompre son vocabulaire, à lui faire employer de ces expressions qui feraient tache dans la conversation la plus négligée »: il n'en reconnaît pas moins la force de l'écriture de l'auteur de La Comédie humaine, souvent pris par les affres du « démon explicatif4».

Peut-on parler d'ailleurs d'une appétence balzacienne pour l'argot? Eric Bordas souligne l'intérêt et le goût de Balzac pour l'argot en mettant en avant dans le récit balzacien le concept de «sociolecte», qui se caractérise par la parfaite adéquation stylistique à la personnalité de celui qui s'exprime, dans la mesure où il appartient à un groupe social déterminé disposant d'un vocabulaire et d'une forme d'expression spécifique ${ }^{5}$.

Ces jugements de la postérité nous ramènent à la réalité vécue par l'auteur lui-même, créateur d'un nouveau genre littéraire : à travers l'apparition de l'argot dans l'écriture du roman se profilent divers enjeux littéraires apparus en 1830 pour un auteur parti à la conquête du public parisien. Quels sont les usages de l'argot en littérature au moment où

\footnotetext{
2 Fenimore Cooper (1789-1851), pionnier du roman américain, auteur du Dernier des Mohicans en 1826, qui a largement influencé Balzac.

${ }^{3}$ F. Mauriac, Mémoires intérieurs, p. 148.

${ }^{4}$ M. Proust, Contre Sainte-Beuve, p. 189.

${ }^{5}$ Voir E. Bordas, Balzac, discours et détours..., p. 62 et suivantes.
} 
naissent les romans-feuilletons ? Qui peut porter la paternité de cette apparition ? L'enjeu est de taille pour les écrivains parisiens à la mode qui cherchent à imposer leur style.

On s'interrogera enfin sur la vision radicale du roman que Balzac veut porter à travers l'introduction dans celui-ci d'une forme nouvelle de langage.

\section{Les usages de l'argot en littérature selon Balzac}

Apparaître comme l'inventeur d'un style, tel est le but recherché par les premiers romanciers du début du XIXe siècle : l'argot est introduit en style direct pour faire parler un personnage dans son environnement, ce qui permet de proposer au lecteur une nouvelle forme d'expression. Du même coup, l'écriture devient conforme à son objet : il y a là volonté de l'écrivain de retrouver à travers les mots une authenticité, une pureté expressive, qui donnent au texte une réalité physique, une substance matérielle, une véritable sonorité.

Balzac n'a pourtant jamais théorisé cet usage. Il découle naturellement du style que celuici décide d'adopter dès qu'il signe de son nom ses premiers textes. Dès le départ, Balzac manifeste un grand intérêt pour les formes de parlers locaux. Ainsi, c'est dans une perspective de caractérisation du langage populaire de l'Ouest breton qu'il faut sans doute considérer les ellipses et prononciations dialectales figurant dans Les Chouans: le dialogue entre Pille-Miche et Marche-à-Terre met en avant à plusieurs reprises une forme de parler qualifié de "patoisant», dans lequel plusieurs expressions font l'objet d'explications, comme " godaine », selon Balzac un «mot assez bizarre » désignant « un superlatif du patois de ces contrées, qui sert aux amoureux à exprimer l'accord d'une riche toilette et de la beauté ${ }^{»}$.

Le verbe "toper7", également mentionné dans le discours chouan, se retrouve singulièrement dans Gobseck, nouvelle publiée quelques mois plus tard, à travers les exclamations de l'usurier, terme auquel il faut ajouter l'expression de «taxé de

\footnotetext{
${ }^{6}$ H. de Balzac, Les Chouans, p. 88. Pour l'ensemble des citations extraites de La Comédie humaine, voir l'édition critique en ligne (dorénavant: $\mathrm{CH}$ ) présentée par le Groupe international de recherches balzaciennes et le groupe ARTFL (Université de Chicago), disponible sur Internet :

http://www.v1.paris.fr/commun/v2asp/musees/balzac/furne/aatable.htm.

$7 \mathrm{Au}$ sens de «frapper dans la main pour conclure un marché ». Le mot figure dans le premier dictionnaire d'argot: Dictionnaire de l'argot ou guide des gens du monde, 1827.
} 
bégueulisme » utilisé par l'avoué Dervilles. Des verbes au sens unique et propres à une action sont utilisés dans de nombreux cas : «faire endêver », indiqué comme « mot local » dans la région de production du vin de Vouvant, en Touraine, est employé pour « faire enrager ${ }^{9} »$.

Des expressions idiomatiques «professionnelles " peuvent servir à un autre usage que celui auquel elles sont destinées : ainsi, le trio de journalistes bien connus de La Comédie humaine, Bixiou, Nathan et Lousteau, se refusant à questionner deux officiers ministériels au cours d'un dîner, renoncent à les « faire poser en style lorette ${ }^{10}$ »! Le verbe " écarter », appliqué à des pistolets en cours de duel, est suffisamment suggestif pour ne mériter aucune explication $d^{\prime}$ auteur en dehors $d^{\prime}$ une impression en italique ${ }^{11}$. Les postillons de diligence ont eux aussi leur expression favorite : sur la route de Nemours à Paris, là où commence Ursule Mirouet, Balzac ne manque pas de signaler l'allure qui consiste à « aller à tout brésiller ${ }^{12}$ ». Chez les journalistes parisiens, « ne rien avoir dans le ventre ${ }^{13}$ », que Balzac indique comme un « mot consacré en argot du journalisme », représente « un arrêt souverain » qui condamne à mort le jeune journaliste qui échoue dans sa tentative de se faire connaître.

Dans le salon de la belle Anaïs de Bargeton, le verbe est roi : celle-ci fait l'usage $\mathrm{d}^{\prime}$ «immenses phrases bardées de mots emphatiques, si ingénieusement nommées des tartines en argot du journalisme », consistant à tout «typiser, individualiser, synthétiser, dramatiser, supérioriser, analyser, poétiser, prosaïser, colossifier, angéliser, néologiser et tragiquer ${ }^{14}$. » Dans ce cas, $c^{\prime}$ est l'emploi de verbes savants qui figure ici comme une forme argotique.

\footnotetext{
${ }^{8} \mathrm{Au}$ sens de faire le difficile, le " père la pudeur ». Voir CH, Gobseck, p. 392-395.

${ }_{9}^{\mathrm{CH}}$, L'Illustre Gaudissart, p. 337.

${ }^{10} \mathrm{CH}$, Un Homme d'affaires, p. 128.

${ }^{11} \mathrm{CH}$, L'Illustre Gaudissart, p. 352 : «En prenant de gros pistolets d'arçon et les chargeant jusqu'à la gueule, on ne risque jamais rien, les pistolets écartent, et chacun se retire en homme d'honneur ».

${ }_{12}$ L'expression revient à indiquer une vitesse très rapide, à faire exploser en morceaux (brésilles) la diligence. Voir CH, Ursule Mirouet, p. 6.

${ }^{13}$ La forme est employée à trois reprises dans Les Illusions perdues et ne vient en explication qu'à la fin du roman pour désigner le peu d'expérience professionnelle de Lucien de Rubempré comme journaliste. Voir $\mathrm{CH}$, Les Illusions perdues, p. 388.

${ }^{14}$ Ibid., p. 32-33. Voir à ce sujet A. Deruelle, Glose et prose romanesque..., p. 108-109.
} 
Une dernière forme d'argot est largement promue par Balzac, c'est celle du Palais de justice, valorisée à travers un jugement de saisie de l'imprimerie du héros des Illusions perdues, David Séchard: le résultat de la procédure judiciaire se résume en ces termes suggestifs : «mettre le feu aux affaires d'un homme $\mathrm{d}^{15}$ ».

Ces intrusions par petites touches d'un vocabulaire argotique déjà répertorié peuvent faire figure de banc d'essai pour l'auteur de La Comédie humaine; plusieurs autres procédés significatifs ont été identifiés dans l'œuvre de Balzac. Il s'agit tout d'abord de l'usage d'interjections ou de jurons dont l'origine est à puiser dans l'imagination langagière supposée d'une profession aux mœurs jugées caricaturales, comme celle des avoués dans La Transaction, titre originel du Colonel Chabert : "saquerlotte ${ }^{16}$ ", "berlik berlok $^{17}$ ». Quant au fameux "Quesaco? », il s'agit d'un véritable xénisme, qui est reproduit sans explication d'auteur à deux reprises par un même personnage, Margaritis, vigneron «d'origine italienne», dont la personnalité vaguement méridionale suffit à Balzac pour lui prêter des mots de la langue d'oc ${ }^{18}$.

Les tournures expressives au caractère elliptique font aussi partie d'un répertoire mis en valeur par Balzac. Ainsi : «Il y a gras!», qualifié de mot d'argot en vigueur dans les ateliers d'artistes pour désigner un objet de grande valeur ${ }^{19}$. Plus loin, on trouve une expression rabelaisienne que Balzac met dans la bouche du peintre Joseph Bridau pour dissimuler une question relative à la fortune de ses hôtes, adressée à son compère Grassou : «Y a-t-il aubert en fouillouse ${ }^{20}$ ? ».

\footnotetext{
${ }^{15}$ Ibid., p. 456.

${ }^{16}$ Le terme est à rapprocher de «saperlotte», «saperlipopette » et «sacrebleu». Il est à noter que Balzac fait renforcer l'interjection par «sakerlotte » avec un $\mathrm{k}$ au sens de «mettre un point sur les $\mathrm{i}$ », dont il rapproche l'expression. Voir CH, Le Colonel Chabert, p. 3.

${ }^{17} \mathrm{Au}$ sens de actuel de «patati et patata ( ( Cause toujours, tu m'intéresses!»). Le terme peut être voisin de « de brique et de broque », déjà employé par Balzac. L'expression pourrait venir du picard ou du wallon et n'est sans doute pas une simple invention verbale, comme l'écrit Patrick Bertier dans son édition du Colonel Chabert. ${ }^{18}$ Il s'agit bien sûr ici de la traduction en occitan de «Qu'est-ce que c'est? ». Voir CH, L'Illustre Gaudissart, p. 341 et 346 .

${ }^{19}$ Voir CH, Pierre Grassou, p. 72.

${ }^{20} \mathrm{Ibid} .$, p. 76. L'expression, que l'on trouve déjà dans Pantagruel, signifie ici très exactement : «Y a-t-il de l'argent à se mettre dans la poche?»
} 
Il est également intéressant de souligner la suffixation gratuite, qualifiée par l'auteur luimême $d^{\prime}$ «espèce d'argot", qui est une sorte de «jeu d'esprit» collectif au sein d'un groupe. Balzac a pu recueillir le procédé au sein de divers milieux qu'il a fréquentés, notamment celui des employés et commis voyageurs. À la pension Vauquer, Rastignac et certains colocataires rivalisent ainsi dans la manifestation verbale de ce «diorama »; l'introduction du vocable «rama» crée un événement à épisodes: «Il fait un froitorama ", dit Vautrin. L'un des étudiants réplique en annonçant l'arrivée de la « soupeaurama ». Un troisième propose de boire à la « santérama ». Quant à Rastignac, il signale qu'il n'est pas marquis sous le nom de « Rastignacorama ${ }^{21} »$. Plus tard, Rastignac reprend le jeu avec Popinot en lançant un «petit dramorama» pour se rappeler le «mauvais bon temps ${ }^{22} »$.

Nous assistons à travers cette pseudo-dérivation à une mutilation des mots qui est censée accentuer la différence sociale en renforçant la complicité au sein du groupe, en l'occurrence ici celui des étudiants. À cette forme de cryptage, on pourrait ajouter une autre forme de jeu verbal mise en exergue par Balzac pour donner les mêmes effets : il s'agit des phrases introduites dans la conversation par Mistigris, un « rapin », prête-nom du peintre Léon de Lora, qui s'évertue au début de sa carrière d'artiste à multiplier les expressions proverbiales et familières déformées comme «Plus on est debout, plus on rit $^{23} ! »$

Dans le même ordre d'idées, Balzac se sert largement, jusqu'à en abuser, de la facette langagière de plusieurs personnages de forçats, sur le modèle hugolien du condamné Claude Gueux : il s'agit dans ce cas du développement d'un véritable discours argotique, repris à plusieurs reprises dans diverses situations.

Trois grandes figures se détachent sur l'ensemble de l'œuvre de Balzac: Vautrin, Collin et Herrera parmi les "fanandels », la «fine fleur de la haute pègre », avec la scène exceptionnelle du préau de la Conciergerie : l'arrivée de Sa Majesté le «Dab» au milieu de ses anciens compagnons est l'occasion d'un dialogue entièrement codé en argot entre

\footnotetext{
${ }^{21} \mathrm{CH}$, Le Père Goriot, p. 342, 343, 382.

${ }^{22} \mathrm{CH}$, L'Interdiction, p. 127.

${ }^{23}$ Voir $\mathrm{CH}$, Un Début dans la vie, p. 471. La liste est longue: «vieux comme les Russes", «connu comme le houblon », le voilà «comme un âne en plaine », «faire une pierre deux sous », « les cordonniers sont toujours les plus mal chauffés », etc.
} 
Jacques Collin et ses « collègues ${ }^{24}$ ». Une autre scène mythique de La Comédie humaine est célèbre pour son expression, celle du grognard Goguelat, ancien fantassin de la campagne de Russie, qui, à travers un long récit familier, très éloigné du discours convenu, raconte dans une grange l'épopée napoléonienne en usant à satiété d'une verve "picaresque », et surtout d'un vocabulaire drolatique émaillé d'expressions militaires, pour décrire ce qu'il a vécu ${ }^{25}$. L'irruption au début des Paysans du personnage du père Fourchon, rencontré fortuitement au bord d'une rivière par le journaliste parisien Blondet, est également une scène très représentative du but recherché par l'auteur: ellipses, accidents phonétiques, prononciations locales très appuyées, censées constituer un sorte d'argot paysan, visent à camper un personnage typique des campagnes de l'Yonne $^{26}$. Dans le cas d'Ida Gruget, la «lorette», c'est au moyen d'une lettre écrite phonétiquement que Balzac introduit son personnage aux côtés de Ferragus, le « chef des dévorants » : les fautes d'orthographe grossières permettent ici de caractériser l'état de la rédactrice ; le vocabulaire employé, même déformé, est en revanche plutôt châtié, ce qui tranche avec d'autres personnages de prostituées mis en scène dans La Comédie humaine27. La dernière forme de discours que Balzac emploie dans un sens argotique, c'est celle qui reproduit l'accent régional ou étranger, écrit phonétiquement pour mieux caricaturer un personnage : le premier dans l'ordre d'apparition sur la scène est le banquier Nucingen, dont le discours en style direct baigne dans une gangue jargonesque à caractère germanique : «Puisqui matame fous encache, fous etes sir d'edre pien ressi28. "

Dans ce cas, Nucingen ne parle ni une langue ni un dialecte propre : il s'agit seulement de restituer la prononciation, dont l'effet revient à individualiser un discours et à en transcrire le moindre mot en italique pour souligner la nature étrange et étrangère du

\footnotetext{
24 Voir H. de Balzac, La Dernière Incarnation de Vautrin, p. 63-85.

25 Voir CH, Le Médecin de campagne, p. 432 à 447. Par exemple, à propos de la campagne d'Italie : « Et l'on marche la nuit, et l'on marche le jour, l'on te les tape à Montenotte, on court les rosser à Rivoli, Lodi, Arcole, Millesimo, et on ne te les lâche pas. » (p. 433).

26 Voir CH, Les Paysans, p. 499 et suivantes.

27 Voir R.-S. Marzel, « Le langage de la prostituée dans le roman du XIXe siècle ». L'expression du personnage est à rechercher dans $\mathrm{CH}$, Ferragus, p. 29-31.

28 À traduire de la façon suivante: «Puisque Madame vous engage, vous êtes sûr d'être bien reçu. » Cette première réplique adressée à l'Opéra à Rastignac est accompagnée d'une indication physique : « épais Alsacien, dont la figure ronde annonçait une dangereuse finesse ». Voir CH, Le Père Goriot, p. 404.
} 
discours. L'homme d'affaires alsacien réapparaît par la suite à de nombreuses reprises dans La Maison Nucingen et Splendeurs et misères des courtisanes, mais aussi dans César Birotteau, Un Homme d'affaires et La Cousine Bette, avec le même particularisme qui repose sur une transcription directe de la prononciation alsacienne d'une phrase française bien tournée, dans laquelle Balzac se garde d'introduire la moindre erreur de syntaxe.

Un autre personnage alsacien, moins connu que le précédent, constitue lui aussi un modèle caricatural, reproduit par Balzac de façon ludique avec les mêmes libertés dans le code écrit et le même mimétisme phonique : Kolb, le fidèle employé de l'imprimerie de David Séchard à Angoulême, s'exprime sans détours, mais cette fois avec quelques fautes de genre qui dénotent son niveau d'instruction : "Chesbère edre assez riche ein chour pire lui domper sire le gazaquin, a ced ome te chistice! Ch'aime pas sa visache ${ }^{29}$. "

Après l'Alsacien, Balzac s'intéresse au Méridional de langue d'oc dans Les Comédiens sans le savoir, avec le fameux Gazonal, le cousin du Roussillon du peintre Léon de Lora. Animé du même souci stylistique, mais sans faire œuvre de philologue, Balzac reproduit de façon littérale une phrase en signalant les caractéristiques de l'accent:

«Mone proxès, dit-il en grasseyant les $\mathrm{r}$ et accentuant tout à la provençale, est queleque chozze de bienne simple, iles veullente ma fabrique. Je trrouve ici uneu bette d'avocatte à qui jé donne vinte francs à chaque fois pour ouvrirre l'oeil, et jeu leu trouve toujours enedôrmi ${ }^{30}$ !»

Sont naturellement reproduits ici tous les clichés de l'époque sur le parler méridional, dont le ton même prête à sourire ; en se dégageant de toute convention littéraire, l'auteur cisèle un personnage dont l'originalité réside finalement dans la seule façon de s'exprimer.

Balzac, au gré de ses romans, a progressivement trouvé une classification, une sorte d'étiquetage des argots ou des «styles » correspondant à différentes catégories sociales et milieux qui disposent d'un véritable code d'accès au groupe : ainsi, à côté de $\mathrm{l}^{\prime}$ «argot militaire », figurent $l^{\prime}$ «argot des coulisses », $l^{\prime}$ « argot des ateliers », $l^{\prime}$ «argot du Palais », $l^{\prime}$ «argot bureaucratique », $l^{\prime}$ «argot typographique», $l^{\prime} « \operatorname{argot} d u$ journalisme », et

\footnotetext{
${ }^{29}$ À traduire ainsi : «J'espère être assez riche un jour pour lui tomber sur le cataquin, à cet homme de justice ! J'aime pas sa [sic] visage. » Voir CH, Les Illusions perdues, p. 451.

30 Voir CH, Les Comédiens sans le savoir, p. 158.
} 
surtout $l^{\prime}$ «argot de la pègre», celui qui domine tous les autres par son histoire et sa richesse sémantique. Le constat est dressé : «Autant de professions en France, autant d'argots » écrit-il en $1841^{31}$.

Les argots propres aux métiers et milieux sociaux sont mis en exergue dans un contexte d'uniformisation des apparences propre à la période post-révolutionnaire. C'est tout le paradoxe de la démarche qui, tout en distinguant le métier, nivelle les strates de la société, du voleur au soldat en demi-solde, du notaire à la «lorette», en passant par le banquier, l'artiste-peintre, l'imprimeur ou le journaliste. Tous passent par le même creuset, celui d'une prose romanesque qui met à plat tous les discours, ne laissant de distance qu'entre le narrateur et les autres, comme en témoigne l'usage presque systématique de l'italique.

L'usage de l'argot semble bien arrimé au projet littéraire balzacien en ce qu'il met la langue en adéquation avec le monde, allant même jusqu'à tenter de colmater toutes les fissures possibles entre les différentes strates de la société. À ce stade, il est intéressant de s'interroger sur le rôle qu'a pu jouer Balzac dans l'entrée de l'argot en littérature.

\section{Balzac, précurseur au cour de la bataille du roman-feuilleton}

Au moment où sont publiés le Dictionnaire de l'argot et les Mémoires de Vidocq (1828), l'argot suscite auprès du public une vraie curiosité. Comment Balzac s'empare-t-il si rapidement du sujet pour le faire sien ? Nous savons qu'il connaît dès cette époque, grâce à l'époux de son amie Laure, Gabriel de Berny, conseiller à la cour royale de Paris, Vidocq, le célèbre chef de la police parisienne de 1818 à $1827^{32}$ : leur relation a pu se

\footnotetext{
${ }^{31}$ Voir CH, Ursule Mirouet, p. 6.

32 Dans le Code des gens honnêtes (éd. de 1825), aujourd'hui attribué à Balzac, figurent des observations qui font penser que celui-ci s'intéresse au milieu de la pègre parisienne : « Les voleurs ont un langage particulier, leurs chefs, leur police.» Plus loin, il semble déjà connaître Vidocq : «La police parisienne a un besoin perpétuel d'agents secrets [...] Cette armée, dont le sieur Vidocq est le général, peut passer pour les Invalides des voleurs [...] Ces agents inconnus forment encore un monde à part, qu'il ne sera donné à personne de décrire à moins que M. Vidocq ne publie ses mémoires. » Voir H. de Balzac, CEuvres diverses, p. 156 et 200.
} 
développer avant 1830, comme en témoignera beaucoup plus tard l'ami Léon Gozlan ${ }^{33}$. Balzac lui-même affirmera que le policier parisien est le modèle de Vautrin ${ }^{34}$.

Balzac est-il le premier à envisager l'usage de l'argot dans le roman ? Victor Hugo, qu'il fréquente à l'époque, est censé avoir écrit en trois semaines, entre novembre et décembre 1828, Les Derniers Jours d'un condamné, œuvre dans laquelle le narrateur apprend dans le préau de la Conciergerie à «rouscailler bigorne» (parler l'argot). À la lecture de sa correspondance, on apprend que de son côté, Balzac travaille à un ouvrage sur la chouannerie depuis le mois d'août 1828 : en septembre, il est à Fougères chez le général de Pommereul, un ami de la famille, pour étudier les lieux.

Quoi qu'il en soit, l'ouvrage Les Chouans ou la Bretagne en 1799, publié en mars 1829 chez l'éditeur Canel, est le premier roman où Balzac égrène dans un récit de nombreuses expressions populaires et patoisantes, des mots écrits phonétiquement pour mettre en valeur une prononciation d'usage courant dans la paysannerie de l'Ouest. Il y ajoute même des expressions militaires typiques du vocabulaire de l'époque. Le milieu choisi n'est pourtant pas, à proprement parler, celui qui fait usage du langage du dictionnaire d'argot publié en 1827.

L'introduction d'un vocabulaire "populaire» dans le récit romanesque n'est pas remarqué par la critique à ce stade de la carrière de l'écrivain; il est pourtant systématiquement mis en usage par Balzac les années suivantes dans Gobseck, avec le personnage de l'usurier (1830); dans La Transaction (1832), avec les avoués ; dans Ferragus (1833), où est mentionné pour la première fois le terme $\mathrm{d}^{\prime}$ «argot» au sens de «bureaucratique ${ }^{35}$ »; dans L'Ilustre Gaudissart (1833), où le commis voyageur dispose de

33 Pour R. Borderie, qui a édité en 2001 Ferragus, Vidocq pourrait avoir rencontré Balzac dès 1822 et avoir participé à la rédaction de ses Mémoires. Voir L. Gozlan, Balzac intime, p. 311 et suivantes, qui raconte une entrevue Balzac-Vidocq en septembre 1844 au domicile de l'écrivain.

${ }^{34}$ Voir M. Bardèche, Balzac romancier..., p. 437, n. 2. L'auteur cite le droit de réponse de Balzac paru le 11 octobre 1846 à la suite de la lettre d'Hippolyte Castille dénonçant l'immoralité de La Comédie humaine, réponse dans laquelle est clairement affirmé le modèle de Vidocq pour la personnalité de Vautrin. Il indique également que selon Quérard, le bibliographe, les rédacteurs des Mémoires de Vidocq sont les journalistes Morice et L'Héritier de l'Ain; il se trouve que Balzac travaille avec ce dernier au cours des années 1830-1832 à la publication des Mémoires de Sanson.

${ }^{35} \mathrm{CH}$, Ferragus, p. 99. 
«son $\operatorname{argot}^{36} »$; dans Le Médecin de campagne (1833), avec les grognards de l'Empire; jusqu'au Père Goriot (1835), où pour la première fois Balzac s'intéresse au langage de la pègre, avec les débuts de Collin-Vautrin le bagnard et les explications sémantiques sur les mots de « sorbonne » et de « tronche ${ }^{37} »$.

Au cours de cette période, le champ d'application de l'argot est large, Balzac a peu de concurrents sur le terrain, si ce n'est la publication du journaliste Maurice Alhoy sur le bagne de Rochefort en $1830^{38}$, qui propose une nouvelle déclinaison du monde des prisons déjà présenté par Vidocq. Balzac impose un style qui étonne, notamment lorsqu'il fait revivre, en pleine genèse de la légende napoléonienne, les campagnes des anciens soldats de l'Empire, décrites avec leurs propres mots.

Les premiers accents du bagnard Collin et les débuts de Lucien Chardon à Paris inquiètent pourtant les adversaires de Balzac, qui y voient une sorte de dérapage dans la fange, où l'auteur finirait par se complaire. Parmi ces ennemis irréductibles s'illustre Janin qui, dans un long article de la Revue de Paris de juillet 1839, se plaît à dénoncer un style dans lequel l'introduction du parler argotique donne au récit une tonalité toujours plus vulgaire :

«M. de Balzac excelle à reproduire les affreux détails de la misère [...], donc fermons les yeux, retenons notre haleine, mettons à nos jambes les bottes imperméables des égoutiers et marchons tout à notre aise dans cette fange [...] Rien ne lui échappe, pas une ride, pas une croûte gluante de cette lèpre immonde [...] Un écrivain n'est pas un chiffonnier [...] Pourquoi donc voudriez-vous faire de la littérature de ce pays un vaste cloaque? Une fois là, vous n'êtes plus dans la vérité, vous êtes dans le crime. Vous n'êtes plus l'historien de la société, vous êtes l'historien du bagne ${ }^{39}$. »

Au cœur de l'apparition du nouveau style de roman populaire, il faut à présent souligner la lutte sourde que se livrent écrivains, journalistes et essayistes pour la conquête du marché du roman-feuilleton, en expansion rapide. La comparaison avec Eugène Sue, l'étoile montante du roman-feuilleton, est rapidement établie par certains critiques dès

\footnotetext{
${ }^{36} \mathrm{CH}$, L'Illustre Gaudissart, p. 319.

${ }^{37}$ CH, Le Père Goriot, p. 453. Voir aussi P. Brunel, « Le sublime et le grotesque chez Balzac », p. 31-68.

${ }^{38}$ Maurice Alhoy (1802-1856), journaliste, créateur du Figaro en 1826, s'est intéressé particulièrement au monde de la pègre : bagnes, brigands célèbres, prisons de Paris, physiologie de la lorette.

39 Voir J. Janin, « Un grand homme de province à Paris », p. 175.
} 
1840 : chez Balzac, «Le style pèche souvent, il se ressent du déplorable goût de cette époque et se sert d'une langue qui, dans quelques années, ne sera plus qu'un objet de curiosité $^{40}$ »; chez son rival Eugène Sue, c'est plutôt l'improvisation qui est dénoncée, même si l'écrivain est reconnu comme le romancier qui plaît le plus au public ${ }^{41}$.

À cet égard, le grand succès des Mystères de Paris d'Eugène Sue ${ }^{42}$ au cours des années 1842-1843 est très symptomatique du climat qui règne alors dans le petit milieu littéraire parisien: l'argot de la pègre parisienne, très présent dans l'écriture de Sue, atteint les sommets de la reconnaissance littéraire. Balzac, qui lutte pour sa survie d'écrivain, qui a subi les assauts de ses adversaires en raison de la vulgarité de certains de ses personnages, accuse le coup : sa réaction négative tourne à la rivalité d'homme à homme ; il va devoir vaincre le «complexe Eugène $S_{\text {ue }}^{43}$ » en se résolvant à ne plus faire $\mathrm{du}$ Balzac mais «du Sue tout pur » selon ses propres termes ${ }^{44}$. Puis il se ravise à nouveau et s'en ouvre à Mme Hanska :

«Vous lirez l'étrange comédie d'Esther et vous verrez un monde parisien [...] qui vous sera toujours inconnu, bien autre que le faux Paris des Mystères et constamment comique, et où l'auteur, comme dit G. Sand, applique un coup de fouet à faire sauter toutes les enveloppes et les guenilles mises sur les plaies ${ }^{45}$.»

Un plus tard, il insiste en affichant de bonnes résolutions :

«Je ne peux pas, je ne dois pas, je ne veux pas subir la dépréciation qui pèse sur moi par les marchés de Sue et par le tapage que font ses deux ouvrages [Les Mystères de Paris et Le Juif errant], je dois faire voir par des succès littéraires [...] que ces œuvres en détrempe sont des

\footnotetext{
${ }^{40}$ Voir Le Constitutionnel du 8 mai 1840, revue littéraire, « Euvvres de M. de Balzac, premier article signé L. R. ».

${ }^{41}$ Journal des débats du 14 juin 1842: «M. Eugène Sue. Le Morne-au-Diable ou l'aventurier par CuvillierFleury ».

42148 livraisons du Journal des débats, du 19 juin 1842 au 15 octobre 1843.

${ }^{43}$ Voir K. Murata, «Assimilation de l'esthétique dans le roman-feuilleton chez Balzac », p. 1, citation du texte de R. Guise, «Balzac et le roman-feuilleton...», p. 297.

${ }^{44}$ Voir H. de Balzac, Lettres à l'étrangère, t. 2, lettre du 31 mai 1843, p. 171. Voir aussi A. Lascar, «Balzac et Sue, échanges à feuilletons mouchetés », p. 201 et suivantes.

${ }^{45} \mathrm{H}$. de Balzac, Lettres à l'étrangère, t. 3, p. 301, lettre du 5 février 1844.
} 
devants de cheminée [...] Or, si j'éteins à mon profit cette furia francese qui se porte aux Mystères comme à la polka [...], je puis trouver $200000 \mathrm{~F}^{46}$. »

Descendu dans l'arène du roman populaire tout en prenant acte de l'évolution du marché littéraire pour y affronter le nouveau maître du feuilleton, Balzac a décidé de réorienter sa recherche romanesque. En réalité, il va réussir son pari en mettant en pratique ses idées.

Après avoir initié des projets avortés d'imitation de Sue, comme Les Enfers de Paris, il lance chez l'éditeur Hippolyte Souverain en décembre 1843 une nouvelle publication intitulée Les Mystères de province, regroupant plusieurs anciens romans comme La Muse du département. Ce dernier échec le contraint à attaquer finalement sur deux fronts.

Le premier front est celui de la production littéraire : après l'indifférence avec laquelle est reçue Esther (deuxième et troisième parties de Splendeurs et misères des courtisanes) de juillet 1843 à septembre 1844, après l'échec de la sortie des Paysans en décembre 1844, Balzac s'est effacé, si l'on en croit la presse: «Si quelques-uns des rois du feuilleton [Alexandre Dumas et Eugène Sue] commencent à pâlir, d'autres sont à peu près oubliés. Que sont devenus en effet MM. Soulié et de Balzac ${ }^{47}$ ?»

Le grand retour s'effectue en octobre-décembre 1846 avec La Cousine Bette, publié dans le Constitutionnel en quarante livraisons ${ }^{48}$. La Cousine Bette met en scène plusieurs personnages féminins du monde parisien dont la principale, Lisbeth Fisher, surnommée «Bette» (sic!), la «sauvage Lorraine», sorte de Vautrin femelle, ancienne paysanne pauvre des Vosges devenue ouvrière passementière à Paris, et d'autres personnages secondaires, comme la courtisane Valérie Marneffe ou la grande figure de la prostituée parisienne, Atala Judici. L'argot est peu présent dans le texte, mais il est mentionné à plusieurs reprises pour caractériser le langage d'une catégorie sociale: $l^{\prime}$ «argot des coulisses des théâtres », celui des «ateliers », celui de la Bourse et celui des "gamins de

\footnotetext{
46 Ibid, p. 433, lettre du 17 septembre 1844.

47 Voir L'Univers du 15 septembre 1846, « Nouvelles du pays littéraire », article signé Eug..., cité par R. Guise,

«Balzac et le roman-feuilleton», p. 327.

${ }^{48} \mathrm{Du} 8$ octobre au 3 décembre 1846 ; il s'agit d'un résultat très honorable, qui ne supporte néanmoins pas la comparaison avec Le Juif errant de Sue (150 livraisons de juin 1844 à août 1845) et Le Comte de Monte-Christo de Dumas (175 livraisons d'août 1844 à janvier 1846).
} 
Paris $^{49}$ ». C'est le retour du succès, ce que Balzac proclame aussitôt : « Il y a une immense réaction en ma faveur. J'ai vaincu ${ }^{50}$ ! »

Le second front, proche du premier, est celui de la grande livraison romanesque sous forme de feuilleton dans La Presse en avril-mai 184751, La Dernière Incarnation de Vautrin, qui obtient un succès d'estime : censé conclure le cycle Illusions perdues - Splendeurs et misères des courtisanes, l'ouvrage est le fruit d'une véritable préparation à laquelle Balzac s'est soumis en fréquentant l'univers du palais de justice de Paris ${ }^{52}$, dont il va présenter une description très réaliste.

Entièrement consacré au milieu du crime, le récit, largement ponctué du vocabulaire des prisons, de dialogues et d'expressions typiques du milieu criminel, apporte un regard nouveau sur un univers auquel Balzac applique désormais de façon privilégiée et définitive le terme d'argot pour qualifier son langage mystérieux. De plus, la présence d'un septième chapitre intitulé «Essai philosophique, linguistique et littéraire sur l'argot, les filles et les voleurs » contribue à consacrer Balzac comme le premier théoricien de ce phénomène littéraire.

$\mathrm{Au}$ terme de ces deux décennies de combat littéraire où l'usage de l'argot a tenu une place importante, Balzac peut apparaître aux côtés d'Hugo comme un précurseur, utilisant le langage argotique avec une remarquable constance, de 1829 jusqu'à la fin de sa vie d'écrivain.

\section{L'expression d'une vision radicale}

Nous avons vu Balzac utilisant à l'origine le terme $\mathrm{d}^{\prime}$ « argot» de façon très large, le déployant au-delà de ses bornes naturelles, lui conférant une certaine valeur poétique selon les situations et les personnages. Balzac ne peut manquer d'avoir un intérêt personnel pour l'argot: amoureux de Rabelais, il s'intéresse à la forme dialectale et historique des mots. Sans passion particulière pour la philologie, il a en revanche un goût

\footnotetext{
${ }^{49}$ CH, La Cousine Bette, vol. 12, p. 50, 139, 208 et 339.

50 Voir H. de Balzac, Lettres à l'étrangère, t. 4, lettre du 18 octobre 1846, p. 78. R. Guise, dans «Balzac et le romanfeuilleton ", p. 283 et suivantes, prétend que ce succès est dû à la lassitude du public face aux nouveautés devenues stéréotypées d'Eugène Sue comme Martin, l'enfant trouvé.

${ }^{51}$ Le texte fait l'objet de 17 livraisons du 13 avril au 4 mai.

52 Il a obtenu une autorisation de visiter les lieux, ce qu'il fait le 13 décembre 1845.
} 
avéré pour le secret, le travestissement et le masque : le langage codé l'intéresse au même titre que les noms qu'il se donnait dans sa jeunesse ; en même temps qu'il accompagne les avatars successifs de ses héros, l'argot donne une force symbolique à certains moments de La Comédie humaine; à cette occasion, le narrateur suggère, convertit, transforme le visage de ses personnages.

C'est que Balzac fait tout d'abord de l'argot un mode documentaire de l'expression romanesque: il s'agit au départ pour lui d'engager une démarche de sociologue en traduisant au plus près une réalité sociale qui constitue la colonne vertébrale de son œuvre. Pour mettre en lumière les expressions qui sont dans l'esprit de son époque, il lui faut se rapprocher le plus possible d'une vérité et d'une certaine authenticité. Le mode de langage fait partie des outils indispensables de création pour l'écrivain ; vient en parallèle ou par la suite la question du sujet: les affaires judiciaires, qui sont censées donner au public le sens d'un romanesque «vrai», au «sensationnel» de proximité, font naturellement partie de l'arsenal des thèmes balzaciens depuis les premières œuvres de jeunesse ${ }^{53}$.

L'argot au service de la technique romanesque, c'est aussi ce que Balzac finit par maîtriser. Pour caractériser la psychologie de ses personnages, il a plutôt tendance à dresser des portraits donnant lieu à de longs développements. L'usage de l'argot comme expression idiomatique traduisant l'origine sociale lui permet alors de construire des dialogues qui finissent par ouvrir de larges perspectives à l'action romanesque.

À la différence de Sue et même de Dumas, trop préoccupés de construire une action sans cesse en mouvement en évitant de perdre du temps dans la description psychologique, Balzac fait du dialogue de ses personnages sous une forme expressive et calculée le mode de révélation des couches profondes et des drames de la société.

Un autre trait est apporté par l'argot dans l'écriture romanesque de Balzac: le recours à l'actualité. L'idiome du milieu qu'il décrit lui permet de se situer pleinement dans le présent, ce qui renforce la cohésion de son œuvre tout en suscitant l'intérêt du public. Il lui faut pour cela se nourrir d'une matière première référencée, la vie dans les prisons, les couloirs du Palais, l'antichambre des hôtels princiers ou des études de notaires et d'avoués, les coulisses des théâtres.

53 Depuis la parution d'Annette et le criminel en 1822. 
Cette matière première, qui devrait se situer à la périphérie de Paris, est mise en scène au centre même de la ville, posant la présence du peuple et de sa misère comme toile de fond du roman. Ici, le récit n'est plus seulement affaire d'imagination, mais aussi et surtout d'observation de l'existence la plus ordinaire.

Si Balzac a vu dans l'« être argotique » plusieurs catégories sociales qui s'entrecroisent, la «fille» en duo avec le «bandit» (Ida Gruget et Ferragus), le commis voyageur de commerce et le producteur agricole (Gaudissart et Margaritis), le juge et l'avoué (Derville et Popinot), le fonctionnaire ministériel, le chef de bande et le bagnard (Ferragus et Vautrin), etc., tous finissent par se retrouver dans un même monde, où on se côtoie sans se ressembler.

Sans doute le succès des Mystères a-t-il influencé Balzac en le forçant à concentrer sa recherche sur l'expression secrète en vigueur dans le milieu du crime. Mais lorsqu'il parle $\mathrm{du}$ « milieu » parisien et de son langage, il se différencie très clairement d'Eugène Sue, car il se refuse à montrer un ouvrier résigné plaignant les bourgeois pour leur ignorance de la pauvreté. Balzac préfère stigmatiser l'imbrication de la société bourgeoise avec le monde des voleurs et des « filles », dont le langage, l'argot, est devenu à la mode.

Balzac développe sa théorie sur l'argot dans le septième chapitre de La Dernière incarnation de Vautrin: dans ce texte de six pages, qui figure en introduction de la scène de l'arrivée de Vautrin au cœur du préau de la Conciergerie, il entreprend d'en théoriser l'usage. Il affirme en premier lieu que ce langage est celui « des Grecs [! ] des filous, des voleurs et des assassins », reléguant toute autre forme de langage codé à des pratiques professionnelles dérivées ou assimilées et renonçant par là même au large spectre d'idiomes en usage dans toutes les strates de la société. Il situe néanmoins les origines de l'argot dans «la haute Antiquité », avec un dixième de gaulois et un autre dixième de «langue romane $\mathrm{e}^{54} » !$

Cette analyse lui permet de rompre avec le climat ambiant en ramenant l'argot de la pègre à un langage du crime, violent, bestial, affreux, mais aussi rusé, destiné à lutter contre l'ordre social. Il répond ainsi à ceux qui l'accusent d'avoir contribué à rendre

${ }^{54}$ CH, La Dernière Incarnation de Vautrin, p. 30. Voir P. Citron, « La Dernière Incarnation de Vautrin », p. 370-372. Balzac ouvre ici le débat sur la signification de l'argot, langue du crime ou langue de la misère, débat que Victor Hugo poursuivra après la mort de Balzac avec la publication des Misérables en 1862. 
l'argot fashionable, en effaçant la gravité du vocabulaire du crime, en le confondant avec toute forme de langage abâtardi, en lui faisant pénétrer la langue commune au nom du « pittoresque » et du «fantastique ». Cet « encanaillement » littéraire ne correspond pas à son projet, et il ne peut que déplorer de voir « cet étrange vocabulaire » passer « sur les

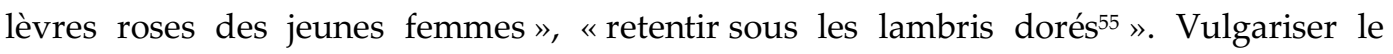
vulgaire tout en dénonçant sa «gentrification», telle est sans doute le but ultime des dernières pages, les plus abouties, de La Cousine Bette. Balzac a ici tout naturellement en ligne de mire le succès parisien d'Eugène Sue.

Balzac se démarque en fin de compte radicalement de Sue pour ne pas céder à la tentation politique et cultiver sa propre poétique du roman : il maintient un équilibre savant entre le récit feuilletonesque, qui correspond aux goûts du public, et une intrigue exigeante et correspondant aux impératifs de sa propre construction romanesque. Morale et bon goût n'entrent pas dans les règles de l'écriture balzacienne ; l'usage de l'argot n'y figure pas non plus, avec les stéréotypes que développe tout observateur des quartiers parisiens.

$\mathrm{Au}$ contraire, les laideurs contemporaines, dérangeantes, qui privent les classes dominantes de l'alibi de l'ignorance, tel est le monde de Balzac, un monde fantastique au fond de sa «caverne sociale»: l'argot devient un mode d'expression de cette poésie «noire», violente et terrible, éloignée de toute vertu, qui a définitivement rejeté l'idée poétique du bien. C'est le grand naufrage du beau romanesque idéalisé et de la poésie qui s'y rattache; l'univers de Vautrin préfigure sans doute celui de la poésie de Baudelaire.

Balzac a voulu se donner comme but de composer un discours adapté selon la nature sociale des personnages: «l'historien du bagne» raillé par Janin, qui est accusé de complaisance pour la saleté et la misère, est passé maître dans l'art d'user du langage des criminels et des classes laborieuses des villes comme des campagnes, ce qui vient à point nommé pour que ses détracteurs contemporains incitent à rejeter son œuvre. C'est d'ailleurs à la lecture des Paysans et de La Cousine Bette qu'Engels, à la suite de Marx, a exprimé clairement son admiration pour cette œuvre d'analyse et de description de la société bourgeoise de son temps :

${ }^{55} \mathrm{CH}$, La Dernière Incarnation de Vautrin, p. 29. 
«Il décrit comment les derniers vestiges de cette société modèle ont succombé devant l'intrusion du parvenu vulgaire et enrichi ou ont été corrompus par lui [...]. J'ai appris plus de lui que de tous les historiens, économistes et statisticiens réunis de l'époque ${ }^{56}$. »

À la différence de ceux d'Eugène Sue, dont les Mystères ne sont que des objets imaginaires et non des objets de connaissance, les personnages de Balzac sont réalistes et le milieu dans lequel ils évoluent est conforme à l'analyse de classe qu'opère le philosophe sur la société de la monarchie de Juillet. Balzac s'affirme ainsi comme l'antiSue : sa peinture sociale est différente, fondée sur le rejet de toute démagogie ; sa vision se déploie selon le schéma qu'il a défini quelques mois avant sa mort : «Je fais partie de l'opposition qui s'appelle la vie ${ }^{57}$. »

La contribution de Balzac au statut littéraire de l'argot est fondamentale: La Comédie humaine participe à la naissance d'un réalisme « langagier ». Balzac voit dans cet idiome une forme d'expression qui traverse plusieurs classes de la société, même si l'argot prédomine dans le milieu du crime.

Le roman-feuilleton a eu une efficacité hautement politique : comme Sue, mais de manière différente, Balzac fait circuler grâce à l'argot des fictions dans l'espace public sous une forme crue et quotidienne qui a vocation à constituer une forme originale de texte politique; en envoyant au feuilletoniste des témoignages vécus sur la misère des uns et la corruption des autres, le récit balzacien en argot constitue une sorte de lieu de parole. Le contenu peut éventuellement revêtir un sens politique fort à la veille de la révolution de 1848: Vautrin, le bagnard, l'assassin, transformé en chef de la police, devient ermite et se fait rentier, en plaçant sans doute ses économies à la banque Nucingen. Cette conclusion pleine d'ironie du cycle Vautrin a conduit Balzac à explorer

56 Correspondance de Friedrich Engels et Karl Marx, lettre d'Engels à Margaret Harkness à Londres, avril 1888, p. 503 : « He describes how the last remnants of this [...] model society gradually succumbed before the intrusion of the vulgar monied upstart, or were corrupted by him. [...] I have learned more than from all the professed historians, economists and statisticians of the period together. "

57 H. de Balzac, Correspondance, lettre à Laure Surville, 20 octobre 1849. Cité par G. Picon, Balzac par luimême, p. 158. 
les limites du possible ${ }^{58}$. L'argot fait en fin de compte partie de la masse scripturale que Balzac a transmutée progressivement en idée d'œuvre, celle de La Comédie humaine. L'image de Balzac en ressort toujours aussi inclassable et inattendue. Le jugement de son confrère et ami Théophile Gautier ramène Balzac à sa vraie dimension : pour exprimer une multitude de détails, de caractères et de types, ce dernier a été obligé « de se forger une langue spéciale, composée de toutes les technologies, de tous les argots de la science, de l'atelier, des coulisses, de l'amphithéâtre même... »; grâce à cette langue nouvelle, il a imposé son style, « le style nécessaire, fatal, mathématique de son idée ${ }^{59}$ ».

\section{Bibliographie}

BALZAC, Honoré de, La Comédie humaine, édition critique en ligne, Groupe international de recherches balzaciennes et groupe ARTFL (Université de Chicago) : http://www.v1.paris.fr/commun/v2asp/musees/balzac/furne/aatable.htm

BARDÈCHE Maurice, Balzac romancier. La formation de l'art du roman chez Balzac jusqu'à la publication du Père Goriot (1820-1835), Genève, Slatkine reprints, 1967, 630 p.

BORDAS Eric, Balzac, discours et détours: pour une stylistique de l'énonciation romanesque, Toulouse, Presses universitaires du Mirail, 2003, 367 p.

BRUNel Pierre, «Le sublime et le grotesque chez Balzac: l'exemple du Père Goriot», L'Année balzacienne, 2001, p. 31-68.

CASTEX Pierre-Georges, "Introduction», dans La Comédie humaine, vol. 1, Paris, La Pléiade, 1976, p IX-LXXVI.

Citron Pierre, «Dernière incarnation de Vautrin », L'Année balzacienne, 1967, p. 375-377.

CorRespondance de Friedrich Engels et Karl MarX, éd. du Progrès, Moscou, 1953.

\footnotetext{
${ }^{58}$ Selon P.-G. Castex, l'examen du manuscrit du Père Goriot permet de penser que Balzac a imaginé un temps faire arrêter Jacques Collin / Vautrin par Vidocq lui-même! Voir l'introduction à l'édition de La Pléiade de La Comédie humaine, t. 1, Études de mœurs, scènes de la vie privée, p. XXVII.

${ }^{59}$ T. Gautier, Honoré de Balzac, p. 135.
} 
Deruelle Aude, «Glose et prose romanesque », dans J.-L. Diaz et A. Guyaux, Illusions perdues, actes du colloque organisé par la Société des études romantiques et l'université Paris IV - Sorbonne, Paris, Acta fabula, 2004, p. 105-118.

DiCTIONNAIRE DE L'ARGOT ou guide des gens du monde pour les tenir en garde contre les mouchards, filoux, filles de joie et autres fashionables et petites-maîtresses de même trempe, par un monsieur comme il faut, ex-pensionnaire de Ste-Pélagie, Paris, Chez les marchands de nouveautés, 1827.

DUFOUR Philippe, «Les Illusions perdues: une histoire des mœurs langagières », L'Information littéraire, 2004, vol. 68, p. 14-23.

DURRENMATT Jacques, « Polices du langage, présentation », Romantisme, 2009, no 4, p. 3-8.

GAUTIER Théophile, "Honoré de Balzac », dans CEuvres complètes de H. de Balzac, A. Houssiaux, 1855, vol. 1, p. 1-16.

GozLAn Léon, Balzac intime, Balzac en pantoufles, Paris, Librairie illustrée, 1886, 397 p.

GUISE René, « Balzac et le roman-feuilleton », L'Année balzacienne, 1964, p. 283-338.

JANIN Jules, «Un grand homme de province à Paris», Revue de Paris, juillet 1839, t. VII, p. 145-178.

LABBÉ Mathilde et LIÉBART Landry (dir.), Normes et littérature au XIXe siècle, actes des journées doctoriales 2010 de la Société des études romantiques et dix-neuviémistes (SERD), [en ligne], Fondation Singer-Polignac, 2011, 89 p.

LASCAR Alex, "Balzac et Sue : échanges à feuilletons mouchetés", L'Année balzacienne, 2010, n 11, p. 201-221.

LÉVI AlvaRÈs David, Les omnibus du langage, Bruxelles, 1829, 149 p.

LYON-CAEN Judith, «Lectures politiques du roman-feuilleton sous la monarchie de Juillet », Mots. Les langages du politique, mars 1998, no 54, p. 113-122.

MARZEL Shoshana-Rose, «Le langage de la prostituée dans le roman du XIXe siècle », dans Actes du Ve congrès de la Société des études romantiques et dix-neuviémistes (SERD), Paris, 2012 [en ligne], Fondation Singer-Polignac, 2013, 10 p.

MATORÉ Georges, Le vocabulaire et la société sous Louis-Philippe, Paris, Droz, 1951, 369 p. 
MAURIAC François, Mémoires intérieurs, Paris, Flammarion, 1959, 260 p.

MURATA Kyoko, «L'assimilation de l'esthétique du roman-feuilleton chez Balzac », dans

«Balzac et alii, génétiques croisées, histoires d'éditions », actes du colloque du Groupe international de recherches balzaciennes (GRIB), juin 2010, Paris, 15 p. dactyl.

PICON Gaëtan, Balzac par lui-même, Le Seuil (Écrivains de toujours), Paris, 1953.

Proust Marcel, Contre Sainte-Beuve, Paris, Gallimard, 1954, 446 p.

RosA Guy, "Essais sur l'argot: Balzac (Splendeurs et misères des courtisanes) et Hugo (Les Misérables)», http://groupugo.div.jussieu.fr/Default_Etudes.htm. Publication en ligne, groupe Hugo, université Paris VII.

SAINT-Hilaire Raban et SAINT-Hilaire Marco, Mémoires d'un forçat ou Vidocq dévoilé, Paris, Langlois, 4 vol., 1828-1929.

SARMENT Jacqueline et TULARD Jean, Balzac et le monde des coquins, catalogue d'exposition, Paris, Maison de Balzac, 1985, 78 p. ill.

Thorel-Cailleteau Sylvie, Splendeurs de la médiocrité: une idée du roman, Paris, Droz, 2008, 256 p.

VIDOCQ François, Mémoires, Paris, Tenon, 1828, 4 vol.

\section{Résumé}

Des Chouans à La Dernière Incarnation de Vautrin, l'usage balzacien de l'argot a beaucoup mobilisé la recherche historique et littéraire: les rencontres avec le policier Vidocq, la concurrence d'Eugène Sue et même de Victor Hugo, la référence à Villon et Rabelais, ces nombreux éléments mettent en lumière un intérêt majeur pour ce que l'on pourrait qualifier de « procédé littéraire » dans La Comédie humaine. On se propose d'examiner l'ensemble de la question au regard d'une perception nouvelle de l'œuvre, qu'il convient de faire reposer sur les enjeux apparus autour de l'émergence du roman populaire et de la langue balzacienne en pleine période romantique. 



\title{
L'œuvre provençale de Castil-Blaze, précurseur du mouvement félibréen
}

\author{
Roger Klotz \\ Professeur certifié de lettres modernes honoraire \\ Docteur en lettres, habilité à enseigner le provençal
}

\begin{abstract}
Extrait de : CABOURET Bernadette (dir.), La communication littéraire et ses outils : écrits publics, écrits privés, éd. électronique, Paris, Éd. du Comité des travaux historiques et scientifiques (Actes des congrès nationaux des sociétés historiques et scientifiques), 2018.

Cet article a été validé par le comité de lecture des Éditions du Comité des travaux historiques et scientifiques dans le cadre de la publication des actes du 139e Congrès national des sociétés historiques et scientifiques tenu à Nîmes en 2014.
\end{abstract}

François Blaze est né à Cavaillon le 1er décembre 1784 et est mort à Paris le 11 décembre 1857. C'est sous son nom de plume, Castil-Blaze, qu'on le connaît d'abord comme critique musical puis comme adaptateur d'œuvres lyriques de Rossini, de Mozart et de Weber. C'est cependant à son œuvre provençale que Castil-Blaze semble accorder le plus d'importance. Dans son Molière musicien, il écrit :

«Né soldat du pape, à Cavaillon dans le Comtat-Venaissin, je suis encore moins Français que ceux de Marseille... Je n'attache de prix qu'à mes œuvres provençales. C'est le seul bagage poétique et musical que je lègue à la postérité1. »

Ce n'est pourtant qu'en 1865, huit ans après la mort du poète cavaillonnais, que Mistral et Roumanille publièrent vingt-sept poèmes de Castil-Blaze dans Un Liame de rasin. Le recueil comprend également des poèmes d'Adolphe Dumas, de Jean Reboul, de Glaup, de Toussaint Poussel. Dans la dédicace à la comtesse Lamsdorff, Mistral et Roumanille justifient la publication de ce recueil collectif : « [...] quàuquis-un de nostis ami e coumpan en Felibrige èron mort aquéslis an, avans d'agué liga soun fais, valent-à-dire, publica e adouba coume se dèu la rejouncho de sis obro²».

\footnotetext{
${ }^{1}$ Castil-Blaze. Molière musicien, t. 1, p. 484.

${ }^{2}$ J. Roumanille et F. Mistral, Un Liame de rasin, p. $5:$ : [...] quelques-uns de nos amis en Félibrige étant morts cette année, avant d'avoir publié l'ensemble de leur œuvre » (traduction de l'auteur).
} 
En publiant des poèmes de ces auteurs, Mistral et Roumanille ont voulu rassembler des œuvres qui constituent les racines immédiates du Félibrige, dont Castil-Blaze est donc un précurseur.

Deux poètes provençaux nous livrent une image de Castil-Blaze dans Un Liame de rasin. En 1858, un an après la mort de l'écrivain, Adolphe Dumas compose un poème «à la memori d'un brave ome». Après avoir rappelé la place que Castil-Blaze a tenue dans l'histoire de la musique, il écrit :

«Un pau de pebre, un pau de sau,

Soupavo de faiou baneto ;

Pièi disiè de vers prouvençau,

E cantavo de cansouneto...

Nous parlavo de la Prouvenço,

Mai iè poudiè plus reveni ${ }^{3}$. »

Castil-Blaze apparaît comme un homme aux goûts simples qui, à Paris, rêve de la Provence qu'il ne peut que «canta » dans ses « cansouneto».

En 1858 également, Toussaint Poussel publie un Adessias - A la memori de Castil-Blaze:

«Moussu, quand nous disias, enco de Roumaniho,

Vosti conte galoi-que nous fasien passa

De tant bon quart-d'ouro, en famiho,

Moussu Blaze, i a'n an, quau s'anavo pensa

Que devias ansin nous leissa ${ }^{4}$ ?»

Toussaint Poussel nous livre ainsi l'image d'un conteur plein d'humour. On note que Castil-Blaze a été reçu chez Roumanille, sans doute dans la boutique de la rue SaintAgricol, à Avignon, où il a pu ainsi être en contact avec les créateurs du Félibrige.

Gustave Bénédit, l'auteur de Chichois, confirme l'image donnée par Toussaint Poussel :

${ }_{3}^{3}$ Ibid., p. 121 sq. : «Un peu de poivre, un peu de sel / Nous soupions de haricots ; / Puis il disait des vers provençaux, / Il chantait des chansonnettes... / Il nous parlait de la Provence, / Mais ne pouvait plus y revenir. » (Traduction de l'auteur).

${ }^{4}$ Ibid., p. 260 : «Monsieur, quand vous nous disiez chez Roumanille / Vos contes joyeux qui nous faisaient passer / de si bons moments en famille / Monsieur Blaze, certains pensaient: / Devriez-vous nous laisser ainsi ? » (Traduction de l'auteur). 
«Despièi que sies parti, lou sénat deï blagä̈ré

A bello fa de bru, moun cher, maï ri plus gaïré5. »

Bénédit rencontrait Castil-Blaze au café Bodoul, près de la rue Saint-Ferréol, à Marseille. Horace Bertin écrit que le poète cavaillonnais « racontait là chaque soir les histoires les plus folles et les fables les plus bouffonnes ${ }^{6} »$. Il apparaît donc que Castil-Blaze a une réputation de grand blagueur. À sa gaieté naturelle, il faut joindre un amour certain de la parole, une verve toute méditerranéenne.

On note surtout qu'il est estimé par les écrivains qui ont participé à la renaissance provençale. Mistral et Roumanille donnent les raisons littéraires de cette estime :

«Ero un Prouvençau dins l'amo... Aquèu troubaire s'estaquè touto sa vido à faire ressourti soun ouregino, en counservant en plen Paris, lou parla naciounau e li maniero sèns façoun de la Prouvènço [...] Castil-Blaze es esta di proumié qu'an sachu, dins noste siècle, rèndre à la lengo prouvènçalo soun gàubi poupulàri, sa forço d'espressioun e soun franc naturau. Ero, dins touto la forço dou terme ço qu'appellon vuei un realisto ${ }^{7}$. »

On note également que Castil-Blaze est à Paris un véritable "mainteneur » du «parla naciounau » de la Provence. Il a rendu au provençal «sa forço d'espressioun »; Mistral et Roumanille le situent donc parmi les «réalistes ». Emile Ripert, dans La Renaissance provençale, évoque surtout « les réalistes marseillais » qui, comme Bénédit, l'ami de CastilBlaze, participent, par une langue pleine de verve et de truculence, à la résurrection du provençal. Il est clair cependant que ce courant réaliste ne se cantonne pas à Marseille. Emile Ripert signale également Désanat, de Tarascon, et Pierre Bonnet, de Beaucaire. À une époque où la poésie française est dominée par Lamartine, Musset et Vigny, sans doute peut-on inscrire la poésie de Castil-Blaze dans un courant réaliste provençal.

\footnotetext{
${ }^{5}$ G. Bénédit, «Epitro à Castil-Blaze», p. 373 : « Depuis que vous êtes parti / Le sénat des blagueurs fait du bruit mais ne rit plus. » (Traduction de l'auteur).

${ }^{6}$ H. Bertin, Histoire anecdotique des cafés de Marseille, p. 32.

${ }^{7}$ J. Roumanille et F. Mistral, Un Liame de rasin, p. 7-8 : «Il était provençal dans l'âme ; ce poète a souligné toute sa vie son origine en conservant à Paris le parler national de la Provence. Castil-Blaze a été le premier qui a su rendre au provençal son caractère populaire, sa force d'expression et son franc naturel ; c'est ce qu'on appelle un réaliste. » (Traduction de l'auteur).
} 
Des vingt-sept poèmes publiés dans Un Liame de rasin, onze sont des chansons, dont Castil-Blaze a lui-même composé la musique. C'est ainsi le cas de la romance qu'il a écrite sur Lou vin de Tavèu. Cinq poèmes sont écrits sur des airs d'opéra. Il y a ainsi $L^{\prime} E r$ d'intrado de Figaro ou La Calounnio, des adaptations en provençal d'airs du Barbier de Séville de Rossini, que Castil-Blaze a par ailleurs adapté en français. On trouve aussi une Cansoun d'ibrougno, composée sur un air de Robin des bois; il s'agit là, on le sait, de l'adaptation par Castil-Blaze du Freischütz de Weber. L'œuvre provençale de Castil-Blaze ne se distingue pas, on le voit, de ses travaux d'adaptation musicale.

Le plus long poème de Castil-Blaze porte sur Lou musician et est dédicacé à Bénédit. Le musicien apparaît d'abord comme un artiste pour qui seul l'art compte ; il peut négliger sa tenue, l'argent, les soucis matériels. Mais cette « vie de bohème » a des limites, puisque l'envie règne sur le monde des artistes :

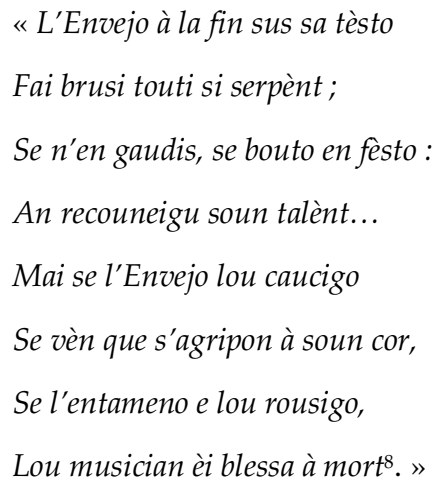

Castil-Blaze décrit ici l'envie d'une manière qui rappelle un peu la façon dont Beaumarchais dénonce la calomnie dans Le Barbier de Séville. Il n'y a peut-être pas là que des souvenirs littéraires : Castil-Blaze, qui, dans le Journal des débats, a critiqué beaucoup de monde, a subi à son tour des critiques venimeuses. Peut-être le musicographe, professionnellement "blessa à mort», a-t-il trouvé une certaine consolation dans la littérature provençale.

À travers son œuvre provençale, Castil-Blaze recrée son univers comtadin. Ses poèmes évoquent la région de Cavaillon : on voit apparaître le «Ventour », Vedène, la Sorgue,

\footnotetext{
8 Ibid., p. 83-85 : «Sur sa tête, l'envie / fait retentir les serpents ; / On a ainsi reconnu son talent... / Mais l'envie le foule aux pieds ; / si elle s'agrippe à son corps, / si elle le blesse et le ronge, / le musicien est blessé à mort » (traduction de l'auteur).
} 
Bédarride, Courtéson, Tavel. Lou Vioulounaire décrit un bal au début du XIXe siècle : le thème de la musique croise l'étude de mœurs, car le bal a joué un grand rôle dans la vie rurale jusqu'en 1914 : c'est là que les jeunes gens se rencontraient. L'Ome prepauso évoque la conquête de l'Algérie, qui avait sensibilisé l'opinion provençale. Dans Lou Vin de Tavèu enfin, on trouve toute une série de plats, simples mais préparés avec des produits du terroir :

«Pourgès l'anchoio emé la sardo,

Porri, andouieto, emai cavia,

Anguielo cuecho à la moustardo,

Aco nous vai desautera9. »

La reconstitution de cet univers comtadin, fait de joies simples, correspond peut-être pour Castil-Blaze à un « retour à la quiétude du sein maternel ${ }^{10} »$. Peut-être recherche-t-il dans l'évocation de l'univers de son enfance un apaisement contre les agressions parisiennes de sa vie professionnelle.

Mistral et Roumanille ont sans doute eu raison de voir dans l'œuvre provençale de CastilBlaze une des sources de la littérature félibréenne. Les poèmes publiés dans Un Liame de rasin tiennent effectivement une place importante dans l'œuvre de Castil-Blaze : ils font apparaître un aspect essentiel de sa personnalité. Cette production montre surtout que la littérature provençale fait aussi partie de la littérature française.

\section{Bibliographie}

BÉNÉDIT Gustave, «Epitro à Castil-Blaze», dans Chichois, Marseille, Librairie nouvelle, 1879.

BERTIN Horace, Histoire anecdotique des cafés de Marseille, Marseille, Bellue, 1869.

CASTIL-Blaze, Molière musicien, Paris, Dondey-Dupré, 1852.

\footnotetext{
${ }^{9} \mathrm{Ibid} .$, p. 24 : «Tu donnes l'anchois et la sardine, / Le poireau, l'andouillette et le caviar, / L'anguille cuite à la moutarde ; / Tout cela va nous désaltérer » (traduction de l'auteur).

${ }^{10} \mathrm{~J}$. Servier, Histoire de l'utopie, p. 327.
} 
ROUMANILLE Joseph et MISTRAL Frédéric, Un Liame de rasin, Raphèle-lès-Arles, CPM Marcel Petit, 1980.

SERVIER Jean, Histoire de l'utopie, Paris, Gallimard (Folio), 1991.

\begin{abstract}
Résumé
Castil-Blaze (1784-1857), né à Cavaillon, est d'abord connu comme critique musical. Il a tenu la chronique musicale du Journal des débats. Il a également adapté en français des opéras de Weber et de Rossini. Sa version du Barbier de Séville se joue encore aujourd'hui. Castil-Blaze accordait une grande place à son œuvre provençale, peut-être parce qu'il donnait une certaine importance à son enracinement comtadin. En 1865, Mistral et Roumanille publient, dans Un Liame de rasin, vingt-sept poèmes provençaux de Castil-Blaze. Parmi ces œuvres, il y a onze textes chantés; on reconnaît ainsi l'air d'entrée du Figaro du Barbier de Séville de Rossini. En général, les poèmes de Castil-Blaze évoquent essentiellement la région de Cavaillon. Mistral et Roumanille le considèrent comme un précurseur du mouvement félibréen ; ils estiment qu'il a été un des premiers à rendre au provençal sa force d'expression et a donc participé à ce qu'Émile Ripert a appelé la « renaissance provençale ».
\end{abstract}




\title{
Les détails occultés : la correspondance de l'écrivain occitan Jean-Baptiste Fabre et de son neveu Favre de Saint-Castor au prisme de l'honneur et de l'identité (1774-1782)
}

\author{
Danielle Bertrand-Fabre \\ Membre de l'Académie de Nîmes \\ Chercheuse associée au Centre de recherches interdisciplinaires \\ en sciences humaines et sociales (CRISES), université Paul-Valéry - Montpellier III
}

\begin{abstract}
Extrait de : CABOURET Bernadette (dir.), La communication littéraire et ses outils : écrits publics, écrits privés, éd. électronique, Paris, Éd. du Comité des travaux historiques et scientifiques (Actes des congrès nationaux des sociétés historiques et scientifiques), 2018.

Cet article a été validé par le comité de lecture des Éditions du Comité des travaux historiques et scientifiques dans le cadre de la publication des actes du 139e Congrès national des sociétés historiques et scientifiques tenu à Nîmes en 2014.
\end{abstract}

Le corpus de la correspondance de l'abbé Fabre est pour l'essentiel constitué par les lettres échangées avec son neveu Favre de Saint-Castor, garde du corps à Versailles. Cette correspondance a été conservée avec les manuscrits littéraires de l'abbé Fabre par les tuteurs d'Adélaïde, la fille de Saint-Castor, en tant que garantie des frais engagés pour l'enfant. Adélaïde était en effet élevée à Montpellier depuis 1783, date du départ de ses parents pour Saint-Domingue et du décès de son grand-oncle l'abbé Fabre, écrivain déjà célèbre. La tutelle a conservé ces documents, qui s'étendent sur quarante ans. Ils sont entrés en plusieurs lots à la médiathèque de Montpellier et ont été mis en ligne en tant que manuscrits d'un auteur majeur des lettres occitanes'. Marcel Barral puis Guy Barral ont édité cette correspondance, respectivement en 1960 et 2001, auprès de l'Entente bibliophile de Montpellier². Les lettres n'avaient pas vocation à être lues hors du cercle

\footnotetext{
${ }^{1}$ Médiathèque de Montpellier, Manuscrits de l'abbé Fabre, ms. 523-527 et ms. 54 bis.

${ }^{2}$ L'édition par Guy Barral des dernières lettres retrouvées est postérieure à la soutenance en 1999 de ma thèse sur l'abbé Fabre: "Être curé en Languedoc au XVIII siècle : l'abbé Jean-Baptiste Fabre entre ministère et littérature occitane (1727-1783)».
} 
familial : silences et allusions sont donc à décrypter en fonction de l'actualité, de l'autocensure et de décisions prises au préalable.

Quels sont les non-dits de la correspondance et quels sont les enjeux du silence observé? Ce qui est occulté concerne la vie de Favre de Saint-Castor et ses projets d'ascension sociale, mûris avec l'aide de protecteurs au sein de cette famille peu nombreuse. Pour avancer dans la carrière militaire, l'honneur doit être sauf, et bien des non-dits concernent l'identité sociale de Favre de Saint-Castor. De même, sa situation administrative est falsifiée, puisque le curé de paroisse Fabre (fig. 1) modifie l'identité de ses proches pour anoblir ce lignage d'origine très modeste. La moindre des transformations a consisté en un changement de patronyme.

Par ailleurs, pour comprendre le statut de l'épouse de Saint-Castor, Victoire de Marceillan, il a fallu s'intéresser à d'autres sources; on a pu alors s'apercevoir qu'elle avait été la victime d'un bigame lors de sa première union. Le mot «bigamie» ne fut jamais écrit par quiconque, et l'affaire fut considérée ainsi comme un secret de famille - le secret d'une autre famille. Seule l'existence d'une enfant née de cette union a été évoquée par les Fabre dans les lettres conservées. Parmi cet ensemble de missives et de documents, trois lettres de soutien aux jeunes gens : deux de Saint-Priest, intendant du Languedoc, protecteur de l'abbé Fabre et de Favre de Saint-Castor, et la dernière d'une proche de Victoire, évoquent la crise provoquée par la rencontre amoureuse de 1780 et sa résolution.

\section{La correspondance entre l'oncle et le neveu homonymes, tous deux dénommés Jean Baptiste Castor Fabre}

\section{Une correspondance tranquille, où la mort n'est pas exclue}

La correspondance court sur huit ans, de 1774 à 1782, avec une fréquence théorique d'une lettre par mois. Les courriers se répondent, sauf en cas de maladie. Les lettres régulières couvrent environ deux pages tandis que d'autres, qui rendent compte d'un fait familial particulier, sont plus courtes. Leur nombre n'atteint pas la centaine, elles sont quatrevingt-huit précisément, et les deux tiers sont de l'oncle. Le déséquilibre n'est qu'apparent et tient au moindre nombre de lettres du neveu conservées pour les années 1774 et 1775 . La correspondance débute quand le jeune homme, après avoir longtemps vécu au domicile de son oncle, rejoint le corps des gardes du corps où il entre à 21 ans. Il adopte 
un nom de guerre: Favre de Saint-Castor. Les lettres sont respectivement adressées à «Monsieur le chevalier de Saint-Castor » et à «Monsieur le prieur de Cournonterral ». Néanmoins, la cure de Cournonterral n'est pas un prieuré-cure, mais une cure à portion congrue, moins lucrative et moins honorifique. Le titre de prieur est donc usurpé pour Cournonterral, mais il est valable pour Celleneuve, où Fabre a exercé plus tard. Quant au neveu, il est encore loin d'avoir accédé à la noblesse, l'intégration se faisant après plusieurs générations d'officiers. Il y a donc usurpation de statut sur le papier; mais l'intérêt était de pouvoir tirer profit des apparences. Fabre neveu vouvoie son oncle, qui fait de même dans un premier temps, puis revient rapidement au tutoiement familier, qui convient au jeune homme.

Dans cette correspondance au long cours, il est question de la famille, notamment de la mère du jeune homme, qui est restée vivre auprès de l'abbé Fabre, son beau-frère, après le départ de son fils. Elle n'est pas destinataire des lettres et n'ajoute rien de sa plume ; elle devait être proche de l'illettrisme.

La correspondance peut s'apprécier en miroir. Le jeune homme détaille ses journées, l'oncle fait de même. Favre de Saint-Castor manque d'argent, on lui en envoie. Puis il lui est conseillé de faire des économies ou de renoncer au métier des armes si le coût en est trop élevé, s'il est trop dépensier ou même peut-être joueur. Il est bien sûr question de la santé des uns et des autres. Quand la mère de Saint-Castor décède, les deux hommes expriment leur douleur. L'abbé Fabre, installé à Celleneuve, annonce la nouvelle le 23 février 1782, sur un mode grandiloquent :

«Tu n'avois pas reçu ma dernière lettre lorsque tu m'as écrit celle que je viens de recevoir de toi, je le vois bien. Mais dois-je arracher de mon cœur le poignard qui le déchire pour le plonger dans le sein de ce qui me reste d'uniquement cher au monde. Vien, mon fils, pars à lettre vüe, vien consoler et conserver s'il est possible à la vie un oncle que toi seul, ta chère épouse et ta fille pouvez y attacher désormais. Que je vous rende ce que doit un père tendre à ses enfants, et ces devoirs sacrez une fois remplis que la providence me retire de cette vallée de larmes. J'irai rejoindre avec joye le trésor précieux qu'elle vient de m'enlever. Tu ne m'entends que trop, grand Dieu ! Je meurs si je m'explique plus clairement ${ }^{3}$. »

${ }^{3}$ M. Barral (éd.), J.-B. Favre. Lettres à son neveu, lettre XXXVII, 23 février 1782, p. 133. 
L'oncle écrit «Je meurs » pour ne pas écrire «Elle est morte». Saint-Castor répond le 3 mars 1782 :

« Je nachèverai jamais ma lettre cela est impossible, mon état n'est pas fait pour pouvoir être décrit depuis votre derniere lettre, je ne vis plus, Dieu connoissoit l'attachement et la tendresse que j'avois pour la mere la plus digne qui fut au monde et il est themoin de ce qui se passe en moy $^{4}$. »

Le garde du corps exprime son émotion et son attachement à sa mère, mais il se réfère à Dieu, qui sait ce qu'il éprouve, comme dans une mise à distance des sentiments. Sa compagne, Victoire, est plus détachée :

«Mon cher et très aimable oncle, je n'essairai point de vous consollé sur la perte que nous venons de faire je sens trop que ce seroit en vain. Si la part que je prends a votre juste douleur pouvoit la calmé je serois en partie consollé d'un malheur que je ressens auttant que Monsieur de St Castor. Sa santé se ressent de l'impressions que luy a fait cette nouvelles d'autant plus cruelle qu'il ny étoit pas préparé. Nous nous hatons mon cher oncle de vous aller trouver ${ }^{5} »$.

Douleur et malheur, écrit Victoire. La mort était omniprésente et frappait l'entourage des jeunes adultes, qui étaient nombreux à l'époque à se marier orphelins de père ou de mère, voire des deux ; lors du mariage de ce couple, en effet, seul le père de Victoire était encore en vie.

Il est aussi question dans la correspondance de la vie en société. On donne des nouvelles des connaissances du jeune homme à Cournonterral. Fabre lit ses œuvres à Montpellier, chez l'intendant; son neveu fréquente à Amiens des salons où il est à l'aise du fait de l'éducation qu'il a reçue. Ils achètent des livres pour compléter une bibliothèque dont pourrait hériter Saint-Castor, qui est le seul descendant de l'abbé Fabre. La bibliothèque de Fabre se composait notamment de classiques du XVII ${ }^{e}$ siècle et aussi de romans, comme Amadis des Gaules's, ce qui est une originalité chez un curé. Il s'agit d'une

\footnotetext{
${ }^{4}$ G. Barral (éd.), Abbé Jean-Baptiste Fabre, lettre Ch 30, 3 mars 1782, p. 142-144. L'orthographe d'origine a été conservée.

${ }^{5}$ Ibid., p. 143.

${ }^{6}$ D. Bertrand-Fabre, « Être curé en Languedoc au XVIIIe siècle », p. 521-522.
} 
bibliothèque de travail, puisque l'œuvre majeure de Fabre est le premier roman des lettres d'oc, l'Histoire de Jean l'an pres, censé se dérouler près de Nîmes.

Saint-Castor écrit en 1778 :

«Jai fait l'emplette d'un Brantomme livre que tout le monde estime et pour sa raretté et pour sa bonté et sans lequel je ne vas jamais tant je l'aime il mamuse et minstruit le hazart l'a encore fait tomber en mes mains avec quelques autres très curieux et très rares ${ }^{7}$. »

La vie religieuse est également présente avec l'évocation des activités du curé. L'archevêque de Paris est entouré de bigots, estime le jeune homme. La vie politique n'est pas occultée non plus : chez qui s'arrêtera Monsieur, frère du roi et futur Louis XVIII, qui traverse le Languedoc en juillet 1777 ? Il s'est arrêté chez l'intendant, se réjouissent les deux protégés. Fabre vit alors à Cournonterral et raconte :

« Nous allâmes, ta mère et moi, sur le grand chemin prez de la Barthe pour voir passer Monsieur, à son retour de Cette. Je le vis à peu près comme Moïse vit le bon Dieu ; la vitesse de sa marche et la glace poudreuse de sa voiture ne peuvent mieux se comparer qu'à la fente du Rocher et à la rapidité avec laquelle le tout puissant daigna modérer l'éclat de sa majesté, pour ne pas ébloüir son serviteur. Ce que j'ai de plus positif et peut-être de plus intéressant à te dire à ce sujet, c'est que Monsieur a enchanté ici tout le monde, et qu'il a marqué être très sensible aux témoignages qu'il a reçus d'un zèle et d'un amour universel. Le premier président se flattoit de le recevoir au palais, l'évêque chez lui, l'Etat major à l'hôtel du gouvernement et M. de Saint-Priest qui sçait toujours sur quoi compter a eu la préférences. »

L'abbé Fabre semble donc à première vue favorable au régime. La suite de la correspondance est cependant d'une autre tonalité. Le prince, «le bon petit homme», continue-t-il, ne s'est pas arrêté chez l'évêque à Lavérune, il a pu «négliger les bienséances » parce qu'il a « une grandissime idée de sa personnette »; il représente «les vils intérêts d'un État qui souvent ne connaît [pas] les droits de la justice et de la raison ». Texte allusif et alambiqué, qu'il faut décrypter : le prince est présenté deux fois comme petit («petit homme» et «personnette»), ce qui s'oppose à «bon» et «grandissime», à prendre donc de façon ironique. Les voies de l'autocensure politique empruntent des sentiers obscurs en cette époque de monarchie absolue. Favre de Saint-Castor lui répond :

\footnotetext{
${ }^{7}$ G. Barral (éd.), Abbé Jean-Baptiste Fabre, lettre Ch 17, 24 septembre 1778, p. 92.

8 M. Barral (éd.), J.-B. Favre. Lettres à son neveu, lettre XVII, 1er juillet 1777, p. 83-84.
} 
« Je suis tres aise de la petitte mortification que ont essuyé léveque et le premier président mais ils devoient si attendre Monsieur avoit son itineraire bien marqué et Mr de St Priest est trop bien en cour pour ne pas lemporter sur d'aussi petits concurrents ${ }^{9}$. »

L'abbé Fabre évoque aussi sa carrière littéraire et ecclésiastique et les occasions qui s'offrent à lui de devenir prieur, ce qui adviendra avec sa nomination à Celleneuve. Il est question d'autre part de la carrière militaire et des possibilités d'avancement du jeune homme. Mais à l'époque de la guerre d'Amérique, il est absent de son corps pour affaires privées, c'est-à-dire à partir de 1780.

\section{La correspondance inquiète : la vie de couple et de famille du garde du corps}

En 1780, une rencontre amoureuse modifie le cours de la vie de Favre de Saint-Castor, en la personne de Victoire de Marceillan, la fille de François Desmarets, comte de Marceillan (fig. 2).

Après une maladie, le garde du corps, âgé de 27 ans, est invité en avril chez un ami pour se reposer. Il fait ainsi la connaissance de Victoire. Si des lettres ont été écrites par le jeune homme à son oncle pendant ce séjour de plusieurs mois à Nantes, elles n'ont pas été conservées. La jeune femme de 21 ans vient de voir son premier mari emprisonné sans jugement pour bigamie, son mariage annulé et sa fille Sophie, née en 1778, déclarée légitime. Victoire attend des règlements financiers avant de retourner vivre auprès de son père dans son île natale de Saint-Domingue ${ }^{10}$.

Elle découvre qu'elle est enceinte des suites de sa liaison avec Saint-Castor. La correspondance reprend alors selon l'ordre chronologique, avec une lettre de l'intendant du Languedoc Saint-Priest, datée du mois de septembre 1780, où nous apprenons que Saint-Castor a quitté Nantes et se trouve chez son oncle à Cournonterral.

Le garde du corps repart chercher Victoire, et les lettres de l'oncle les atteignent dans le sud-ouest de la France où elle attend à la fois des malles, les papiers de son procès et son accouchement. Leur vie précaire est au centre des préoccupations. Victoire redoute les jugements hostiles de son père. Elle écrit le 11 août 1782, enceinte à nouveau et déterminée :

\footnotetext{
${ }_{9}^{9}$ G. Barral (éd.), Abbé Jean-Baptiste Fabre, lettre Ch 13, 19 juillet 1777, p. 79.

10 J.-A. Tournerie, Justice et identité sous la Restauration. Loubette et Eugène, p. 158-185.
} 
« Je suis malade mon cher oncle à peinne pui-je tenir la plumes. Certainne lettre qu'on a fait ecrire a mon pere et qu'on ma envoiez il y a deux jour, ne m'a pas mit beaucoup de beaume dans le sang. Mais il falloit sy attendre. Tout cela ne doit découragé aucun de nous, un peu de fermeté, voilà tout. Si mes parents ont ecrit moi je parlerai je ne tremble pas aussi facillement qu' on ce lait imaginée, tout s'arengera parce que cela ne peut etre autrement ${ }^{11}$. »

Les malles arrivent alors que la guerre maritime est à son paroxysme. On voyage en convoi pour se protéger des pirates anglais. Le couple rejoint finalement Cadix peu avant la naissance de leur deuxième enfant, Jeanne, au début de 1783, et poursuit son voyage jusqu'à Saint-Domingue.

Dans les derniers courriers, le garde du corps se préoccupe de ne pas être rayé des cadres de l'armée puisqu'il aurait dû avoir rejoint son corps depuis longtemps. Il semble bien rayé dans le registre d'incorporation à la date de 1781 et rien n'indique dans les sources qu'il ait effectué un service militaire ou civil à Saint-Domingue, qui manquait pourtant d'encadrement. Victoire attendait, peut-être à tort, grâce aux relations de l'intendant Saint-Priest à Versailles, un poste et donc des revenus pour son futur mari. Quant au curé Fabre, il craint de perdre la cure de Celleneuve et évoque les belles vendanges qu'il aura comme prieur. La préoccupation des trois adultes est Adélaïde, encore au sein de sa nourrice, qui avait été jugée trop jeune à trois ans pour suivre ses parents à SaintDomingue, car la mortalité infantile était alors très élevée. La petite fille vient après le sevrage chez son grand-oncle à Celleneuve, mais en mars 1783, peu après l'arrivée d'Adélaïde chez lui, l'abbé Fabre, malade, décède.

\section{D'autres ensembles cohérents de documents}

\section{Des documents concernant Adélaïde Favre de Saint-Castor}

Une série de documents concerne la tutelle d'Adélaïde, puis ses recherches en 1828 pour savoir où et quand elle était née. On pouvait vivre à l'époque sans pièce d'identité. Arrivée à l'âge de 47 ans, dix ans avant sa mort, elle convainc la veuve de son tuteur de la laisser consulter ses papiers en promettant de rembourser ses dettes. Adélaïde, née en 1781, sera, comme ses deux sœurs ${ }^{12}$, bénéficiaire des indemnités versées à cette époque

\footnotetext{
${ }^{11}$ G. Barral (éd.), Abbé Jean-Baptiste Fabre, lettre Ch 32, 11 août 1782, p. 149-150.

12 Sophie, née de la précédente union de sa mère en 1778, et Jeanne, née en 1783.
} 
par l'État d'Haïti, nouveau nom de Saint-Domingue, qui avait en 1804 nationalisé les biens fonciers des propriétaires blancs. Les lettres qu'elle a écrites à divers ministères sont conservées dans des dépôts d'archives publics et confirment sa quête d'identité administrative ${ }^{13}$.

\section{Des missives conservées par Fabre ayant trait à ses activités littéraires occitanes}

La plus ancienne des lettres conservées est émouvante. Datant du 6 août 1755, usée, pliée, noircie, elle est adressée par l'évêque de Nîmes à Fabre, vicaire d'Aubais, pour lui signifier la possibilité d'être nommé à titre provisoire à Congénies pour remplacer le curé Darles, ce desservant âgé ne pouvant plus assurer le service de sa paroisse. Fabre n'ayant conservé aucune de ses lettres de nomination à une cure, le fait qu'il ait gardé celle-ci montre qu'elle a eu de l'importance pour lui. Cependant, comme il a été nommé curé de paroisse au même moment dans le diocèse de Montpellier, il n'ira jamais exercer à Congénies, proche d'Aubais. La personnalité de Gaspard-Joseph Darles, écrivain de langue d'oc, a dû jouer dans la décision de l'abbé Fabre de conserver cette lettre, par fidélité à ce modèle de prêtre versifiant en français et en occitan ${ }^{14}$. Les manuscrits de Darles se trouvent à la médiathèque de Nîmes.

D'autres lettres concernent des activités littéraires: Deydé prête à Fabre Las Fouliés dau Sage, un livre d'Isaac Despuech, auteur montpelliérain de langue d'oc du XVII siècle; le père Berbiguier lui demande une copie du Siège de Caderousse, son célèbre poème en oc ${ }^{15}$.

Des missives proviennent de protecteurs, la famille du marquis d'Aubais et l'intendant Saint-Priest. Des ecclésiastiques de haut rang sont contactés, qui répondent poliment sans donner suite ; ce n'est donc pas dans le domaine de la littérature apologétique que Fabre fit carrière. Les réseaux actifs sont les réseaux des grands seigneurs, qui ont le souci de leur réputation, selon l'idéal nobiliaire du temps. Le marquis d'Aubais, seigneur du lieu de naissance de Favre de Saint-Castor, est apparenté à l'intendant Saint-Priest. Tous deux ont collectionné les manuscrits de l'abbé Fabre, dès les premières œuvres pour Aubais.

13 D. Bertrand-Fabre, «Le roman familial de Jean-Baptiste Favre de Saint-Castor et Victoire de Marceillan », p. 204-205.

${ }^{14}$ D. Bertrand-Fabre, « Être curé en Languedoc au XVIII" siècle », p. 249-250.

15 G. Barral (éd.), Abbé Jean-Baptiste Fabre, lettre Div 14, Deydé, 14 novembre 1775, p. 63 et 6 novembre 1779; lettre Div 23, Berbiguier, p. 109-110. 
Reconnaître les mérites d'un écrivain permet d'accroître son propre mérite et celui de son lignage aristocratique. Les Fabre se placent dans cette logique de reconnaissance du mérite, celui de l'écrivain de langue d'oc devant rejaillir sur le neveu, qui opte pour le métier des armes, sur recommandation du marquis ${ }^{16}$.

\section{Le style de l'écrivain et son auvre en français}

Les lettres de Fabre témoignent de sa façon d'écrire. Ainsi, quand le neveu n'écrit pas et que sa famille le suppose malade :

«Mon cher ami, qu'est-ce donc, et d'où vient le cruel silence que tu gardes avec ta mère et moi depuis un mois et demi ? Nous ne sçaurions y tenir d'avantage. Abrège nos allarmes, je $t^{\prime}$ en supplie, et ne nous laisse plus dans un etat de detresse auquel nous ne sçaurions longtemps résister. Es-tu malade? La chute, que tu fis, auroit-elle eu malheureusement des suites facheuses ${ }^{17}$ ?»

La construction ternaire des questions est progressive : pourquoi ne réponds-tu pas, es-tu malade, si oui, qu'as-tu? Le rythme haché du début est suivi d'une hypothèse plus amplement exposée. Le professeur qu'il était savait manier la rhétorique. Dans la même lettre, l'abbé Fabre compatit :

«Je partage, mon cher ami, avec une sensibilité dont tu ne doutes pas, tout ce que les fatigues de ta position actuelle, les rigueurs de la saison, et les bizarres procedez des ames mal faites, peuvent te faire souffrir ; bientôt je l'espère, tu en perdras le souvenir dans les bras du repos et de ta famille, et il n'y aura pas de ma faute si les attentions de mon amitié ne $t^{\prime}$ en dédommagent entièrement ${ }^{18}$. »

Une autre fois, en 1777, l'abbé Fabre demande à son neveu de s'adresser à une dame qui aurait des bontés pour son œuvre littéraire - mais pour qui exactement a-t-elle des bontés?

«Je suis pénétré de reconnaissance pour toutes les bontez dont madame d'Alders veut bien honorer un inconnu à ta priere. Je te charge de la lui temoigner telle que je la sens; cherche

\footnotetext{
${ }^{16}$ Ibid., lettre Div 9, marquis d'Aubais, 16 février 1771, p. 38.

${ }^{17} \mathrm{Ibid}$. , lettre 13, 13 février 1780, p. 111.

$18 \mathrm{Ibid}$. , lettre 8,28 août 1777, p. 82.
} 
les expressions dans ton cœur. Je ne puis t'indiquer un meilleur interprète de ce qui se passe dans le mien à ce sujet. »

L'abbé Fabre continue au paragraphe suivant, à propos de son œuvre en français :

«Si tu n'as pas encore donné le manuscrit d'Amphitrite à quelque libraire de Paris, tache de le faire pour en tirer quelque chose, et réserve t-en deux ou trois exemplaires. Cette lecture, toute frivole qu'elle est, te fera un jour quelque plaisir, je m'en flatte, ne fut-ce que pour te rappeller le souvenir de la tendresse qu'eut toujours pour toi son auteur. J'ai fait imprimer ici mon petit poème de la fontaine du Peyrou que j'ai dédié à Mr de St Priest. Cela lui a fait un plaisir assez sensible pour ne pouvoir le dissimuler, quelque modestie qu'il ait montré dans le remerciement qu'il m'en a fait ${ }^{19}$. »

Acidalie, poème sur la construction du château d'eau du Peyrou à Montpellier, a été la seule œuvre imprimée de Fabre, anonyme selon l'usage et publiée à compte d'auteur. On a longtemps pensé que Fabre se trompait sur l'originalité d'une autre de ses œuvres, Amphitrite. Ce genre de poésie mythologique, relatant les aventures de nymphes, est d'un intérêt médiocre, et on remarque dans cette lettre récemment découverte qu'il la juge luimême « frivole » et l'excuse par une destination familiale.

En 1777, Fabre profite d'une nouvelle législation qui facilite l'activité des imprimeurs de province en supprimant le monopole des libraires parisiens. Se développe une édition de petits volumes destinés à un public local, ce qui est le cas avec Acidalie. La lettre montre également comment un écrivain entretient des liens de protégé à protecteur en littérature, par exemple en lui dédiant un livre.

\section{Les conseils aux Fabre : lettres du temps de crise}

\section{Les conseils de l'intendant Saint-Priest adressés à l'abbé Fabre, son protégé}

Saint-Castor se réfugie chez son oncle après un incident survenu à Nantes, dans la famille de Victoire, où il a laissé des papiers personnels déchirés et la jeune femme enceinte. L'intendant du Languedoc Saint-Priest est consulté par l'abbé Fabre, qui lui a exposé la situation par écrit. Dans une longue lettre d'un millier de mots, écrite le 19 septembre 1780, l'intendant dispense des conseils ${ }^{20}$. Il les doit à son protégé Favre de Saint-Castor, à

\footnotetext{
${ }^{19}$ Ibid., p. 84.

${ }^{20}$ Ibid., lettre Div 25 et Div 26, M. de Saint-Priest, 19 et 24 septembre 1780, p. 116-120.
} 
qui il a prêté son adresse pour son incorporation en 1772. L'intendant parsème son texte de «j'estime», «selon moi », «ce que je ne saurais croire » puis de «il doit», « il faut», «je conseille fortement». Après l'analyse de la situation, il expose la conduite à tenir. Il précise à deux reprises qu'il ne répond qu'en fonction de ce qui est écrit et que « s'il dissimule quelque chose», ces conseils ne valent pas d'être suivis. Que pourrait dissimuler Saint-Castor ? Ce pourrait être « l'altération » de son certificat, sa falsification, une usurpation d'identité faite de sa propre main. Son ami aurait révélé à sa famille qu'il n'était pas ce qu'il prétendait être. Saint-Priest savait que «Saint-Castor » était un nom forgé. Personne n'avait porté ce patronyme auparavant en France. Le jeune homme se serait-il targué auprès de la famille de Victoire d'une noblesse usurpée?

Il ne lui avait pas été nécessaire d'être noble pour devenir garde du corps en 1772. Selon Gilbert Bodinier, la noblesse de ce corps avait « piètre réputation » : petite, récente ou très pauvre. Environ $30 \%$ des gardes du corps servant en 1789 étaient cependant des roturiers et, si G. Bodinier a identifié l'ascendance d'une partie des gardes pour son dictionnaire, il est loin d'avoir tout retrouvé. Nombre de ces familles s'efforçaient de vivre noblement, sans être nobles ${ }^{21}$. C'est la voie que suivaient les Fabre.

La deuxième lettre de l'intendant revient sur les certificats : si la famille de la jeune femme en demande d'autres, il conseille d'être très vigilant pour veiller à ce que le bureau du tribunal de Montpellier délivre le même. Le premier n'était donc pas parfaitement conforme à la réalité et relèverait ainsi du certificat de complaisance. Ce qui préoccupait Saint-Castor était de savoir s'il encourait un ordre du roi (c'est-à-dire la prison), s'il avait été suivi, si l'on avait ouvert ses malles qui n'étaient pas encore arrivées. On se souvient que le premier mari de Victoire était emprisonné par ordre du roi à la même époque. Saint-Priest se veut rassurant.

Ce qui préoccupe l'intendant est exprimé en début et en fin de lettre : l'avenir militaire du jeune homme, et par voie de conséquence, son honneur à lui, en tant que protecteur. Si Saint-Castor est en congé militaire, qu'il rejoigne son corps dès la fin du congé ; sinon, il doit s'attacher à le faire prolonger, car il risque d'être rayé des cadres. Saint-Priest critique sévèrement la conduite pitoyable de son protégé, qui montre de «véritables pusillanimités». L'intendant reproche à Saint-Castor de manquer de courage et de

${ }^{21}$ G. Bodinier, Les gardes du corps de Louis XVI, tableau p. 40-41. 
fermeté, de fuir ses responsabilités. Il serait très mauvais que ses supérieurs en conçoivent l'opinion qu'il ne saurait pas commander des troupes. Il faut donc qu'il s'active et s'adresse à son protecteur militaire, le comte de Pontécoulant. Que SaintCastor dise la vérité, et l'intendant écrira une lettre au comte à son tour.

L'intendant écrit une seconde lettre peu après, qui contient une copie de celle qu'il a écrite à Pontécoulant. Saint-Priest exhorte le jeune homme à écrire, si ce n'est déjà fait. Il s'agit du domaine de la protection militaire. Pontécoulant, à qui le jeune homme aura demandé sa protection et ses bontés, devra écrire à la suite de cela à son capitaine. Les arguments à utiliser doivent être rationnels, pour s'opposer à la conduite irrationnelle de Saint-Castor, motivée par la peur. S'il a quitté Nantes, c'était pour réfléchir et pour ne pas « s'adonner à la violence » sous le coup de l'émotion. Il est de bonne foi, doit montrer un peu d'indignation, mais pas trop. Enfin, il doit écrire à la dame et à sa famille, en montrant que s'il était resté, il aurait entretenu les sentiments de Victoire.

Au fil de la lettre de l'intendant, la situation est présentée comme plus favorable: si la dame veut se marier, sa famille ne pourra pas s'y opposer. Elle a un statut juridique particulier, avec un mariage dissout et une fille légitime, supposons-nous. Elle ne pourra pas demander des dommages et intérêts comme lors de la dissolution de sa première union. Les choses finiront par s'arranger. Saint-Castor aurait d'ailleurs été bien incapable d'offrir le même dédommagement que le premier mari, le marquis de Beauvau-Craon. Saint-Priest n'apparaît pas surpris ni désapprobateur devant l'identité inventée de «Saint-Castor». Dans sa propre famille, on pratiquait la chasse aux épithètes dans les actes privés ou publics. «Haut et puissant seigneur messire » était l'épithète utilisée par l'intendant, tandis que ses fils semblaient viser plus haut dans ces années-là22.

\section{Après les arrangements, la « tante " de Victoire s'adresse à son « neveu »}

Des accommodements sont trouvés et, un mois plus tard, des lettres sont échangées entre Saint-Castor, son oncle, Victoire et une femme avec qui elle réside et qui signera plus tard «Duroure de Lostande ${ }^{23} »$. Seule la lettre de cette supposée tante de Victoire à SaintCastor a été conservée. On y apprend qu'il va mieux et qu'il est en mesure de venir

\footnotetext{
${ }^{22}$ L. Mondet, « Monsieur de Saint-Priest, intendant de Languedoc (1751-1785) », p. 42-43.

${ }^{23}$ G. Barral (éd.), Abbé Jean-Baptiste Fabre, lettre Div 36, Madame de L'Ostende/Lostande, 21 octobre 1782, p. 153154 .
} 
chercher Victoire ; que cette dernière est aimée par eux deux ; que Victoire attend SaintCastor et qu'il a raison de vouloir reporter le voyage à Saint-Domingue à l'année suivante, après l'accouchement. La «tante» le presse de partir, d'indiquer quand il prendra la route, afin que Victoire soit prête. Elle lui recommande de ne pas tomber de cheval à nouveau pendant son voyage. Elle fait des politesses à l'oncle («votre cher oncque»), et à la mère de Saint-Castor, à qui elle transmet ses respects. La «tante» termine sa lettre à son « cher neveux » (sic) en rappelant qu'elle-même l'aime du meilleur de son cœur. On peut y voir la confirmation que Victoire aime Jean-Baptiste²4.

Cette personne proche de Victoire pourrait être la même qui est connue dix ans plus tard à Paris, où une Demoiselle Duroure de Lostande reçoit en 1791 un secours du gouvernement de 300 livres, pour les motifs suivants : «Abandonnée par sa famille, et ne vivant que par les secours de personnes charitables ; paralysée d'un bras, et âgée ${ }^{25}$ ».

Cette «tante» attendait de Saint-Castor qu'il tienne ses engagements concernant le mariage. La lettre, écrite sur un ton d'affection et à l'orthographe phonétique, a dû toucher le jeune homme, au point qu'il l'a conservée.

Il fallait réparer ses torts en épousant la jeune femme, et dans ce cas l'honneur de la famille était primordial - sans compter les sentiments, qui devaient être réels, comme le supposait l'intendant. Sur le marché du mariage, chacun des deux jeunes gens avait des points faibles, ce qui les rapprochait: l'un n'avait ni fortune ni titre, l'autre n'avait qu'un avenir incertain dans son milieu, puisqu'elle était redevenue célibataire avec une fille légitime à élever, une fille dont le père était en prison sous le coup d'une lettre de cachet.

L'intervention de l'intendant Saint-Priest dans une affaire de cœur peut surprendre, mais témoigne des liens de clientèle dans les milieux littéraires et militaires. L'intendant soutenait les ambitions des Fabre dans la limite de la légalité et des usages de l'époque. Le curé Fabre a abusé de sa position et camouflé l'identité de son neveu en le faisant naître non à Aubais mais à Castelnau-le-Lez, comme cela figure sur son acte de mariage à

\footnotetext{
${ }^{24}$ Ibid., lettre Div 27, Madame de L'Ostende/Lostande, 20 octobre 1780, p. 120 et Médiathèque de Montpellier, ms. 526-34.

25 Collection générale des décrets rendus par l'Assemblée nationale au mois de mai 1791, Paris, Baudouin, [1791 ?], p. 311, consultation en ligne, Bibliothèque de Lyon. Remerciements à Elisabeth de Fleurian.
} 
Saint-Domingue ${ }^{26}$. Cette falsification avait empêché jusqu'ici la collation des données généalogiques sur les deux branches. Les travaux de l'historien du droit Jean-André Tournerie sur l'identité d'enfants sans papiers sous la Restauration l'ont conduit à s'intéresser aux enfants du marquis de Beauvau-Craon issus de ses deux unions, Eugène et Sophie, la fille aînée de Victoire, l'épouse de Saint-Castor. Victoire peut désormais être resituée dans la famille de Beauvau en ce qui concerne sa première union, et dans la famille de l'écrivain Fabre pour la deuxième ${ }^{27}$.

De son côté, Adélaïde Favre a bénéficié de la conservation des lettres par ses tuteurs et a su de qui, quand et où elle était née, c'est-à-dire en France et non en Amérique ${ }^{28}$. Elle a retrouvé une identité administrative à une époque, 1828, où la noblesse ne conférait plus de privilèges ; mais Adélaïde Favre disposait désormais de papiers justifiant des droits à hériter et avait désormais connaissance de l'identité de sa famille.

${ }^{26}$ Arch. nat. Outre-mer, état civil de Saint-Domingue Haïti, Aquin, paroisse Saint-Thomas d'Aquin, 1776-1794, 85 MIOM 28, 21 septembre 1783.

${ }^{27}$ Généalogie Fabre/Favre de Saint-Castor consultable dans la base en ligne roglo.eu/roglo. D. Bertrand-Fabre, «Trois orphelines en action », p. 74.

28 G. Barral (éd.), Abbé Jean-Baptiste Fabre, lettre de Chamayou, homme d'affaires de Madame Bouschet, à Adélaïde Favre, le 18 décembre 1828, p. 10-12. 


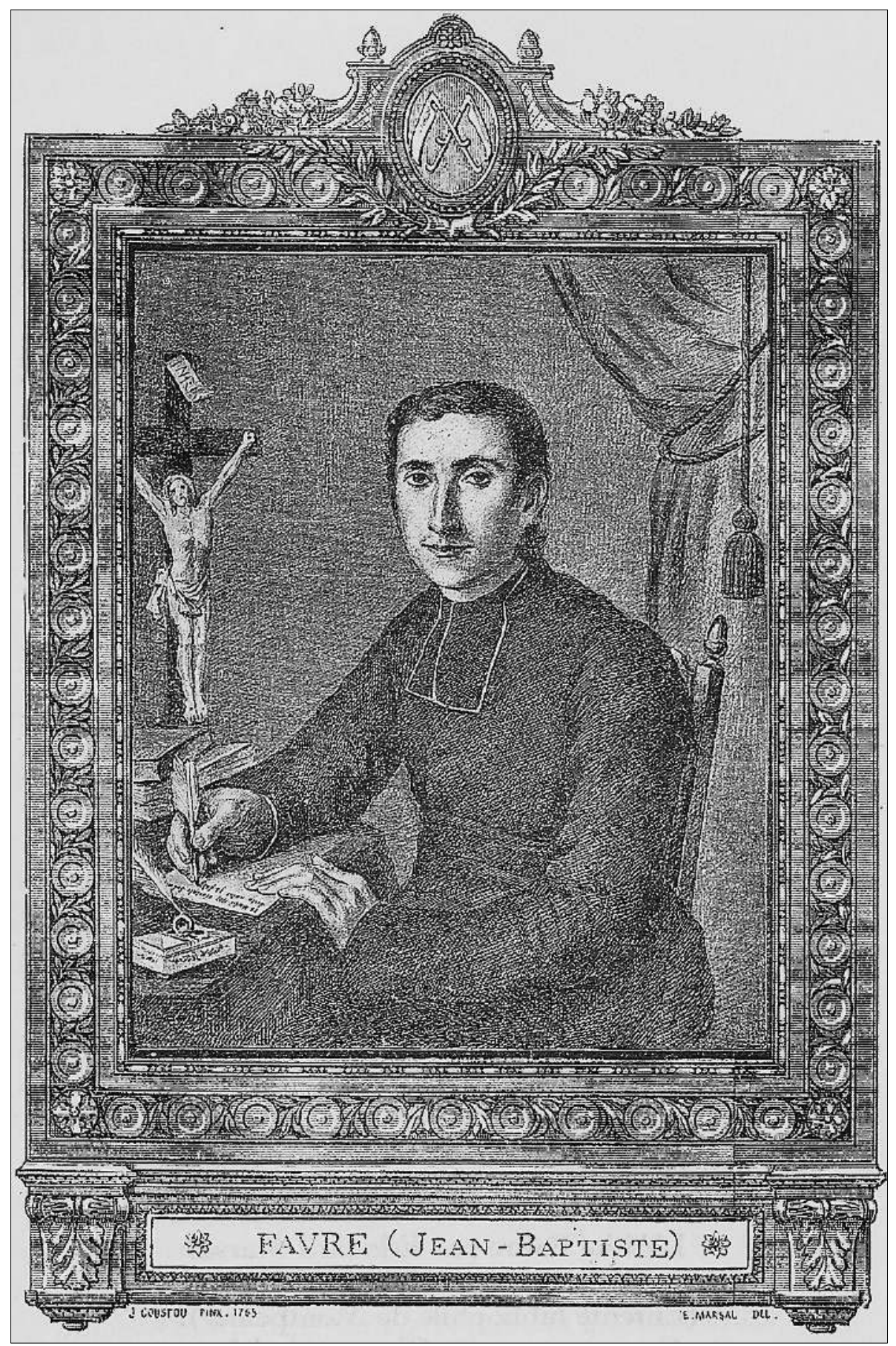

Fig. 1. - Édouard Marsal, portrait de l'abbé Jean-Baptiste Fabre, gravure d'après le tableau de Jean Coustou. Extrait de : J.-B. Favre, CEuvres choisies, 1890, n. p. 


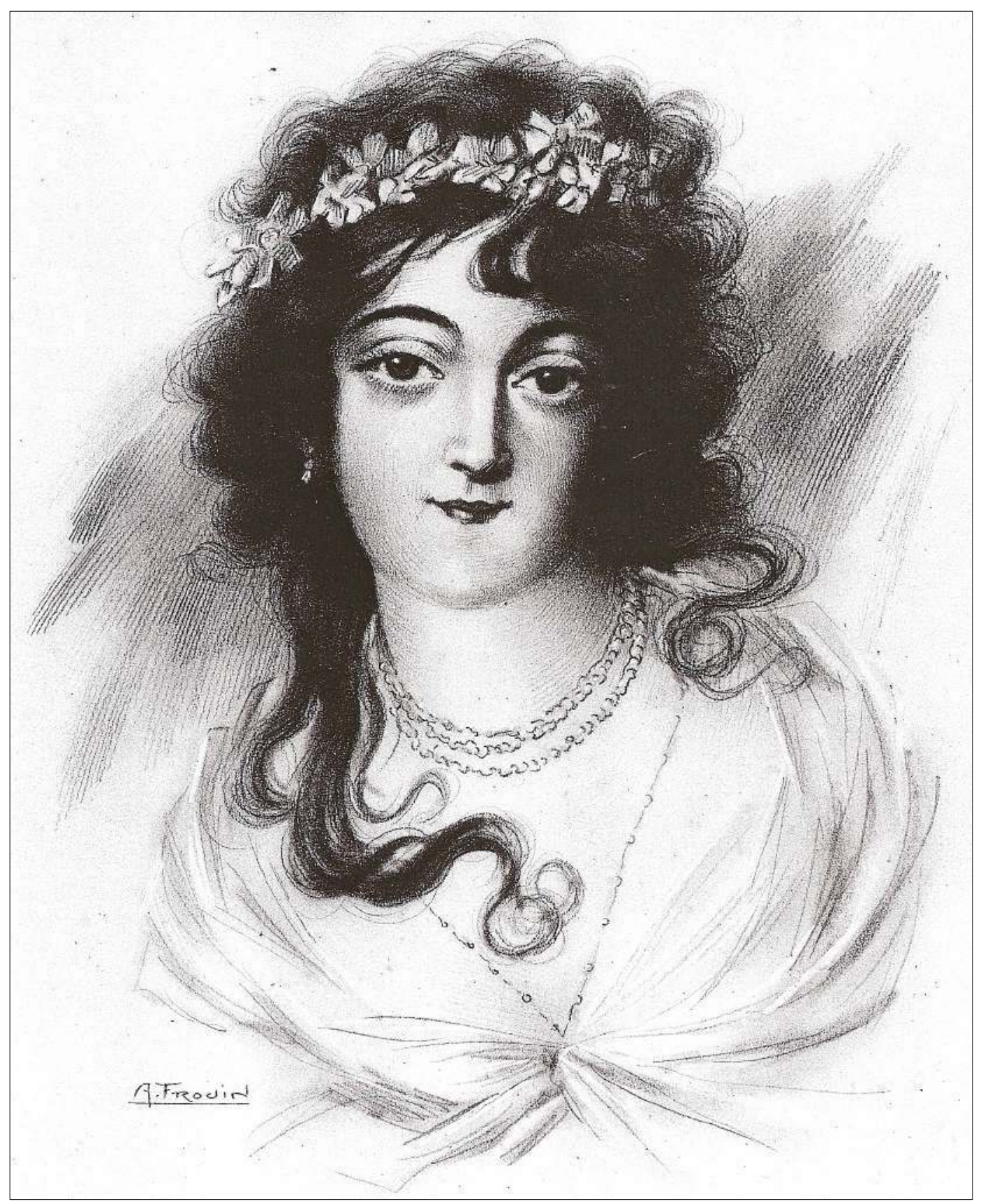

Fig. 2. - A. Frouin, portrait de Victoire de Marceillan, dessin d'après miniature.

Musée de Cholet, propriété de la Société des sciences, lettres et arts de Cholet, don de l'auteur. 


\section{Bibliographie}

BARRAl Guy (éd.), Abbé Jean-Baptiste Fabre. Correspondance et autres documents inédits publiés pour faire suite à l'édition donnée par Marcel Barral en 1960, Montpellier, Entente bibliophile, 2001.

BARRAl Marcel (éd.), J.-B. Favre: lettres à son neveu, le chevalier de Saint-Castor, 1774-1782, Montpellier, Entente bibliophile, 1960.

BERTRAND-FABRE Danielle, «Être curé en Languedoc au XVIII siècle : l'abbé Jean-Baptiste Fabre entre ministère et littérature occitane (1727-1783)», thèse, université Montpellier 3 (1999), Lille, ANRT, 2004.

BERTRAND-FABRE Danielle, « Le roman familial de Jean-Baptiste Favre de Saint-Castor et Victoire de Marceillan. Épilogue à l’histoire de l'abbé Fabre, leur oncle, écrivain occitan du temps des Lumières », dans Amb un fil d'amistat, mélanges offerts à Philippe Gardy par ses collègues, disciples et amis, Toulouse, 2014.

BERTRAND-FABRE Danielle, «Trois orphelines en action. Les filles de Jean-Baptiste Favre de Saint-Castor et/ou de Victoire de Marceillan à travers les guerres et les révolutions (XVIIIe-XIXe siècles) », Mémoires de l'Académie de Nîmes, 2015, p. 73-114.

BODINIER Gilbert, Les gardes du corps de Louis XVI. Étude institutionnelle, sociale et politique. Dictionnaire biographique, Versailles, Service historique de la Défense, 2005.

FAVRE Jean-Baptiste, CEuvres choisies, avec trad. française par Louis Roumieux; ill. d'Edouard Marsal, Montpellier, G. Firmin et Montane, 1890.

MONDET Luc, «Monsieur de Saint-Priest, intendant de Languedoc (1751-1785)», mémoire de maîtrise en histoire sous la direction d'Anne Blanchard, Montpellier, université Paul Valéry - Montpellier III, s. d. [ca. 1980].

TOURNERIE Jean-André, Justice et identité sous la Restauration. Loubette et Eugène, Paris, L'Harmattan, 2001.

\section{Résumé}

Cet article traite de questions d'honneur, d'identité et de secret des familles, à travers une correspondance du XVIII e siècle entre l'abbé Jean-Baptiste Fabre, célèbre écrivain occitan de 
Montpellier, et un de ses rares parents, son neveu Jean-Baptiste Favre de Saint-Castor. Né à Aubais, dans le Gard, Saint-Castor servait comme garde du corps à Versailles. À l'occasion d'une rencontre amoureuse, les allusions que comporte la correspondance se multiplient, troublant la compréhension de la situation. Des sources judiciaires font connaître les protagonistes et le motif du silence observé : une affaire de bigamie impliquait un seigneur de l'Anjou et la compagne du neveu, éphémère épousée. Le couple a sollicité parents et protecteurs, dont l'intendant du Languedoc Saint-Priest, pour pouvoir se marier et donner légitimité à ses enfants. La correspondance, conservée par son tuteur, a permis à une de leurs filles de connaître ses origines familiales et de prétendre à un héritage maternel à Saint-Domingue. 


\section{La correspondance diplomatique de la Renaissance comme document historique? Les lettres de Georges de Selve, ambassadeur à Rome (1537-1538)}

Nicole Lemaitre

Professeur émérite des universités

Extrait de : CABOURET Bernadette (dir.), La communication littéraire et ses outils : écrits publics, écrits privés, éd. électronique, Paris, Éd. du Comité des travaux historiques et scientifiques (Actes des congrès nationaux des sociétés historiques et scientifiques), 2018.

Cet article a été validé par le comité de lecture des Éditions du Comité des travaux historiques et scientifiques dans le cadre de la publication des actes du 139e Congrès national des sociétés historiques et scientifiques tenu à Nîmes en 2014.

La correspondance diplomatique permanente est, en Italie puis en France, une création de la Renaissance. Les modèles à cet égard viennent d'Italie et conduisent en français à la création d'une véritable langue technique ${ }^{1}$. Cette « construction hésitante et fragile » est l'un des aspects de l'adaptation de la Renaissance italienne en France². Sous Charles VIII, nous en étions encore aux légations médiévales ; à la mort du roi François Ier (1547), nous sommes dans le monde moderne. Pour comprendre ces processus de transformation, faute d'archives administratives constituées, il faut observer les hommes en action, dans l'intensification du «négocier» et de la circulation de l'information en ces temps d'échange et d'ouverture.

Dans les registres des négociations diplomatiques du XVIe siècle avec Rome, les Affaires étrangères ont constitué un recueil factice à partir d'une correspondance privée, vers la fin du XVIe ou au XVII siècle; elle est conservée sous les cotes Rome 3 et Rome 4 de la

\footnotetext{
1 P. Prodi, Diplomazia del Cinquecento. Istituzioni e prassi.

${ }^{2}$ L'expression est de L. Bely, qui a accueilli dans son séminaire conjoint avec G. Poumarède les prémices de ce travail. Histoire de la diplomatie française, t. 1, p. 181. Pour le Moyen Âge, voir aussi F. Autrand, «L'enfance de l'art diplomatique en France, XIVe-XVe s. ». Et pour les développements récents de la recherche sur les rapports de la France et du Turc, qui intéressent très directement la thématique des lettres dont il est ici question, G. Poumarède, Pour en finir avec la croisade.
} 
correspondance politique aux archives du ministère des Affaires étrangères. Ces cotes renferment les lettres écrites par Georges de Selve et son collègue Charles Hémard, cardinal de Mâcon, entre Pâques 1537 et juin 1538. Il s'agit de copies, dont les cahiers ont été reliés en désordre au XVIIe siècle. Nous avons exploité, en vue d'une édition, les lettres envoyées depuis Rome par George de Selve, évêque de Lavaur, à l'évêque de Rodez, Georges d'Armagnac, alors ambassadeur à Venise qui était son successeur, pour ne pas dire son disciple. Ces lettres, écrites à Mgr de «Rhodes» ou de «Roudez», ont été oubliées par Charles Samaran puis par moi-même lors de la sortie du premier volume de la correspondance du cardinal d'Armagnac, et ne semblent pas avoir intéressé les érudits ${ }^{3}$. Mais d'autres lettres de Georges de Selve et de son collègue cardinal de Mâcon s'adressent aussi au roi, au connétable de Montmorency et à bien d'autres correspondants français, dont le maréchal d'Humières; ou des lettres en italien, à quelques capitaines comme Guido Capino.

La difficulté de l'utilisation de ces lettres à l'information implicite est que, le plus souvent, nous n'avons pas les réponses... Pas même pour Armagnac, dont une seule lettre active témoigne de son implication dans les affaires en question au long de ces deux années. Or on comptabilise plus de cent lettres envoyées à Venise par de Selve entre ces deux dates. Cela équivaut à une lettre tous les trois jours environ, plusieurs lettres souvent. De Selve signale au minimum 75 lettres reçues de son homologue, toutes perdues. Encore s'agit-il de copies rassemblées bien tard, et donc pas nécessairement exhaustives; à l'évidence, certaines n'ont pas été intégralement recopiées et les incohérences liées à des mots ou des lignes oubliés handicapent parfois la lecture. Mais globalement, cette correspondance apprend beaucoup sur des fonctionnements institutionnels et humains mal connus. Elle n'a pas d'équivalent édité pour cette période en France ou en Italie.

\footnotetext{
${ }^{3}$ C. Samaran et N. Lemaitre (éd.), Correspondance du cardinal Georges d'Armagnac, t. I, 1530-1560, en particulier p. 41-135. L'édition des lettres au roi et à Armagnac est sous presse à la Société de l'histoire de France. Il existe une copie des lettres de Lavaur et Mâcon au seul roi, réalisée vers 1840 sur ordre de Mignet, premier directeur des archives du ministère des Affaires étrangères. Bibliothèque Thiers, T 239-240.

${ }^{4}$ La correspondance de Cosme de Médicis, essentielle ici, est très pauvre pour cette période. G. Spini (éd.), Cosimo I de'Medici, Lettere.
} 
Malgré ces hypothèques graves, qui doivent alerter tout chercheur sérieux avant toute analyse de contenu, on peut cependant dégager quelques remarques. Qui sont les protagonistes, et pourquoi sont-ils intéressants ? De quoi parle l'ambassadeur à Rome, et comment le filtre-t-il ? Quel peut être l'apport des correspondances privées de ces diplomates à cette date ? À travers ces contenus, on peut observer les grandes lignes de la politique française en Italie et la manière dont les ambassadeurs s'informent et se forment à la fois.

\section{Diplomate : un nouveau métier}

Nous connaissons de mieux en mieux les deux protagonistes ; encore que pour les suivre de façon efficace dans la période du règne de François Ier, les sources nous manquent cruellement. Nous ne savons presque rien des conditions de leur nomination, sauf qu'ils sont des fidèles d'Anne de Montmorency, l'homme fort incontesté de cette période. Dans les dictionnaires, Georges de Selve est parfois confondu avec ses frères, eux aussi grands diplomates, dont Odet de Selve. Mais malgré sa courte carrière (1506-1541), l'évêque de Lavaur a un immense avantage sur eux : c'est lui qui est représenté avec son ami Jean de Dinteville sur le fameux tableau des ambassadeurs d'Holbein (1533) .

Georges est le deuxième ou troisième fils de Jean de Selve, président au parlement de Paris, l'un des négociateurs habiles du traité de Madrid. Georges était donc né coiffé. À la mort de son oncle maternel, en 1526, Pierre Du Buis, il a récupéré le bénéfice de Lavaur, dont il a pris possession en 1534 seulement. Comme le montre le tableau des ambassadeurs d'Holbein, c'est un érudit, dont le précepteur fut l'helléniste Pierre Danes, qui est son secrétaire à Rome tandis qu'il a pour official à Lavaur et également comme secrétaire l'humaniste toulousain Pierre Bunel6. En 1533, Georges de Selve était de passage en Angleterre chez son ami, auprès de qui il était peut-être en formation, car François Ier le nomma ambassadeur à Venise cette même année.

De Selve était reconnu comme helléniste ; mais il devint, ce qui est plus rare, hébraïsant, grâce aux cours d'Élie Levita, suivis à Venise en 1534-1535. Il parle italien et connaît

\footnotetext{
${ }^{5}$ S. Foister et al., Making and meaning : Holbein's ambassadors. J. Zwingenberger, Hans Holbein Le Jeune. A. Brun, Trois plaidoyers pour un art holographique. Lavaur n'était pas ambassadeur en titre auprès de Henry VIII. ${ }^{6}$ N. Dauvois (éd.), L'humanisme à Toulouse : 1480-1596.
} 
parfaitement la ville dès avant son arrivée. Sur l'ordre du roi, il a commencé à traduire les Vies parallèles de Plutarque, qui viennent d'être imprimées en grec pour la première fois (avec les «grecs du $\left.\mathrm{roi}^{7} »\right)$. Il est nommé ambassadeur à Venise le 20 janvier 1535 et y reste jusqu'au 18 juin 1536, pour défendre les intérêts politiques et militaires français en Italie, mais aussi pour acheter des manuscrits grecs 8 .

Il poursuit sa carrière comme ambassadeur à Rome en 1536-1538, en Allemagne en 1539, à Vienne en avril 1540 puis en Espagne et aux Pays-Bas cette même année. À cette date, malade peut-être, ou désireux de revenir assurer son salut, car il défendait le devoir de résidence pour les évêques, il revient à Lavaur pour s'occuper de ses ouailles, mais meurt quelques mois plus tard.

Bien que parfois soupçonné de sympathies protestantes, comme son correspondant Georges d'Armagnac, de Selve fait partie avec quelques autres prélats proches du roi ou de sa sœur Marguerite de Navarre des prélats réformistes gallicans engagés dans les réformes tout en refusant de rompre avec Rome9.

Georges d'Armagnac (v. 1500-1585) est l'ultime héritier d'une famille célèbre, dont l'héritage a été en partie récupéré par les Alençon et en partie remis par Louis XII au père de Georges, Pierre d'Armagnac, l'un de ses bons capitaines en Italie. Mais Pierre est mort en 1504, et le garçon a été élevé par les Amboise, puis par Marguerite de Navarre, héritière des terres armagnaques, mais sans en maîtriser les fidélités nobiliaires. En même temps qu'il a reçu une formation curiale de haut niveau, Georges d'Armagnac a aussi fréquenté pendant plusieurs années l'université de Toulouse et acquis une excellente formation de juriste humaniste, qui lui a permis de rester l'homme de confiance de la reine de Navarre, Marguerite: c'est sous son impulsion qu'il est ordonné prêtre par Guillaume Briçonnet en 1527 et devient évêque de Rodez en 1529 en vertu du concordat de Bologne. À cette date, il est l'espoir du parti réformiste gallican (et non protestant), car il connaît tous les membres du groupe de Meaux, condamnés ou rentrés dans le rang; il

\footnotetext{
${ }^{7}$ Grecs du roi : police de caractères grecs créée par Claude Garamond.

8 G. Ribier, Lettres et mémoires d'État, 1666 ; G. Lefèvre-Pontalis (éd.), Correspondance politique de Odet de Selve, p. 346.

${ }^{9}$ L'histoire en est profondément renouvelée depuis plusieurs années grâce à la plongée dans les archives des administrations épiscopales avant le concile de Trente. Pour une approche replaçant le cas français dans un ensemble très controversé encore : P. Benedict et al. (éd.), La Réforme en France et en Italie.
} 
est cousin de toute la noblesse du Midi, héritage Armagnac oblige, et il est également le premier conseiller pour le royaume de Navarre, dont il sera ensuite à plusieurs reprises le représentant à Rome ou à Paris. C'est Marguerite qui a voulu sa carrière, essentiellement italienne jusqu'en 1549, y compris le cardinalat, qu'elle a réclamé pour lui en 1544 directement au pape Paul III et obtenu en $1545^{10}$.

Comme de Selve, Armagnac est aidé par des secrétaires humanistes talentueux, dont Guillaume Philandrier, le commentateur de Vitruve, qui organise dès son arrivée à Venise un salon humaniste dédié à l'architecture, et qui est responsable, par exemple, de la venue en France de Sebastiano Serlio ${ }^{11}$. C'est dans ce cercle que d'Armagnac devient l'ami de Marcel Cervini, le futur pape Marcel II. Il est donc d'emblée un proche des Spirituali italiens, comme de Selve. Pour l'heure, l'un et l'autre s'entendent bien avec le nouveau pape, Paul III Farnese, qui veut établir la paix entre les princes afin de convoquer un concile.

\section{Les problèmes de 1537-1538 vus d'Italie}

De Selve suit la cour pontificale et prend part avec l'autre ambassadeur du roi de France, Hémard Denonville, évêque et cardinal (1536) de Mâcon, aux pourparlers qui aboutissent en juin 1538 à la conférence de Nice. Mais l'essentiel de son activité est de sauver la politique française en Italie, dont il faut bien dire qu'elle tourne alors à la catastrophe, faute d'investissement de la cour de France et en raison de l'activité brouillonne de ceux qui sont présents sur place. C'est tout l'intérêt de cette correspondance semi-privée de montrer les tentatives de coordination - et donc la lucidité - de de Selve.

De Selve connaît bien son correspondant, car ils ont été de concert ambassadeurs auprès de la seigneurie de Venise quelques mois auparavant. On peut dire qu'il a formé Georges d'Armagnac à son nouveau métier pendant quelques semaines, entre mai et juillet 1536,

\footnotetext{
${ }^{10}$ Voir pour une présentation plus fouillée les introductions de l'ouvrage de C. Samaran et N. Lemaitre (éd.), Correspondance du cardinal Georges d'Armagnac, p. VII-LV.

11 F. Lemerle, Les «Annotations» de Guillaume Philandrier sur le De architectura de Vitruve, voir "Charles Samaran». Armagnac et Philandrier sont représentés dans l'un des plus célèbres portraits doubles du Titien vers 1538: Georges d'Armagnac, ambassadeur de François Ier à Venise, peint par Le Titien en compagnie de son secrétaire Guillaume Philandrier, autrefois dans la collection du duc de Northumberland, actuellement à Londres, National Gallery.
} 
entre Ferrare et Venise. Georges d'Armagnac, en effet, ne parlait pas encore italien, selon le témoignage même des Vénitiens, et il ignorait tout de la manière de rédiger une dépêche diplomatique, et plus encore de rédiger une relation «à la vénitienne ». Malgré des longueurs et des redondances, de Selve possède une maîtrise du récit diplomatique qu' on ne trouvera que plus tard chez Armagnac. Venise est en effet l'un des temples de la technique diplomatique, car depuis le XIII siècle, les ambassadeurs y sont tenus de laisser un rapport de leur action au conseil des Dix, rapport placé dans des registres secrets à partir de 1524. En fait, ces rapports circulent sous le manteau avant même leur première édition, en 1589, et ils seront largement utilisés par la suite ${ }^{12}$.

De Selve montre à son collègue les occasions perdues de rencontres entre les flottes barbaresque et française du printemps à l'été 153713. Montmorency, connétable en février 1538, est empêché d'agir, car les deux adversaires n'ont plus d'argent, comme il le souligne à plusieurs reprises.

Le second problème pour l'ambassadeur du roi à Venise est de convaincre la seigneurie de rester neutre entre l'empereur Charles Quint et le roi de France : ne pas l'indisposer, la détacher de l'empereur et du pape et tenter d'ouvrir un front oriental pour affaiblir la puissance impériale, tel est le jeu français. Venise est une plaque tournante, qui se veut indépendante de la géostratégie italienne et méditerranéenne de l'empereur et du pape. C'est tout de même la principale raison qu'a François Ier de développer à Venise une ambassade permanente ${ }^{14}$. Ces années de négociation sont certes bénéfiques pour

\footnotetext{
12 E. Alberi (éd.), Relazioni degli ambasciatori veneti al Senato durante il secolo XVI. Après avoir beaucoup travaillé sur les négociations, les historiens s'intéressent désormais à l'information d'État. À Venise, les nouvelles circulent entre les différentes institutions sous forme de compilations des événements survenus ensuite : F. De Vivo, Information and communication in Venice.

13 Les vaisseaux turcs, conduits par Barberousse, sortent de Salonique le 14 juin selon La Forest (qui est sur place), avec 250 galères. Ils arrivent à La Valonne et sont dans le golfe de Tarente le 27 juillet, attaquent Otrante et Corfou et repartent le 25 août, alors que Doria a fait sa jonction avec les galères de la seigneurie de Venise. Les Français, dirigés par le baron de Saint-Blancard, arrivent dans la zone le 16 septembre seulement, après le retrait des Turcs de Corfou et après la mort de La Forest. Ils ont doublement joué de malchance en perdant une galère et un brigantin en chemin « par fortune de mer ». Mais à l'évidence, ils n'étaient pas prêts.

${ }^{14}$ On peut en suivre le coût financier direct dans le Catalogue des actes de François Ir, t. III, 1889, entre l'été 1536 et le printemps 1539 (18 occurrences directes ou non). On y voit payés les gages de l'ambassadeur à Venise, de mai à août 1536, puis d'août à novembre, pour $1150 £$ à chaque quartier, soit 9,5£ par jour, et à Rome pour ceux du
} 
récupérer des manuscrits grecs et pour apprendre à créer une ambassade et les services de renseignement qui vont avec, mais elles sont peu efficaces du point de vue stratégique : il faut bien dire que la seigneurie de Venise avait inventé la diplomatie avant les Français. Rendue méfiante par les avances de François Ier auprès du Turc et plus encore persuadée de la supériorité de l'empereur dans la péninsule depuis le désastre de Pavie, la Sérénissime a refusé avec obstination de rallier le camp français, ou même de rester neutre. Et ce n'est pas l'agitation des Strozzi et des fuorusciti de Florence installés à Venise qui a pu la faire changer d'avis, au contraire.

L'activité d'Armagnac est aussi de surveiller le passage de troupes impériales et de tenir les possessions françaises en payant des troupes pour sauver ce qui reste des positions françaises en Piémont. Si La Mirandole est le point d'ancrage favori des «Français », on voit passer des « entreprises » plus ou moins fumeuses sur Florence, Crémone et Lodi. Pendant quelques mois, les Français ont pu croire que Florence passerait dans leur camp. Ils se sont heurtés très rapidement à la réalité15. L'attention qu'on accorde à l'État toscan est en rapport direct avec le mariage célébré entre Catherine de Médicis et Henri en 1533 (Henri est dauphin depuis 1536) et la présence à la cour de France des fuorusciti, les exilés florentins de 1530, qui rêvent de reprendre le pouvoir à Florence et multiplient les intrigues et les choix confessionnels compliqués avec l'argent de François Ier: Strozzi, Alamanni, Salviati ${ }^{16} \ldots$

On assiste à une construction postérieure de la mémoire des événements qui suivent l'assassinat d'Alessandro de Médicis par Lorenzzacio le 6 janvier 1537, en France bien sûr, mais aussi en Italie, avec l'œuvre d'un historien comme Jacopo Nardi, qui fit beaucoup pour la transmission de cet esprit «républicain» en France et dans l'Italie

1er janvier au 31 mars 1538, à $10 £$ par jour (nos 9840, 8553, 10364) mais Hémard Denonville reçoit $20 £$ par jour (no 10067) ; on voit aussi les transferts lourds pour payer les capitaines et les courriers. Au total, le roi de France aura versé plus de $24000 £$ pour ses ambassades de Venise et de Rome à ces dates. Encore est-ce un minimum, puisque Georges d'Armagnac préfère être dispensé de décimes sur ses bénéfices.

${ }_{15}^{15}$ G. Galasso et F. Diaz (dir.), Il Granducato di Toscana. C'est autour de Georges d'Armagnac, servi par Guillaume Dinteville (Deschenetz), envoyé par la Cour, que la logistique de ces opérations est préparée, mais les lettres du 10 janvier 1537 au roi et du 12 et du 15 à Strozzi sont bien signées des deux ambassadeurs. Voir C. Samaran et N. Lemaitre (éd.), Correspondance du cardinal Georges d'Armagnac, p. 40-48.

${ }^{16}$ Sur le poids des exilés florentins : J.-F. Dubost, La France italienne, XVI-XVII siècle. Très tôt, leur noblesse a été mise en valeur : L’Hermite de Soliers, La Toscane françoise... 
nouvelle ${ }^{17}$. L'intérêt des analyses à chaud de Selve est donc évident. Après la mort d'Alessandro, l'oligarchie vénitienne élit Cosme, le fils du capitaine mythique que fut Giovanni dalle bande nere (Giovanni de'Medici), mais surtout de Maria Salviati (banque Salviati). Cosme est choisi comme dernier rempart contre l'invasion espagnole. Né en 1519, il est certes jeune, mais il connaît déjà bien la cour d'Alessandro et les vétérans de son père, qui sont prêts à lui faire confiance ${ }^{18}$.

Chez de Selve, le récit des opérations qui mènent au désastre de Montemurlo rend manifeste le manque total d'organisation des conjurés en 1537. C'est ce que disent les historiens à la solde de Cosme, mais aussi les chroniques indépendantes, celle du savonarolien Marucelli par exemple. De Selve ne cache pas que Cosme et Vitelli (le commandant des troupes) savaient tout de l'arrivée brouillonne des rebelles « che non havevono più tra loro esperienza della guerra che bisognassi ${ }^{19} »$. Mais il y a consensus pour estimer que dès la rencontre des chefs des Fuorusciti à Castiglione dei Gaddi, le 9 février 1537, il était évident qu'ils n'avaient pas de ligne d'action commune. Cosme a cherché au contraire à se protéger en envoyant un ambassadeur à l'empereur, et à faire face avant que ses ennemis puissent se renforcer ${ }^{20}$. Ce que dit de Selve à Armagnac sur Cosme de Médicis, le futur duc et grand-duc, semble frappé au coin du bon sens : certes, il n'est qu'un enfant et se fait «embabuiner » par les Espagnols, mais les meilleurs capitaines et les Florentins les moins bavards et les plus riches sont de son côté. S'il y a bien une vacance du pouvoir à Florence après la mort d'Alessandro, vacance dont pourraient

\footnotetext{
17 P. Simoncelli, «Su Jacopo Nardi, I Giunti e la 'Nazione fiorentina' di Venezia ». Voir aussi B. Segni, Storie fiorentine di messer Bernardo Segni...

${ }^{18}$ R. Cantagalli, Cosimo I de'Medici granduca di Toscana.

19 E. Coppi (éd.), Cronaca fiorentina, 1537-1555, p. 7-13. Le chroniqueur ajoute, résigné : « Stavano per il dominio e contado della nostra città tremila Spagnoli or quindi or quinci alle stanze, non con poco danno al luogo ove si trovevano, anzi depredavano e vituperano ogni cosa ; niente di meno ogni cosa era loro comportamento perché da Dio era cosi statuito per gastigo del popolo fiorentino » : «Il y avait dans notre cité trois mille Espagnols ou à peu près en résidence, non sans dommages sur les lieux où ils se trouvaient, et ainsi ils dégradaient et dévaluaient toute chose ; néanmoins tout était en leur pouvoir, car Dieu l'avait ainsi décidé pour le châtiment du peuple florentin » (trad. de l'auteur).

${ }^{20}$ F. Diaz, «Il Granducato di Toscana ». A. D’Addario, « La Formazione dello Stato moderno in Toscana ». Le 21 juin, Cosme a juré fidélité à Charles Quint, qui en échange a promis de laisser les forteresses de Florence, Pise et Livourne aux conditions acceptées en 1536 par Alessandro.
} 
profiter la France ou le pape, Alexandre Vitelli, le capitaine de Florence, choisit d'attendre les ordres de Charles Quint. Pour de Selve, le fils de Giovanni dalle bande nere hérite des fidélités toscanes bien plus que les bannis, et l'empereur joue de façon habile la confirmation de ces fidélités à son profit. Dès 1537, de Selve se méfie de l'activisme de certains Florentins exilés, qui ont réussi à convaincre la cour mais aussi Armagnac. Faire des «coups » séduisait, semble-t-il, le fringant aristocrate, évêque de Rodez, et le roi, si l'on en juge par leurs opérations de juillet 1537, mais pas le sage de Selve.

En fin connaisseur de la géostratégie italienne, de Selve n'approuvait que mollement ces aventures italiennes, leur reprochant d'être à la fois coûteuses et inefficaces. Mais que pouvait-il faire contre les Strozzi, alors au sommet de leur faveur à la cour de France ${ }^{21}$ ? Ils réunissent d'abord une armée de quatre cents fantassins et cent cavaliers sous la conduite de Pierre Strozzi pour prendre Borgo San Sepolcro en avril 1537; ils sont repoussés par Vitelli hors de Toscane ${ }^{22}$. En juillet, ils conduisent quatre mille fantassins et trois cents cavaliers vers Prato et prennent le château de Montemurlo, qu'ils comptent renforcer, en attendant l'arrivée d'autres troupes royales et surtout une rébellion interne de Florence, qui ne viendra jamais. Cette armée est détruite par Vitelli et Piero Colonna (l'un des multiples désastres français) le 1er aout 153723.

L'envoi de secours par le roi de France après la conclusion de la trêve n'y changera rien ${ }^{24}$. Quant à l'espoir caressé par de Selve et Piero Strozzi d'un échange de prisonniers à la

${ }^{21}$ G. Spini, «Cosimo I e l'independanza del principato mediceo». François Ier les encourage d'abord par l'intermédiaire de Bernardo Salviati, chevalier de Malte et frère du cardinal, et offre d'y mettre vingt mille écus. Guillaume Dinteville les rejoint le 9 février avec 15000 écus, mais c'est trop peu alors que dès le 1er mars Cosme a obtenu un prêt des Florentins de 22000 écus au taux de $8 \%$. Il est clair dès avril qu'il n'y a pas assez d'argent chez les Français pour lever des troupes, et que si le fils de Filippo Strozzi, Piero, est avide de gloire militaire et veut en découdre, il ne s'entend pas avec son père, qui souhaite au contraire épargner les soudards aux Toscans et négocier avec Cosme.

${ }^{22}$ Lettre d'Armagnac au maréchal d'Humières, le 27 avril 1537 (C. Samaran et N. Lemaitre (éd.), Correspondance du cardinal Georges d'Armagnac, p. 72).

${ }^{23}$ E. Cochrane, Florence in the forgotten centuries, 1527-1800, p. 32-35.

${ }^{24}$ Voir ce que dit d'Armagnac au duc de Ferrare le 12 et le 17 août: C. Samaran et N. Lemaitre (éd.), Correspondance du cardinal Georges d'Armagnac, p. 104-106. 
faveur d'un coup de force de ce dernier ${ }^{25}$, il ne s'est jamais concrétisé, tandis que Cosme obtenait pas à pas de Charles Quint le droit d'éliminer son plus dangereux rival, Filippo Strozzi. L'empereur a longtemps voulu préserver Filippo, ne serait-ce que pour des raisons financières et à cause des appels à la clémence venus de toute la chrétienté. Mais la situation de Florence sous Cosme et Vitelli lui permettait d'éviter d'y envoyer des troupes tout en contrôlant la situation. À l'entrevue de Nice, en 1538, Charles Quint est obligé de donner des gages à Cosme, de plus en plus puissant et qui voit s'éloigner son rêve d'épouser la veuve d'Alessandro, promise au neveu du pape. C'est ainsi qu'il convainc l'empereur que Filippo Strozzi est impliqué dans l'assassinat d'Alessandro, grâce aux aveux obtenus sous la torture de Giuliano Gondi. Lors de l'entrevue d'AiguesMortes entre le roi et l'empereur les 16 et 17 juillet, l'ambassadeur de Cosme réussit à convaincre Charles Quint. Dès lors, le sort de Filippo est scellé, qui finira « suicidé » le 18 décembre $1538^{26}$.

Quand on voit ce que rapporte de Selve, par petites touches, des rumeurs sur les troupes impériales et de leur financement à Rome ou à Naples, on comprend assez vite que les chiffres, aussi bien financiers qu'humains, sont favorables à l'empereur. Le réseau tissé par les Français en Italie du Nord et entretenu par les ambassadeurs et la duchesse de Ferrare restera en place jusqu'en 1559, mais sans succès notable, et moins encore après la défaite de la guerre de Sienne (1555).

Pour l'heure, c'est de Venise aussi que les meilleurs jeunes diplomates sont envoyés vers le sultan turc: Jean de La Forest, un cousin d'Armagnac également, commence une

\footnotetext{
${ }^{25}$ Lettre de G. de Selve à Armagnac, le 4 août 1537, MAE CP Rome 3, fol. 288 vo-289 : « D’aultre part s'est advisé ledit messire Laurens de despescher a messire Pierre Strocy pour sçavoir ce qu'il a intension de faire et luy ramentevoir qu'il est vraysemblable qu'il ne recouvre jamais son pere sans y mectre grand partye de ses facultez et qu'il pourroit estre qu'en adventurant quelque somme d'argent a renfort de gens promptement, il le pourroit recouvrer par force, l'exhortant plutost a ce moyen que a advenir pour ayder tout a ung coup et au pere et a la patrie. Laquelle oppinion a esté confortée par nous comme fondee ce nous semble en bonne raison comme expedient pour les affaires du roy, pour lesquelz font que le trouble aydant a esté commencé en Tuscane».

${ }^{26}$ A. D'Addario, «La Formazione dello Stato moderno in Toscana», p. 190. L'indépendance de Cosme par rapport à l'empereur Charles Quint ne sera effective qu'en juillet 1543, avec la restitution des forteresses de Florence et de Livourne par les Espagnols, contre le versement de 100000 ducats.
} 
brillante carrière, trop vite interrompue par la maladie à l'automne 153727 . Du point de vue italien, le Turc, ce sont des galères et des armées innombrables qui menacent les côtes et dont on rend compte avec effroi de l'arrivée, pendant l'été surtout. Les mouvements des flottes d'André Doria, le Gênois qui est généralement au service de l'empereur et donc de l'ennemi, sont également scrutés avec soin. La flotte de galères françaises commence à peine à être mise en place par Montmorency, et donc les Français ne comptent pas encore.

Quand le pape est à Rome, la curie devient une formidable caisse de résonance des événements européens, les batailles de Picardie par exemple, dont de Selve semble informé avant Armagnac.

Les ambassadeurs s'occupent aussi des mariages princiers. En 1537, ce sont ceux de l'infant d'Espagne ou du Portugal avec les princesses impériales et anglaises. Ce sont aussi ceux des enfants d'Alexandre Farnese et de Cosme de Médicis bien sûr, résultats d'une stratégie subtile où l'empereur et le pape l'emporteront finalement. Mais l'obsession du pape est bel est bien le concile, pour lequel il tente de construire la paix par tous les moyens, y compris les armes spirituelles ici sorties du fourreau sans complexe contre un roi et un empereur qui ne voudraient pas optempérer.

Paul III semble réussir : la trêve de dix ans conclue lors de l'entrevue de Nice le 18 juin 1538, alors que les deux souverains ont refusé de se voir, réserve à François Ier la Bresse, le Bugey et une partie du Piémont, tandis que le Milanais et le reste du Piémont vont à Charles Quint. Les deux princes se retrouvent cependant, sans le pape, à Aigues-Mortes le 14 juillet 1538, l'un venant de terre et l'autre sur les galères. François Ier croit encore obtenir le Milanais ${ }^{28}$ par la négociation et, pour cela, il n'hésite pas à abandonner Gand en permettant à Charles Quint de passer en France pour châtier la ville rebelle. Le Turc s'estime trahi et Venise estime que Charles Quint a gagné. Mais comme l'avait vu de Selve, Charles Quint refuse de laisser Milan, et il donne la ville à son fils Philippe en octobre 1540. La diplomatie de Montmorency a donc échoué, ce qui n’est pas pour rien

\footnotetext{
27 MAE CP, Rome 3, fol. 349 vo, 6 octobre 1537. C. Samaran et N. Lemaitre (éd.), Correspondance du cardinal Georges d'Armagnac, p. 467-468. Et sur les suites de cette diplomatie: G. Poumarède, «Le "vilain et sale assassinat" d'Antonio Rincon et Cesare Fregoso (1541) ».

${ }^{28}$ Institut de France, Manuscrits, Godefroy, 231/ fol. 173, «Instructions de l'évêque de Lavaur et de Hesselin, envoyés par le Roi de France à l'Empereur, touchant la restitution du duché de Milan », 1538.
} 
dans la mélancolie de plus en plus profonde de Georges de Selve. Il sait que le front italien est désormais secondaire pour le roi de France. La rivalité avec le Habsbourg s'est déplacée vers le nord de la France. L'Italie est espagnole ou pontificale, et la présence du roi de France ne s'impose plus, même s'il offre encore son aide à tel ou tel prince italien.

Il ne faut pas oublier enfin que nos deux correspondants sont des évêques proches des cercles réformistes de Marguerite de Navarre. Le projet de concile du pape Paul III devait donc les enthousiasmer; par la bulle du 2 juin 1536, Paul III a en effet convoqué un concile à Mantoue pour le 23 mai 1537. La reprise de la guerre a tout gelé, d'où les efforts de Paul III pour imposer la paix et le jeu de cache-cache des deux souverains à l'égard du concile, auquel, comme l'a montré Alain Tallon ${ }^{29}$, François Ier était indifférent plutôt qu'hostile, et surtout désireux d'en profiter pour négocier la session de Milan. Force est de dire que si le concile n'est pas totalement occulté par de Selve, il n'apparaît que rarement dans ses lettres à Armagnac. Est-ce parce que l'ambassadeur sait que la Cour et Paris y sont hostiles? Est-ce parce qu'il semble que le concile sera au pouvoir de l'empereur et du pape seuls ? Est-ce parce que les deux cours sont persuadées qu'elles pourront résoudre le problème de la Réforme sans le pape? Comme les Turcs, les Allemands luthériens semblent faire des alliés honorables pour le roi de France, mais celui-ci reste dans la répression après l'affaire des Placards, et donc les projets de colloque tournent court. Les gallicans réformistes ne sont pas hostiles, mais ils refusent l'emprise de l'empereur sur l'événement. Pourtant de Selve note que le pape sollicite Venise comme une puissance neutre pouvant proposer une ville qui accueillerait le concile. C'est ainsi que Vicence est accordée, le 29 septembre 153730.

Devant le manque d'enthousiasme de l'empereur et du roi, les ambassadeurs français n'y croient pas beaucoup non plus, et l'on voit de Selve demander au pape en mars 1538 ce qui se passerait si l'empereur refusait le concile. Le pape répond qu'il persistera, mais de Selve ajoute pour Armagnac: «Sur quoi se pourroit faire des discours dont nous deporterons, nous en remectant a votre bon et sage jugement ${ }^{31}$ ».

\footnotetext{
29 A. Tallon, La France et le concile de Trente, 1518-1563.

${ }^{30}$ MAE CP, Rome 3, fol. 347 vo.

31 MAE CP, Rome 3, fol. 464, 17 mars 1538.
} 


\section{La correspondance, un moyen d'information maîtrisé}

L'information de l'ambassadeur du roi à Venise est aussi cruciale qu'à Rome pour l'efficacité de l'action royale, c'est pourquoi les événements, les hommes et les lieux sont présentés avec le maximum de précision et de redondance par de Selve. Cette minutie, liée à l'angoisse de l'arrivée à bon port des nouvelles, mais aussi à l'analyse au jour le jour des questions pendantes, permet de comprendre le nouveau métier des ambassadeurs, qui ne reçoivent plus seulement des instructions mais doivent aussi interpréter le contexte local ${ }^{32}$.

Bien que privées, les lettres à d'Armagnac forment déjà une correspondance diplomatique normée. Toutes les lettres commencent par poser l'information de ce qui a été reçu et quand. Mais ce qui importe, $c^{\prime}$ est l'origine et la critique des contenus ${ }^{33}$. Les lettres se croisent, et il n'est pas toujours simple de connaître en temps réel l'avis des uns et des autres. On sait mesurer cependant les temps d'acheminement et leurs modalités : environ quatre à six jours entre Rome et Venise. Or de Selve écrit tous les deux à trois jours, donc les flux de nouvelles sont décalés. Remarquable est la régularité, nouvelle sans doute, de la correspondance entre de Selve et Armagnac. C'est la preuve qu'il y a une installation à demeure de la politique française en Italie entre ces deux professionnels de la négociation, bien qu'ils courent le risque d'être soupçonnés par la cour de France de faire cavaliers seuls. Mais c'est aussi la preuve qu'ils cherchent, face aux événements qui se précipitent, le maximum d'efficacité dans l'interprétation des faits au service du roi.

De Selve devait être un impatient: il fait arrêter à plusieurs reprises le courrier prêt à monter à cheval et se désole souvent (vingt fois au moins) de l'absence de lettres de son correspondant, lesquelles lettres arrivent cependant, comme le montre le courrier suivant. Armagnac semble moins précis dans ses réponses, mais malheureusement, nous

\footnotetext{
${ }^{32}$ Des travaux récents examinent ces quêtes nouvelles. Je remercie tout particulièrement J. Petitjean, qui a soutenu une thèse à l'université Paris I en 2011, sous la direction de W. Kaizer, publiée ensuite par l'École française de Rome, L'intelligence des choses. Voir pour l'information publique, sa production et ses utilisations à Venise : J. Petitjean, «Compilation des nouvelles et écriture de l'actualité à Venise au XVIe siècle ».

${ }^{33}$ Des travaux récents ont repris la question des Avvisi : J. Petitjean, « Mots et pratiques de l'information ». Sur une partie des informations transmises par de Selve et issues des «adviz», voir F. Brizay (dir.), Les formes de l'échange..., p. 319-334; cet ouvrage fait partie des approches nouvelles qui permettront de mieux comprendre le filtrage des flux venus du monde turc, particulièrement à Rome et Venise.
} 
n'avons rien de sa correspondance active, trop vite dispersée après sa mort en Avignon en 1585.

Il y a les courriers réguliers dont on connaît les noms, comme le sieur Capin, le Bergamin, Sentinelle ou Livio Crotto; si le premier est un capitaine, le second un serviteur, les derniers feront carrière comme diplomates, à l'image de nombreux jeunes qui se font ainsi remarquer, probablement en devenant «lettres vivantes». Sur un trajet aussi fréquenté que celui de Rome à Venise, les routes semblent assez sûres, plus en tout cas que depuis Lyon vers l'Italie, ou pire encore, de Bresse en Italie ${ }^{34}$. Outre les courriers extraordinaires et les courriers domestiques, l'ambassadeur du roi de France à Rome utilise chaque fois qu'il le peut soit le courrier de la seigneurie de Venise, soit celui des marchands de Lyon, soit le courrier «ordinaire», qui est probablement celui du pape, quand ce n'est pas celui des Impériaux.

Le résultat est que les lettres sont lues avant d'arriver, aussi bien du côté espagnol que du côté français ou italien d'ailleurs. Aussi, un chiffre est utilisé et modifié à plusieurs reprises durant les quelques mois de 1537-1538. Pour la France, nous sommes dans une période charnière, celle où on passe du vieux chiffrage de César, décrypté par Alberti, à des chiffrages plus sophistiqués, appris à Venise, qui combinent à la fois des chiffres et des signes. Tous les secrétaires de personnages aux affaires deviennent des spécialistes du chiffre. De fait, les mentions que nous avons ici renvoient probablement au chiffre de César en 1537, plus qu'à un mélange de chiffres et de lettres dont nous avons des exemples par la suite dans la correspondance d'Armagnac ${ }^{35}$. Il semble pourtant que

\footnotetext{
${ }^{34}$ Même sur la route la plus fréquentée. Par exemple, le 17 août 1537, Selve se plaint au pape des courriers détroussés sur la route de Bologne: "Nous luy avons faict asse plaincte des deux courriers destroussez depeschez a Rome. Par les coupables de quoy elle nous a promys se ressentir vifement envers les imperiaulx et la Seigneurie et ne doubte assé que de votre vous n'ayez faict envers eulx l'office regiz si ce destrossement a esté faict sur leurs terres et en effet ce nous sera une merveilheuse decision s'il se n'y est faict quelque provision », MAE Rome 3, fol. $306 \mathrm{v}^{\mathrm{o}}$.

35 Par exemple et parmi d'autres, le 26 août 1537 : «Monsieur, nous vous voulons encores recorder que nous vous pryons que tout ce que vous nous escryrez des affaires de Levant soit tousjours bien mys en chiffre et de n'estre tout ce qui concerne Sa Sainteté et encore trouverez nous fort bon quant vous viendra a point que vous nous escripassiez en chiffre separement ce qui concernera lesdites affaires turquesques et ceulx de Sa Sainteté et sans signes pour eviter tous inconveniens et escripvre en une lettre separer les aultres choses qui se perceront pour de part affin que nous passions quelque foys monstrer voz lettres mestans Sa Sainteté pour le tirer et
} 
de Selve et Armagnac se faisaient beaucoup d'illusions sur l'efficacité du chiffre français imposé par Montmorency : «les propoz chatouilleux » doivent être chiffrés pour que les «mauvais gens» puissent n'en «avoir l'intelligence»; mais en fait, les lettres des Français saisies par les gens de l'empereur ou ceux de Florence et de Venise ont toujours été déchiffrées par les adversaires du roi de France, et ceci même en contexte de détente ${ }^{36}$. Les passages de troupes, d'ambassadeurs, d'argent même n'avaient aucun secret pour eux. Les méthodes françaises d'espionnage étaient balbutiantes en regard de la puissance grandissante du système espagnol, qui connaît son âge d'or à la fin du siècle ${ }^{37}$.

En lisant de près la correspondance, on voit aussi l'affinement rapide du vocabulaire, qui trie l'information, «Untel m'a dit», «Untel a dit à SS», «On dit que», «s'entend dire $» . . .$, analyse qui devient la base du travail de l'ambassadeur permanent. Cette façon d'affiner l'observation est propre au monde diplomatique et appartient à la mission d'État de l'homme du roi, soucieux de réfléchir parfaitement l'image de son souverain, selon Daniel Ménager ${ }^{38}$.

Si l'orateur du roi peut parfois être assimilé aux anges messagers, la nouveauté est aussi sans doute l'intérêt de de Selve pour le financement des opérations. Il détaille avec minutie les revenus potentiels de l'empereur et du pape et estime les capacités des lieux ou des hommes à payer effectivement. Bref, c'est un technocrate qui apparaît ici. Comme nous n'avons pas les réponses, il est difficile de dire si Armagnac a tenu compte des avis de celui qui est son cadet par l'âge mais son aîné dans la carrière, et donc un administrateur habitué au maniement de l'argent. Une chose est sûre: on trouve plus tard le cardinal, chargé à plusieurs reprises par le roi de France de surveiller la levée des impôts dans le Midi, dans des zones réputées pour ne pas payer...

En 1538, de Selve, ambassadeur à Rome, semble désabusé, soit par la cour romaine, soit par l'action royale. Il manie alors un certain un humour qui en dit long sur les hommes et

beaucop de souspeçons et elle entre assez facillement et nomectrons a vous dire a ce propoz que ce jours icy entre quelques imperiaulx se murmuroit qu'il avoit esté intercept ung paquet de monsieur de La Forest venant de Raguse », MAE, Rome 3, fol. 313. Sur l'évolution du chiffrage : D. Kahn, The Codebreakers.

${ }^{36}$ MAE CP Rome 3, fol. 324 vo, 6 septembre 1537.

37 A. Hugon, Au service du roi catholique.

38 D. Ménager, Diplomatie et théologie à la Renaissance. 
les choses d'Italie. On le voit par exemple commenter avec lucidité les négociations d'octobre 1537 :

«L'empereur dict voloir la paix et quiter l'estat de Milan mais en garde toutesfoys la possession jusques a ce que le mariage de monsr d'Orleans avec la fille du roy dez romains soit consommé et ne parle de voloir envoyer grande joy pour cest effect ${ }^{39}$. »

Ou encore, quelques jours plus tard, lors de la négociation de la Ligue du pape à propos du renvoi des troupes contre le Turc :

«Et par la peult l'on veoir que l'intention de l'empereur est bien differente de celle de ladite Seigneurie car la ou elle veult convertir cestedite ligue en prouffit publique de la chrestienté et en faire sortiront comme union layssant en arriere les respectz et particulier prouffit ${ }^{40}$. »

Mais cet humour peut aussi s'exercer à l'encontre du pape ; ainsi, le 7 mars 1538 :

«Vela quoy nous en sommes comme l'oyseau sur la branche sans scavoir resolutivement de quel a esté et quant se prendra le vol et ne vous esmerveillez si nous vous escrimes aussi en double les conceptions de Sa Sainteté car elle les tient si occultes et mises a faire plus pour plus qu'il est mal costé41. »

Ou encore à l'encontre de la seigneurie de Venise, le 16 septembre 1537 :

«L'ambassadeur de la Seigneurie hyer au soir notiffia a notre Sainct Pere que la Seigneurie, apres avoir bien pensé a la requisition que Sa Sainteté leur avoit faict et se veoyant assailliz du Turc en leur isle de Corfou, s'estoient finablement resolus non moins pour le bien universel de la chretienté que pour le leur particulier de consentir au vouloir de sadite Sainteté de venir a la guerre ouverte avec le Turc non seulement deffensive ${ }^{42}$. »

De Selve a donc réussi à prendre une grande distance par rapport à ce qu'il observe. Mieux encore, il réussit à l'exprimer à l'égard de son collègue et du roi.

De Selve est un vrai professionnel, qui a des oreilles partout, y compris chez l'ennemi. Il sait hiérarchiser les informations selon leur qualité, c'est pourquoi sans doute ces lettres ont été conservées quand s'est constituée l'administration des Affaires étrangères. Il est

\footnotetext{
${ }^{39}$ MAE, CP, Rome 3, fol. 355, 9 octobre 1537.

${ }^{40}$ Ibid., fol. 358 vo-359, le 17 octobre 1537.

${ }^{41}$ Ibid., fol. 461.

42 Ibid., fol. $336 \mathrm{v}^{\mathrm{o}}$.
} 
capable d'assurer la formation permanente de ses jeunes collègues, dont certains, comme le protonotaire de Noailles, feront ensuite une brillante carrière.

C'est une correspondance qui tente de saisir la complexité de la situation italienne et d'en rendre compte, au cardinal de Tournon par exemple ; mais de Selve agit aussi pour éviter aux finances royales de dépenser trop et en vain. On y voit les difficultés d'argent, avec des dotations qui arrivent de façon discontinue, des problèmes logistiques, par exemple quand de Selve suit le voyage du pape vers Nice. On y voit les difficultés à maintenir des itinéraires sûrs pour le courrier royal, les problèmes d'espionnage... Mais l'enjeu primordial est pour lui cette présence permanente à la cour pontificale, pour défendre le roi contre les calomnies des Impériaux, pour apprendre à trier l'information et tordre le cou à la désinformation, pour comprendre vite les subtilités des situations et des changements d'alliance. Au-delà de l'écume des événements, le « négocier » permanent semble bien le premier souci de l'ambassadeur : rester en contact avec le pape, écouter les rumeurs et les démentir ou au contraire s'en servir. Défendre la paix, comme le veut le pape ou comme le veut l'évêque, qui souhaite rejoindre ses ouailles au plus vite.

De Selve ne nous dit rien de son point de vue religieux, mais il fait partie de ceux qui croient à la réforme menée par le roi tout autant qu'à la réforme par le pape. Faute de documentation complémentaire à croiser avec les considérations de Georges de Selve, il est bien difficile d'en savoir plus, mais le Saint-Office veille dans les années 1540. Se pourrait-il qu'Armagnac et de Selve aient détruit les lettres compromettantes à cet égard ? La ruse autant que la prudence font partie de leur métier.

\section{Bibliographie}

AlBERI Eugenio (éd.), Relazioni degli ambasciatori veneti al Senato, Florence, Società editrice fiorentina, 1839-1863.

ALLAIN Jean-Claude et al. (dir.), Histoire de la diplomatie française, vol. 1 : Du Moyen Âge à l'Empire, Paris, Librairie académique Perrin, 2005.

AUTRAND Françoise, "L'enfance de l'art diplomatique en France, XIVe-XVe s. », dans Dixhuitième siècle, no 31 : L. Bély (dir.), L'invention de la diplomatie, 1999, p. 207-224. 
Benedict Philip, Seidel Menchi Silvana, Tallon Alain (dir.), La Réforme en France et en Italie. Contacts, comparaisons et contrastes, Rome, École française de Rome, 2007.

BRIZAY François (dir.), Les formes de l'échange. Communiquer, diffuser, informer de l'Antiquité au XVIII siècle, Rennes, Presses universitaires de Rennes, 2012.

BRUN Nicolas A. A., Trois plaidoyers pour un art holographique, Paris, L'Harmattan (L'art en bref), 2008.

CANTAgalli Roberto, Cosimo I de'Medici granduca di Toscana, U. Murcia, 1985.

COCHRANE Eric, Florence in the Forgotten Centuries: 1527-1800, Chicago, University of Chicago Press, 1973.

CoppI Enrico (éd.), Cronaca fiorentina : 1537-1555, Florence, Olschki, 2000.

D'ADDARIO Arnaldo, La Formazione dello Stato moderno in Toscana, da Cosimo il vecchio a Cosimo I de'Medici, Lecce, Adriatica, 1976.

DAuvoIS Nathalie (dir.), L'humanisme à Toulouse : 1480-1596, actes du colloque international de Toulouse, mai 2004, Paris, Champion, 2006, 639 p.

De VIVo Filippo, Information and Communication in Venice: Rethinking Modern Politics, Oxford University Press, 2007.

DIAZ Furio, «Il Granducato di Toscana, I Medici », dans G. Galasso (dir.), Storia d'Italia, vol. 13, 1, Turin, Utet, 1976, p. 50-83.

DuBOST Jean-François, La France italienne, XVIe-XVII siècle, Paris, Aubier, 1997.

FOISTER Susan, ROY Ashok, WYLD Martin, Making and meaning: Holbein's ambassadors, Londres, National Gallery, 1997.

HugON Alain, Au service du roi catholique, "honorables ambassadeurs » et «divins espions » : représentation diplomatique et service secret dans les relations hispano-françaises de 1598 à 1635, Madrid, Casa de Velázquez, 2004.

KAHN David, The Codebreakers : the story of secret writing, New York, MacMillan, 1996.

L'HeRMITE DE SOLIERS (dit J.-B. Tristan), La Toscane françoise contenant les éloges historiques et généalogiques des princes, seigneurs et grands capitaines de la Toscane, lesquels ont esté 
affectionnez a la couronne de France, ensemble leurs armes gravées et blasonnées en taille douce, avec les couronnes, manteaux, colliers, timbres et autres ornements, Paris, J. Piot, 1661.

LeFÈVRE-PontALIS Germain (éd.), Correspondance de Odet de Selve, ambassadeur de France en Angleterre (1546-1549), Paris, F. Alcan, 1888.

LEMERLE Frédérique, Les «Annotations » de Guillaume Philandrier sur le De architectura de Vitruve, Paris, Picard, 2000.

MÉNAger Daniel, Diplomatie et théologie à la Renaissance, Paris, Presses universitaires de France, 2001.

Petitjean Johann, "Compilation des nouvelles et écriture de l'actualité à Venise au XVIe siècle ", Hypothèses, 2009 / 1, p. 73-82. http://www.cairn.info/revue-hypotheses2009-1.htm.

Petitjean Johann, "Mots et pratiques de l'information: ce que aviser veut dire", Mélanges de l'École française de Rome, Italie-Méditerranée, 122/1, 2010, p. 107-121.

Petitjean Johann, L'intelligence des choses. Une histoire de l'information entre Italie et Méditerranée (XVI-XVII siècle), Rome, École française de Rome, 2013 (thèse université Paris I, sous la dir. de W. Kaiser, 2011).

PouMARÈDE Géraud, Pour en finir avec la croisade, Paris, Presses universitaires de France, 2004.

POUMARÈDE Géraud, « Le "vilain et sale assassinat" d'Antonio Rincon et Cesare Fregoso (1541). Un incident diplomatique exemplaire? » dans L. Bely et G. Poumarède (dir.), L'incident diplomatique, Paris, A. Pedone, 2010, p. 7-44.

Prodi Paolo, Diplomazia del Cinquecento. Istituzioni e prassi, lezioni tenute alla Facoltà di Magistero dell'Università di Bologna nell'anno accademico 1962-63, Bologne, Patron, 1963.

RIBIER Guillaume, Lettres et mémoires d'Estat, des Roys, Princes, Ambassadeurs et autres Ministres sous les Regnes de François Ier, Henry II et François II, Paris, chez F. Clouzier et la veuve Avbovyn, 1666, 2 vol. 
SAMARAN Charles, "Georges d'Armagnac, ambassadeur de François Ier à Venise, peint par Le Titien en compagnie de son secrétaire Guillaume Philandrier », Comptesrendus de l'Académie des inscriptions et belles-lettres, 1966, t. 110, p. 38-44.

SAMARAN Charles et LEMAITRE Nicole (éd.), Correspondance $d u$ cardinal Georges d'Armagnac, tome I : 1530-1560, Paris, Éditions du CTHS (Documents inédits sur l’histoire de France, série in-8, vol. 41), 2007.

SEGNI Bernardo (1499-1558), Storie fiorentine di messer Bernardo Segni [...] dall'anno 1527 al 1555, Saluces, 1723.

SIMONCELLI Paolo, «Su Jacopo Nardi, I Giunti e la 'Nazione fiorentina' di Venezia », dans L. Borgia, F. De Luca, P. Viti, R. M. Zaccaria (éd.), Studi in onore di Arnaldo D'Addario, Lecce, Conte, 1995, p. 937-949.

SPINI Giorgio (éd.), Cosimo I de’Medici : Lettere, Florence, Valecchi, 1940.

SPINI Giorgio, Cosimo I e l'independanza del principato mediceo, Florence, Valecchi, 1980.

TALLON Alain, La France et le concile de Trente, 1518-1563, Rome, École française de Rome, 1997.

Zwingenberger Jeanette, Hans Holbein le Jeune: l'ombre de la mort, Londres, Parkstone, 1999.

\section{Résumé}

Sous le règne de François Ier, le royaume de France entre dans la pratique des ambassades permanentes. Entre 1537 et 1538, Georges de Selve, ambassadeur à Rome, écrit une centaine de lettres à son collègue Georges d'Armagnac, nouvel ambassadeur à Venise, où il remplace de Selve. La correspondance privée entre les deux amis serait perdue sans sa copie par les Affaires étrangères, au début du XVII siècle. En partie destinées à former Armagnac, en partie informatives, ces lettres sont malheureusement sans réponse connue de ce dernier. Nous savons par de Selve qu'Armagnac a répondu et qu'une lettre sur quatre environ a été perdue en chemin. Ceci pose la question de l'utilisation de la correspondance pour l'histoire. Il faut se méfier des avis unilatéraux, mais pourtant le parti pris pédagogique de Georges de Selve permet ici d'expliquer le monde, le pape et la curie, la lente désagrégation de la politique française, étranglée par l'absence d'investissement et les coups mal préparés. De Selve est de plus en plus désabusé, mais il suit la cour pontificale et raconte. 


\title{
Un Rouennais aux états généraux de 1789 : Pierre Nicolas de Fontenay
}

\author{
Anne Mézin \\ Chargée d'études documentaires aux Archives nationales, \\ département du Moyen Âge et de l'Ancien Régime (DMAAR)
}

\begin{abstract}
Extrait de : CABOURET Bernadette (dir.), La communication littéraire et ses outils : écrits publics, écrits privés, éd. électronique, Paris, Éd. du Comité des travaux historiques et scientifiques (Actes des congrès nationaux des sociétés historiques et scientifiques), 2018.

Cet article a été validé par le comité de lecture des Éditions du Comité des travaux historiques et scientifiques dans le cadre de la publication des actes du 139e Congrès national des sociétés historiques et scientifiques tenu à Nîmes en 2014.
\end{abstract}

Entre le 1er mai 1789 et le 23 juillet 1791, Pierre Nicolas de Fontenay a écrit six cent vingtsix lettres à Marie Élisabeth Ribard, son épouse ${ }^{1}$. Ne serait-ce qu'en raison de leur nombre, ces lettres forment un ensemble remarquable.

Trois thèmes seront évoqués successivement : la présentation de Fontenay, de sa famille et de son milieu, une description générale de la correspondance, et les principaux sujets abordés dans ses lettres.

\section{Fontenay, sa famille, son milieu}

Né à Rouen le 27 septembre 1743, Pierre Nicolas de Fontenay était le fils de Nicolas Eustache de Fontenay, négociant à Rouen², et de Marie Marthe Marguerite Grandin, issue d'une des plus anciennes familles qui figuraient à Elbeuf dans le commerce et la manufacture de la draperie, et alliée aux autres familles importantes de la ville (Flavigny, Godet, Sevaistre, Duruflé etc.). Pierre Nicolas de Fontenay se trouvait de ce fait apparenté

\footnotetext{
${ }^{1} \mathrm{M}^{\text {me }}$ de Fontenay rejoignit son mari du 5 au 21 août 1789, du 22 avril au 16 octobre 1790, puis du 24 juillet au 30 septembre 1791, ce qui interrompit leur correspondance. Les autres papiers de Fontenay gardés par sa descendance sont des lettres à son épouse pendant qu'il siégeait au Sénat entre 1804 et 1806.

${ }^{2}$ Guilbert, Éloge nécrologique de M. de Fontenay, p. 4 ; D. Sebban, « Pierre-Nicolas Defontenay ou la bourgeoisie au pouvoir »; L. Soublin, Le premier vote des Normands, 1789, ch. VI, « Deux industriels du XVIII⿸ siècle, J.-B. Decrétot et P.-N. Defontenay », p. 231-241.
} 
à tous ceux qui comptaient dans ce riche et influent milieu industriel normand. Il avait deux frères, Jean Eustache, officier de dragons ${ }^{3}$, et Alexandre, dit Alex, avec qui il travaillait.

Fontenay avait épousé le 6 novembre 1770 à Rouen, en premières noces, Élisabeth Marguerite Thérèse Hurard5, et en secondes noces, le 3 juin 1776 à Saint-Vincent de Rouen, Marie Élisabeth Ribard6, fille de Jean Philippe Nicolas Ribard, conseiller-échevin et juge-consul de Rouen et de Marie-Catherine Guillemard. De ce second mariage, Pierre Nicolas de Fontenay eut de nombreux enfants, parmi lesquels Marthe Élisabeth (épouse Jacques Lézurier), Catherine Constance (épouse Pierre Grandin), Alexandre Nicolas, Marie Joséphine (épouse Ambroise Belhomme de Franqueville), Céleste Marie, Augustin Félix et Jacques (fig. 1).

Après des études dans les meilleurs établissements de Rouen, au séminaire de Joyeuse, à Rouen, qui accueillait les fils de bonne famille, puis chez les Jésuites ${ }^{7}$, Pierre Nicolas prit la suite de son père dans le commerce des tissus et des fils, dans le cadre duquel il importait de la laine d'Espagne et exportait des toiles en fil de lin. Il s'y consacra jusqu'en 1783, en collaboration avec son frère Alexandre, ce dernier s'occupant de la partie commerciale en France et à l'étranger.

\footnotetext{
${ }^{3}$ Jean Eustache de Fontenay (né à Rouen, baptisé le 19 octobre 1744, mort à Louviers le 24 novembre 1803), gendarme de la garde du roi (1776), colonel attaché au corps des dragons en 1789, chevalier de Saint-Louis (1789). Lettre 134, 28 septembre 1789.

${ }^{4}$ Alexandre de Fontenay (né à Rouen, baptisé le 3 février 1748 ; mort sans alliance à Rouen le 12 octobre 1833), négociant à Rouen; il fut l'un des principaux industriels français de son époque; membre du tribunal de commerce de Rouen dès 1801, il fut élu membre de la chambre des Cent-Jours; chevalier de la Légion d'honneur, il était également franc-maçon : «Nicolas Ribard m'a fait part du zèle que mon frère Alex a montré dans tous nos troubles. Il est né trop tôt, il est dévoré du patriotisme avant d'avoir une patrie. Il mérite bien que nous lui en donnions une » : lettre 82, 23 juillet 1789.

${ }^{5}$ Née à Rouen le 2 juillet 1753, fille de Pierre Louis Hurard, banquier, et d'Élisabeth Marguerite Ribard ; morte à Rouen le 30 août 1771.

${ }^{6}$ Née à Rouen le 28 septembre 1757 ; morte à Paris le 26 décembre 1809. Parmi les souvenirs de la famille Fontenay, aujourd'hui dispersés, figurait une miniature représentant Élisabeth de Fontenay en robe décolletée, un king-charles dans les bras.

7 Guilbert, Éloge nécrologique de M. de Fontenay, p. 4.
} 


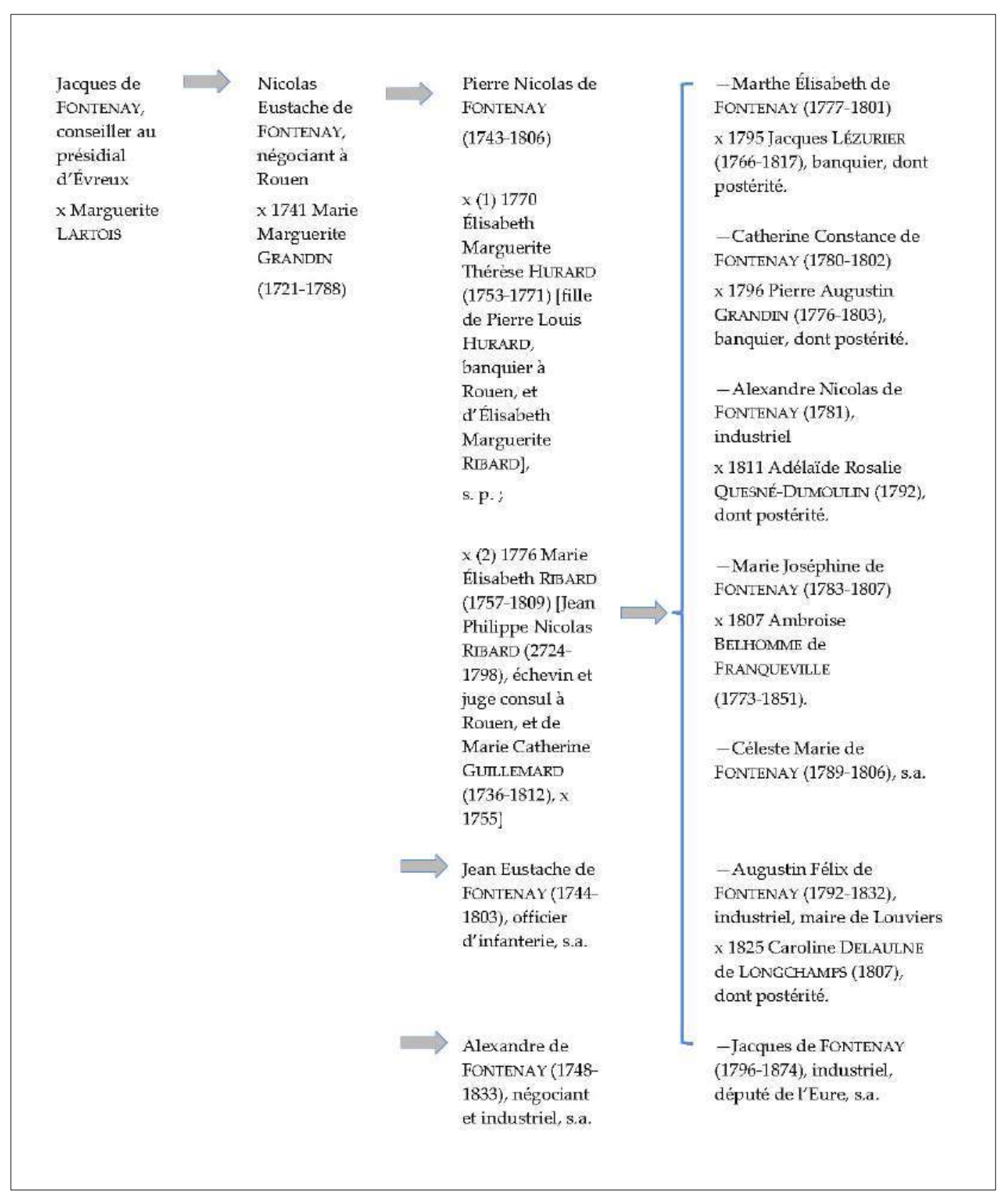

Fig. 1 - Tableau généalogique des Fontenay. Doc. A. Mézin.

Passés à l'industrie, les frères Fontenay participèrent à la mutation de Louviers lorsque le travail du coton fut ajouté à la production traditionnelle des draps de laine, qui avait fait la richesse de la ville. Dès 1780, ils avaient acheté au faubourg Saint-Germain, sur l'île de la Salle du Bois, des moulins à blé et à tan, en vue d'y installer leur future manufacture 
hydraulique de coton ${ }^{8}$. Désormais industriels, ils figurèrent parmi les «premiers et des plus forts actionnaires de la filature de Louviers ${ }^{~ ", ~ f i l a t u r e ~ a p p e l e ́ e ~ " u s i n e ~ d e ~ l a ~}$ Mécanique », dont la création fut décidée en 1784. Elle fut l'une des toutes premières manufactures françaises utilisant le water-frame, une machine qui permettait de carder et filer le coton à l'aide de la force hydraulique, seul moyen de «diminuer le prix de la main-d'œuvre $[\ldots]$ pour soutenir la concurrence anglaise ${ }^{10} »$.

«Dans ladite machine, tout marche ensemble d'un mouvement égal et réglé comme celui d'une horloge. Une seule roue peut faire aller 6000 broches à la fois et avec elles, toutes les opérations préparatoires, en sorte que cette seule roue produirait dans toutes les machines 160000 mouvements particuliers et différents ${ }^{11}$. »

En 1786, l'usine de la Mécanique de Louviers comptait «dix-huit mécaniques à carder, trente-six mécaniques à filer de cinquante-huit fuseaux chacune, sans compter les mécaniques pour filer en gros, le tout mis en mouvement par une seule roue hydraulique $^{12} »$. Les Fontenay s'associèrent à Jean-Baptiste Decrétot ${ }^{13}$ et aux frères Petou. Pour développer leur production, les associés firent appel à John Theakston, dit Wood, et John Flint, dit Hill, deux « artistes mécaniciens » anglais, anciens ouvriers des ateliers de Cromford. Alexandre de Fontenay fit plusieurs voyages en Angleterre pour y étudier les techniques de fabrication. Les bâtiments ${ }^{14}$ de l'usine de la Mécanique furent construits en

${ }^{8}$ V. Quesney, Éloge de Monsieur P.-N. Defontenay, de Rouen.

${ }_{9}$ Ibid., p. 5. Voir également J.-M. Chaplain, La chambre des tisseurs, p. 41, 73, 78 ; B. Bodinier, « L'industrie en Révolution ».

10 J.-M. Chaplain, La chambre des tisseurs, p. 137, citation tirée de la demande de privilège faite en 1784 (Arch. nat., $\mathrm{F} / / 12 / 1339)$.

11 Ibid., p. 80 (Arch. nat., F//12/1339).

12 Id. (Arch. nat., F//12/1365).

13 Jean-Baptiste Decrétot (1743-1817), industriel en textiles à Louviers, qui avait implanté sa grande fabrique en forme de H rue de l'Hôtel de Ville (actuelle rue Mendès-France) ; élu le 23 mars 1789 député du tiers état pour le bailliage de Rouen (Pont-de-l'Arche).

${ }^{14}$ Ils avaient la forme d'un grand T et enjambaient un bras de l'Eure. Leur rez-de-chaussée était construit avec des pierres et des briques, et les étages en pans de bois. Ils disparurent à cause d'un incendie à la fin du XIXe siècle et il n'en reste qu'une chute d'eau désaffectée. En 1799, une seconde chute d'eau, située à Villette, a été convertie en filature de coton par les «intéressés de la Mécanique ». Elle fut incendiée accidentellement en 1824. En 1829, Poussin, fabricant à Elbeuf, acquit la société Defontenay et fit construire une manufacture de draps à la place de l'ancienne filature. J.-M. Chaplain, La chambre des tisseurs, p. 140-141, 193 (plan), 194. 
1785-1786, probablement sur des plans de l'architecte François Guéroult15, et des machines furent installées dans leurs quatre étages ${ }^{16}$. Le travail de nuit y fut organisé avant 1790. En 1804, deux équipes de 475 personnes chacune se relayaient jour et nuit pour assurer « une production ininterrompue de filés ${ }^{17}$ ».

En 1787, à la mort de l'oncle Jean Holker ${ }^{18}$, les Fontenay achetèrent aussi les actions vendues par les anciens détenteurs de « la manufacture des velours de coton établie dans l'emplacement de Saint-Paul ${ }^{19}{ }^{\prime}$ située à Rouen et alors au bord de la ruine. Les frères Fontenay prirent des participations dans d'autres affaires. Ils apportèrent leur concours à Descroizilles l'aîné, un chimiste reconnu qui avait adapté à l'industrie le procédé de blanchiment des textiles utilisant l'acide muriatique (procédé découvert par Berthollet ${ }^{20}$ ), ce qui permettait de poursuivre le travail même pendant l'hiver. Fontenay contribua aussi à des armements de navires. De plus, de nombreuses mentions font référence à des remboursements d'avances pouvant aller jusqu'à 16000 livres, avances qu'il semblait avoir consenties à nombre de ses amis et relations.

À l'époque de la correspondance, les Fontenay demeuraient dans une maison de la rue des Charrettes ${ }^{21}$, rive droite, à proximité des quais de Seine et du domicile des Ribard, parents de Mme de Fontenay. Riches citadins, les Fontenay n'avaient pas cherché à se faire passer pour nobles en achetant un domaine rural ou des charges anoblissantes. Ils ne possédaient alors pas de résidence à la campagne et faisaient des séjours chez l'oncle

\footnotetext{
${ }^{15}$ François Guéroult (1745-1804), architecte rouennais.

${ }^{16}$ J.-M. Chaplain, La chambre des tisseurs, p. 140.

17 Ibid., p. 82.

18 Marie Marguerite Thérèse Ribard (1728-1791) avait épousé en secondes noces en 1776 Jean Holker (17191786) ; originaire de Strarford (Lancashire), ce catholique était venu s'établir en France en 1745 et on lui attribue l'introduction en France en 1771 de la jenny, rouet amélioré qui permettait à la fileuse d'augmenter son rendement de 8 à 80 fois. En 1778, les frères Fontenay avaient aussi repris une partie des 82000 livres du papiermonnaie du Congrès continental de leur oncle Holker (Arch. nat., MC/XCVIII/628, 22 décembre 1778 ; M. Zylberberg, Capitalisme et catholicisme dans la France moderne, p. 190, n. 81).

${ }^{19}$ Guilbert, Éloge nécrologique de M. de Fontenay, p. 5.

${ }^{20}$ Claude Louis Berthollet (1748-1822), médecin du duc d'Orléans, chimiste, reçu à 1'Académie des sciences en 1781.

${ }^{21}$ La rue des Charrettes fut complètement détruite lors des bombardements de la Seconde Guerre mondiale.
} 
Joseph Grandin ${ }^{22}$ dans sa propriété de La Villette, à Elbeuf. Fontenay évoquait fréquemment «le jardin $\mathrm{d}^{\prime}$ Alexandre ${ }^{23}$ », qui se trouvait au hameau d'Eauplet, à Sotteville-lès-Rouen, sur la rive gauche. Il s'agissait vraisemblablement d'un verger de bord de Seine et de quelques bâtiments de ferme.

À côté de ses activités professionnelles, Fontenay ne négligea pas son engagement politique dans la cité. Successivement trésorier et administrateur de l'hôtel-Dieu de Rouen (1769), quartenier (1779), puis échevin (1782), il fut élu juge-consul de cette ville à trois reprises, étant entré à la chambre de commerce en 1774 ; il en fut le syndic dix ans plus tard. Au cours de ces mêmes années, il fut initié à la maçonnerie dans la loge de la Céleste Amitié de Rouen²4.

Membre de la commission intermédiaire de l'assemblée provinciale en 1788, il y fut « chargé des dossiers intéressant l'industrie régionale et les travaux publics ${ }^{25}$ ». Il fut élu député du tiers état de Rouen aux États généraux le 21 avril 1789. À l'Assemblée constituante, il fit partie des députés assidus, mais effacés. Il y fut membre du Comité pour l'agriculture et le commerce en septembre 178926. Il fut chargé de présenter le « rapport sur le commerce au-delà du cap de Bonne-Espérance », qui permit par le vote de l'Assemblée du 19 juillet 1790 de concentrer les retours des Indes Orientales à quelques ports comme Lorient et Le Havre, afin de ne pas provoquer de distorsion de prix sur les marchandises importées et d'éviter la fraude. Fontenay indique également qu'il est intervenu pour faire passer un amendement sur les frais des lettres de change venant de l'étranger, qui fut soutenu par Le Couteulx de Canteleu ${ }^{27}$, et dont Le Moniteur fit mention ${ }^{28}$.

\footnotetext{
22 François Louis Joseph Grandin (1728-1805), écuyer, prévôt de la connétablie de France à Elbeuf.

${ }^{23}$ Lettre 8, 8 mai 1789 ; lettre 310, 21 mars 1790 ; lettre 351, 21 octobre 1790 ; lettre 377, 18 novembre 1790 ; lettre 413, 26 décembre 1790 ; lettre 520, 12 avril 1791 ; lettre 521, 13 avril 1791.

${ }^{24}$ Voir à ce sujet les travaux d'É. Saunier, notamment Révolution et sociabilité en Normandie au tournant des XVIII et XIX siècles.

${ }^{25}$ F. Burkhard, « Six destins ».

${ }^{26}$ Lettre 111, 5 septembre 1789.

27 Jean Barthélemy Le Couteulx de Canteleu (1746-1818), l'un des dirigeants de la banque Le Couteulx dès 1788 ; député du tiers état pour la ville de Rouen, membre du Comité des finances de l'Assemblée constituante, dont il fut l'un des principaux orateurs dans les domaines économiques et financiers.

${ }^{28}$ Lettre 458, 9 février 1791.
} 
En décembre 1789, Pierre Nicolas de Fontenay avait rejoint la Société des amis de la Constitution, ou club des Jacobins, rue Saint-Honoré, "où il y a une société assez nombreuse de députés ${ }^{29} »$, qu'il délaissa vers le mois de juin 1790 pour se rapprocher du club de 89, les plus modérés.

De retour à Rouen dès la dissolution de la Constituante le 30 septembre 1791, Fontenay fut élu à plusieurs reprises maire de Rouen (décembre 1789-novembre 1792, octobrenovembre 1793), avant d'être emprisonné sous la Terreur. De nouveau maire après le 9 Thermidor, il reçut Bonaparte lors de sa visite en Normandie, en octobre 1802 ; il fut nommé membre du Conseil général du commerce et des manufactures (1803), puis du Sénat impérial (18 février 1804). Le décret du 1er vendémiaire an XII (24 septembre 1803) ayant intégré les « écharpes d'honneur » à la Légion d'honneur, il en fut nommé chevalier le 8 octobre suivant, puis élevé directement au grade de commandeur le 19 juin 1804.

Il mourut à Paris le 10 février 1806 et fut inhumé dans le caveau de sa famille, situé à Saint-Vincent.

Avec son beau-père, Fontenay figurait en bonne place sur le tableau de Lemonnier ${ }^{30}$, Hommages rendus au roi Louis XVI par la chambre de commerce de Normandie, souvenir de la visite du souverain à Rouen le 28 juin 1786. Ce tableau disparut lors du bombardement de Rouen, en 1944. Le musée des Beaux-arts de Rouen conserve le tableau de Boilly³1. Une Scène de la vie publique de Pierre Nicolas de Fontenay, maire de Rouen en 1792 représentant Fontenay ceint de son écharpe de maire, domptant l'émeute du 25 août $1792^{32}$; une sépia d'Isabey ${ }^{33}$ montrant Bonaparte visitant l'usine de la Mécanique sous la conduite de

\footnotetext{
${ }^{29}$ Lettre 223, 23 décembre 1789.

30 Anicet Charles Gabriel Lemonnier (1743-1824), peintre d'histoire et de genre, qui exposa au Salon de 1785 à 1814 ; prix de Rome (1772); agréé à l'Académie de peinture (1789); administrateur de la manufacture des Gobelins (1810-1816); il participa activement à la création du musée des Beaux-arts de Rouen. Son tableau le plus connu est Une Soirée chez madame Geoffrin (1812). En 1791, Fontenay suivit avec une grande curiosité l'exécution d'un grand tableau allégorique représentant le génie du commerce et la découverte de l'Amérique, également destiné à la chambre de commerce de Rouen.

${ }^{31}$ Louis Léopold Boilly (1761-1845), portraitiste.

${ }^{32}$ Guilbert, Éloge nécrologique de M. de Fontenay, p. 10.

33 Jean-Baptiste Isabey (1767-1855), portraitiste et miniaturiste.
} 
Fontenay font également partie des collections du musée. Enfin, se trouvent à l'hôtel de ville de Rouen son buste en marbre blanc ainsi que ses propres clés de la ville ${ }^{34}$.

\section{Description générale de la correspondance}

Les lettres ont été écrites le plus souvent à la hâte, à la fin de la séance du soir, ou le matin avant d'y retourner, comme une sorte de journal des événements politiques extraordinaires auxquels leur auteur prenait part. Mme de Fontenay, qui avait bien conscience d'avoir épousé un "grand homme», avait numéroté toutes les lettres et les rangea dans des chemises cartonnées, toujours existantes. C'était une correspondance privée, et destinée à le rester.

Malgré la précision des propos et faits rapportés, rien ne permet de dire si Fontenay prenait ou non des notes au cours des séances. Les conditions matérielles n'y étaient pas favorables. Il semble plutôt qu'il écoutait avec attention ce qui se disait, et qu'il en restituait très fidèlement le contenu, après l'avoir confronté avec ce qui était imprimé dans les journaux. Ses écrits sont alertes et donnent une impression d'archives orales. Le ton y est très libre, peu « politique » malgré une partialité tangible, car l'auteur ne cache pas ses opinions et ses sentiments. Tout au plus peut-on observer un peu de prudence dans les premières lettres.

Les nouvelles familiales y sont mélangées avec les informations publiques, qui constituent l'essentiel du propos. Les lettres sont plus ou moins longues, selon la matière et le temps dont disposait leur auteur pour les écrire. Celles de la fin de la période ne sont pas significativement plus courtes que les premières. Quand Fontenay a été témoin direct de ce qu'il décrit, le récit est circonstancié, le style rapide, presque haletant ; quand il s'agit de rapporter des anecdotes ou des faits divers, le propos est mesuré et l'auteur conseille souvent à sa femme de compléter l'information qu'il lui donne par la lecture des journaux. Jusqu'à la fin de la correspondance, il s'applique à donner son point de vue personnel sur les événements, réformes et discussions parlementaires souvent contradictoires. Ces dernières, rapportées dans le détail, offrent un contraste curieux entre une réflexion mûrie et argumentée et une improvisation parfois déroutante.

\footnotetext{
${ }^{34}$ Le tableau de Boilly, le dessin d'Isabey et clés avaient été légués par Jacques de Fontenay, le dernier fils de Pierre Nicolas, au moment de sa mort en 1874.
} 
Le ton affectueux des lettres est celui d'un bourgeois bien ancré dans sa cité, bon époux et père de famille responsable. Très attentif à conserver des relations directes avec ses enfants, il suit avec vigilance les progrès de leurs études et s'implique dans leur éducation. Fortement centrés sur leur famille, les Fontenay étaient aussi engagés dans des œuvres sociales, notamment des quêtes pour les pauvres auprès de leurs amis et relations $s^{35}$.

Les lettres révèlent qu'au-delà de l'action sociale, les Fontenay s'intéressaient sincèrement à la chose publique, ce qui passait en particulier par la lecture de la presse. En plus de l'inévitable Journal de Normandie $e^{36}$, Fontenay essaya toutes sortes de publications, que les circonstances multiplièrent. L'éventail était large, entre Le Point du jour ou Résultat de ce qui s'est passé la veille à l'Assemblée nationale, créé par Barère ${ }^{37}$ en juin $1789^{38}$; le Journal de Paris $^{39}$; L'Observateur à l'Assemblée nationale ${ }^{40}$; le Courrier de Provence, qui est « le journal de Mirabaud ${ }^{41} »$, et qui avait l'avantage de donner des comptes rendus très exacts, mais aussi Le Mercure de France ${ }^{42}$, Le Moniteur universel ${ }^{43}$ et même L'Ami des patriotes ${ }^{44}$.

Cette correspondance montre encore une vie sociale soutenue. Fontenay y évoquait surtout les notables de Rouen, d'Elbeuf et de Louviers. En plus de la famille proche, comme les Ribard et les Hurard, la parentèle formait un premier cercle : les oncles, tantes et cousins Grandin, Godet, Holker, Delisle, Le Vieux. Quand il ne se confondait pas avec la famille, le monde du négoce normand en constituait un second : Decrétot, Le Breton,

\footnotetext{
${ }^{35}$ Lettre 413, 26 décembre 1790.

${ }^{36}$ Lettre 458, 9 février 1791.

${ }^{37}$ Bertrand Barère (1755-1841), avocat au parlement de Toulouse, député du tiers état de la sénéchaussée de Bigorre.

${ }^{38}$ Lettre 79, 20 juillet 1789.

${ }^{39}$ Lettre 89,30 juillet 1789.

${ }^{40}$ Créé par Jean Félix Gabriel Feydel (1744-1827), ce journal parut entre le 8 août 1789 et le 12 octobre 1790.

${ }^{41}$ Lettre 114, 8 septembre 1789. Honoré Gabriel Riquetti, comte de Mirabeau (1749-1791); repoussé par la noblesse de Provence, il fut élu du tiers état de la sénéchaussée d'Aix-en-Provence.

${ }^{42}$ Lettre 181, 12 novembre 1789.

${ }^{43}$ Lettre 346, 20 octobre 1790.

${ }^{44}$ Journal fondé par Michel Louis Étienne Regnaud de Saint-Jean-d’Angély (1760-1819), avocat, député du tiers état de la sénéchaussée de Saint-Jean-d'Angély; également fondateur du Journal de Versailles en 1789 et collaborateur au Journal de Paris. Lettre 413, 26 décembre 1790.
} 
Hellot, Begouën Demeaux, Limozin, Duruflé, Midy. La bonne société rouennaise formait un autre vivier, avec les Barrois d'Orgeval, Legrand de Boislandry, Thouret, Laumonier et autres Quillebeuf. Tous ces parents, amis et connaissances sont donc évoqués au fil des lettres, et notamment deux familles qui se détachent nettement, les Le Couteulx et les Le Carpentier de Chailloué. Les lettres de Mme de Fontenay n'ont pas été conservées ; même si, d'après son époux, elles l'auraient mérité.

\section{Les sujets de la correspondance}

Outre les affaires familiales, les lettres sont largement consacrées aux nouvelles politiques.

Les événements de la Révolution forment un premier sujet. La première lettre mentionne l'émeute tragique survenue à la fabrique Réveillon. Suivirent l'ouverture solennelle des États généraux, l'affrontement entre le tiers état et les deux autres ordres pour parvenir au vote par tête et non par ordre, la constitution du tiers état en Assemblée nationale et le serment du Jeu de paume, le tout sur fond de menace de soulèvement populaire.

Fontenay ne fut pas un témoin direct de la prise de la Bastille, car il se trouvait à Versailles avec la majorité des députés. En revanche, il s'attarde non sans une certaine complaisance sur le massacre commis par la populace le 12 juillet de l'éphémère contrôleur des Finances Foullon et de son gendre Bertier de Sauvigny, l'intendant de Paris. Fontenay fait un récit enlevé de la nuit du 4 août, mais donne l'impression de s'être laissé surprendre par les événements d'octobre, dont il attribue l'unique responsabilité au fameux repas des gardes. Sont également mentionnés les troubles en province, les catastrophes naturelles, l'affaire de l'hôtel de Castries. La mort et les funérailles de Mirabeau, le transfert de la dépouille de Voltaire au Panthéon, la fuite de Varennes et l'arrestation de Duveyrier au Luxembourg sont les derniers événements évoqués.

Le second groupe de nouvelles se rapporte à la Normandie, notamment les événements survenus pendant l'été 1789, avec la mise à sac de Rouen en juillet par des bandits, les Carabots, et la destruction des machines textiles, métiers à tisser et cardeuses mécaniques, accusées de provoquer du chômage ${ }^{45}$. La mise en application des réformes

\footnotetext{
45 Les destructions de machines à filer du mois de juillet 1789 causèrent une vive inquiétude aux Fontenay : « Je le suis surtout des inquiétudes que tu éprouves ainsi que mon frère. Je crains que cela ne prenne sur sa santé. Je
} 
religieuses et l'élection du premier évêque constitutionnel de Rouen, Louis Charrier de La Roche, à laquelle Fontenay prit une part significative, sont aussi rapportées avec force détails.

Les complots et rumeurs forment encore un sujet récurrent de la correspondance. Les conspirations étaient forcément le fait des « aristocrates », qui s'opposaient à la marche de la Révolution; voire de l'étranger, comme par exemple des Anglais, qui auraient eu le projet d'envahir la France à la fin de 1789, ou les armées royalistes du prince de Condé. De même, le vote de la Constitution civile du clergé provoqua une réaction du clergé conservateur. En juillet 1791, un attentat contre l'autel de la Patrie fut déjoué au Champde-Mars à Paris, mais il y eut quelques morts et des blessés, et la loi martiale fut proclamée.

Fontenay évoque les premiers départs en émigration au lendemain de la prise de la Bastille, et surtout celui de Mesdames, tantes du roi, début 1791, donnèrent lieu au vote d'une première législation sur «les absens », qui fut complétée en octobre 1791 et juillet 1792.

Il décrit l'Assemblée nationale, aussi bien son fonctionnement que ses conditions matérielles. De sa plume acérée, Fontenay livre des descriptions vivantes des principaux membres de l'Assemblée, ceux qu'il admire, comme l'Òabbé de Montesquieu, Mirabeau ou Thoureux; ceux qui l'indisposent, tel Necker; ou encore ceux qu'il déteste, comme l'abbé Maury.

L'œuvre de l'Assemblée constituante constitue un volet important de la correspondance. Les réformes politiques y sont largement évoquées, que ce soit la Déclaration des droits de l'Homme et du citoyen, la délicate et inconfortable question de l'esclavage, l'élaboration de la constitution et enfin la réforme administrative du royaume, avec le découpage du territoire en départements.

Un deuxième groupe de réformes évoquées dans les lettres concerne la justice, avec la suppression des parlements et la mise en place d'un nouveau système judiciaire, ainsi que la réforme pénale qui introduisit le jury d'accusation.

sais avec quelle vivacité il prend les choses, quel zèle il avoit mis pour l'établissement des machines à filer et qu'il doit voir avec regret retarder le bien qu'il vouloit faire » (lettre 80, 21 juillet 1789). 
Principale cause de la réunion des États généraux, le rétablissement des finances publiques constitue aussi une partie importante des sujets traités. La recherche des mesures de secours pour combler le déficit public occupa en premier lieu les députés. On essaya d'abord de lancer en août 1789 deux emprunts, qui ne rencontrèrent pas le succès escompté. La contribution patriotique, volontaire et unique, égale au quart des revenus, fut ensuite votée le $1^{\text {er }}$ octobre. On décida aussi de nationaliser les biens du clergé et des corps laïques et on vota au printemps 1790 l'émission de billets de caisse, ou assignats, que l'État garantit sur ces biens nationaux, en leur attribuant un taux d'intérêt de $3 \%$.

Le système fiscal fut reconstruit, avec pour principe l'égalité devant l'impôt et la suppression de certains anciens impôts tels que les droits féodaux, la dîme et la gabelle. Pour les remplacer, une taxe d'habitation fut mise en place. Les droits d'octroi et de péage furent supprimés, mais on institua un nouveau tarif douanier ainsi que des patentes sur les anciens métiers, les médecins et les chirurgiens.

Les réformes religieuses forment une part importante de l'œuvre de la Constituante. Elles touchèrent non seulement les biens du clergé, mais aussi l'engagement personnel de ses membres, avec pour fondement le principe de la liberté individuelle. Les vœux solennels monastiques furent supprimés dès février 1790, et une Constitution civile du clergé fut adoptée en juillet suivant, remettant à l'État le soin de l'organisation administrative du clergé. En novembre, un décret imposa aux ecclésiastiques un serment à cette Constitution civile du clergé, obligatoire pour l'exercice d'un ministère sacerdotal, qui fut sanctionné par Louis XVI en décembre suivant. Les premières prestations de serment, telle celle de Talleyrand, et les nominations des nouveaux évêques sont largement évoquées, de même que les troubles causés par les opposants et la condamnation par le pape de la Constitution civile.

D'autres réformes sont citées, comme celles touchant à l'armée et à la gendarmerie, les réformes civiles ou l'affaire d'Avignon.

Pleinement conscient de participer à des événements historiques exceptionnels, Pierre Nicolas de Fontenay s'enthousiasmait à l'idée de construire un monde nouveau. Une « union des ordres» qui durerait permettrait à la France de reprendre en Europe «la place qui lui appartient » : 
«C'est un fait unique dans l'histoire qu'une aussi grande Révolution se soit opérée par des petits écrits et des conversations. Jamais l'opinion n'a mieux mérité le titre de reine du monde ${ }^{46} . »$

Il croyait à la légitimité des idées nouvelles, étant convaincu qu'elles s'imposeraient et mettraient un terme à l'ancien ordre social. Pour lui, l'éducation du peuple était la condition du succès de la Révolution. Toutefois, s'il pensait qu'elle était bien au-dessus des intérêts personnels, il estimait que «le propre de notre Révolution sera, j'espère, de n'avoir fait l'avantage de personne et le bien de tous ${ }^{47}$ ». Il resta royaliste, même après la fuite de Varennes, et déplora le « républicanisme » de certains.

Avec le retour de son épouse à Paris et jusqu'à la fin de la Constituante, on ne dispose plus des commentaires de Pierre Nicolas de Fontenay sur les travaux de l'Assemblée. On aurait pourtant aimé connaître son opinion sur les ultimes réformes de la Constituante, notamment l'abolition des décorations et signes extérieurs de distinction et de naissance (30 juillet), la fin de la discussion de la Constitution, le vote de la loi organique sur la presse (23 août) ou la promulgation du Code pénal (25 septembre). On aurait aussi voulu vivre par lui les élections à l'Assemblée législative et la dernière journée du 30 septembre 1791.

\section{Bibliographie}

BODINIER Bernard, "L'industrie en Révolution », dans La Normandie orientale en transition, Révolution-Empire, Cahiers Léopold Delisle, t. XLVII, 1988, fasc. 1-2, p. 5-11.

BURKHARD F., «Six destins », dans Comité régional d'histoire de la Révolution française, Haute-Normandie (dir.), À travers la Haute-Normandie en Révolution, 1789-1800, Études et recherches, Luneray, 1992, p. 404.

CHAPLAIN Jean-Michel, La chambre des tisseurs. Louviers : cité drapière, 1680-1840, Seyssel, Champ Vallon, 1984, 302 p.

\footnotetext{
${ }^{46}$ Lettre 57, 27 juin 1789.

${ }^{47} \mathrm{Ibid}$.
} 
COMITÉ RÉGIONAL D'HISTOIRE DE LA RÉVOLUTION FRANÇAISE (Haute-Normandie), À travers la Haute-Normandie en Révolution, 1789-1800, Études et recherches, Luneray, 1992, $448 \mathrm{p}$.

GUILBERT, Éloge nécrologique de M. de Fontenay, ancien maire de Rouen, et membre du SénatConservateur, lu les 1er et 15 mars de l'an 1806, dans les séances de la Société libre d'émulation de Rouen, par Ph. J. Ét. Vt. Guilbert, Rouen, 1806, 19 p.

QUESNEY Victor, Éloge de Monsieur P.-N. Defontenay, de Rouen, par Victor Quesney, chef de division dans les bureaux de la préfecture de la Seine-Inférieure, membre de la Société d'Encouragement pour l'Industrie nationale, et de la Société libre d'Émulation, de Rouen, Rouen, impr. F. Baudry, 1806, 23 p.

SAUNIER Éric, Révolution et sociabilité en Normandie au tournant des XVIII et XIXe siècles, 6000 francs-maçons de 1740 à 1830, Rouen, Presses universitaires de Rouen, 1998, $556 \mathrm{p}$.

SEBBAN Denis, "Pierre-Nicolas Defontenay ou la bourgeoisie au pouvoir », mémoire de maîtrise dirigé par Claude Mazauric et Gérard Lemarchand, université de Rouen, 1987.

SouBLIN Léopold, Le premier vote des Normands, 1789, Fécamp, 1981, 328 p.

ZYLberberg Michel, Capitalisme et catholicisme dans la France moderne. La dynastie Le Couteulx, Paris, 2001, 390 p.

\footnotetext{
Résumé

Entre le $1^{\text {er }}$ mai 1789 et le 23 juillet 1791, Nicolas de Fontenay (1743-1806), riche industriel et député du tiers état de Rouen aux États généraux, a écrit quotidiennement à son épouse Élisabeth Ribard ; cette correspondance a été interrompue à trois reprises, lors des séjours de Mme de Fontenay auprès de son mari. Ces lettres ont été écrites comme une sorte de journal des événements politiques exceptionnels auxquels Fontenay prenait part ; il tenait à y associer sa famille, en particulier son beau-père et son beau-frère. Il s'agit d'une correspondance privée et destinée à le rester. Le ton y est donc très libre et l'auteur ne cache pas ses opinions et ses sentiments. Les nouvelles familiales y sont entremêlées aux nouvelles publiques qui constituent l'essentiel du propos. Les lettres sont plus ou moins longues, selon la matière et le temps dont dispose leur auteur pour les écrire, les dernières n'étant pas
} 
significativement plus courtes que les premières. Rien qu'en raison de leur nombre, les 626 lettres Fontenay forment un ensemble tout à fait remarquable, qui mérite d'être connu. 



\section{Les relations épistolaires au sein des lignages nobiliaires : comment user de la plume pour consolider son pouvoir en Morée au Moyen Âge}

Il est difficile d'évoquer les relations épistolaires des nobles de la principauté de Morée sans décrire au préalable un contexte qui s'inscrit dans la dynamique des croisades, plus particulièrement de la IVe croisade. La principale préoccupation d'Innocent III lorsqu'il accède au pontificat en 1198 est de reprendre les terres des États latins d'Orient tombés aux mains des musulmans après la défaite de Hattin, en 1187. Si les souverains, à commencer par Philippe Auguste, se désintéressent de cette croisade, beaucoup de nobles bourguignons et champenois se croisent, à commencer par Geoffroy de Villehardouin, maréchal de Champagne, chargé d'organiser la croisade avec les Vénitiens.

Lorsque les premiers croisés arrivent à Venise au printemps 1202, les bateaux sont prêts, mais de nombreux chevaliers manquent à l'appel, car ils ont choisi d'autres ports d'embarquement. Le doge propose alors de suspendre la dette si les croisés acceptent de l'aider à reprendre Zara, ancien comptoir de Dalmatie. Après la prise de la ville, les croisés reçoivent les doléances du prince byzantin Alexis qui, en compensation d'une aide lui permettant de retrouver son trône, promet une forte somme d'argent, l'union des Églises et l'entretien d'une armée au service de la croisade. 
C'est ainsi que les croisés se retrouvent sous les murs de Constantinople au printemps 12041. Ils vont non seulement fonder l'empire latin de Constantinople, mais en outre réaliser la conquête de ce qui devient au fil du temps la principauté de Morée ${ }^{2}$ ou d'Achaïe, nom de la province ecclésiastique romaine correspondante. Si la plus grande partie de la péninsule est conquise dans les premières années du XIII siècle, il faut toutefois attendre 1248 pour que le prince s'empare de la dernière poche de résistance grecque, Monemvasie ${ }^{3}$.

La principauté de Morée comprend dès lors une aire géographique plus vaste que la seule péninsule du Péloponnèse, par le seul fait des hommages dévolus au prince. Une large Grèce latine s'étend à l'est avec le duché d'Athènes, au nord avec la seigneurie de Bodonitsa et le marquisat de Salona, à l'ouest avec les îles Ioniennes, et au sud avec le duché de l'Archipel (fig. 1).

Ce cadre spatial optimum est celui du milieu du XIII siècle. Cependant, à partir des années 1260, les frontières de la principauté de Morée reculent au profit du despotat grec de Morée, qui a pour capitale Mistra. Isolé alors en Méditerranée, le prince se tourne vers Charles d'Anjou, roi de Sicile depuis 1266. Les souverains de Naples vont aider la Morée ; mais occupés à mater les révoltes italiennes, ils se désintéressent le plus souvent de cette péninsule balkanique dont la prospérité s'infléchit. L'année 1311 marque une nouvelle difficulté pour la principauté, qui ne peut empêcher les Catalans de conquérir le duché $\mathrm{d}^{\prime}$ Athènes ${ }^{4}$.

Ces événements politiques sont importants, car le renouvellement des effectifs nobiliaires, initialement constitués de Champenois et de Bourguignons, évolue: beaucoup d'Italiens affluent au fil du XIII siècle, puis des Catalans à partir du XIVe siècle. Le territoire de la Morée ne fait alors que rétrécir, la reconquête byzantine s'achevant en

\footnotetext{
${ }^{1}$ Dans l'acte de partage fait par les Latins avant l'assaut, le Péloponnèse est attribué à Venise, qui ne s'intéresse qu'aux côtes et n'occupe réellement que Modon et Coron. Les Vénitiens entendent assurer une domination commerciale sur ces nouvelles terres conquises (M. Angold, The Fourth Crusade, p. 151-161).

${ }^{2}$ Le terme de « Morée » désigne initialement l'Élide, où la culture du mûrier (mouriá) est développée. Le dérivé a créé un toponyme (P. Chantraine, Dictionnaire étymologique de la langue grecque, p. 713).

${ }^{3}$ J. Longnon, Le Livre de la conqueste de la princée de l'Amorée, p. 203-206.

${ }^{4}$ R. Muntaner, Les Almogavres, p. 146 et suiv.
} 
1429 à la mort du dernier prince latin de Morée, sous la pression conjointe des Grecs et des Turcs 5 .

Si notre introduction contextuelle peut paraître longue, c'est volontaire, car dans un État très tôt isolé, seul bastion catholique en Romanie, la solidarité entre les lignages nobles est un élément de résistance. Elle peut être évaluée, même superficiellement, à travers la correspondance entretenue par de nombreux parents. Tandis que les sources sont inexistantes dans ce domaine pour le XIII siècle, les exemples se multiplient au siècle suivant et au début du XVe siècle, notamment au sein des lignages italiens. Pour autant, il ne s'agit ici que de traiter que du milieu nobiliaire, car le fait d'écrire ou de dicter une lettre révèle l'appartenance à une minorité cultivée qui s'exprime en latin parfois, mais le plus souvent, au bas Moyen Âge, en langue vernaculaire : c'est-à-dire, pour ces familles d'origine italienne, dans un italien teinté de latin.

Nous pouvons retrouver le témoignage de ces lettres dans plusieurs ouvrages, dont les plus importants sont édités par Julian Chrysostomidès pour les documents concernant le Péloponnèse $^{6}$, Antoni Rubió I Lluch pour les documents catalans ${ }^{7}$ et Jean-Alexandre Buchon pour les documents épistolaires des dynasties italiennes 8 .

La lettre fonctionne dans le temps et dans l'espace comme une présence absente, un outil de pouvoir à distance, un lien dématérialisé. À travers quelques exemples épistolaires, nous pouvons envisager les centres d'intérêt de ces lignages nobiliaires dans la principauté de Morée et comprendre comment ces relations épistolaires sont exploitées afin de consolider la position sociale de ces nobles au faîte de la société.

\section{Consolider les liens lignagers}

Les lettres sont des sources difficiles, car elles ne constituent qu'une partie des formes anciennes de communication, lesquelles reposaient largement sur l'oral. Or quand les membres de la famille sont loin, comme dans le cas des lignages italiens - mais c'est aussi la caractéristique de tous les lignages nobles de Morée, dont les origines sont occidentales

\footnotetext{
${ }^{5}$ A. Bon, La Morée franque, p. 287 et suiv.

${ }^{6} \mathrm{~J}$. Chrysostomidès (éd.), Monumenta Peloponnesiaca.

${ }^{7}$ A. Rubió I Lluch, Diplomatari de l'Orient català (1301-1409).

8 J.-A. C. Buchon, Nouvelles recherches historiques.
} 
- les relations épistolaires tentent de combler cette absence. En effet, si la distance au fil des générations aboutit à une segmentation des lignages, l'un restant en Italie, l'autre en Morée, les premiers lignagers continuent à entretenir d'étroits liens, notamment affectifs, avant que les générations suivantes s'érigent en dynastie propre9.

Ainsi, tout en s'attachant au système lignager, les Acciaiuoli par exemple n'hésitent pas à accentuer certains traits, portant notamment sur la cohésion du groupe. Les archives familiales livrent de la sorte une partie de la correspondance de Nicolò Acciaiuoli, grand sénéchal de Sicile, seigneur de Corinthe ${ }^{10}$, qui non seulement évoque dans ses missives ses intérêts politiques et militaires en décrivant ses relations avec toute une série de grands personnages contemporains, mais aborde également des thèmes plus personnels liés à sa famille. Il fut grandement récompensé de son soutien politique auprès des Angevins par l'obtention de terres en Morée; mais son implication, ou plus exactement sa curiosité pour les affaires politiques toscanes, se manifeste toujours dans ses lettres, malgré son éloignement.

On peut noter l'attention qu'il porte à ses parents ou amis, auxquels il adresse ses salutations à distance. Dans une lettre du 18 novembre 1353 adressée à Jacopo di Donato Acciaiuoli, Nicolò, après avoir évoqué les affaires politiques de la cité, revient à des considérations plus personnelles :

«Je suppose que de Naples notre maître Zenobio t'écrit souvent sur tout. Je salue messire Andrea et je lui conseille en ce printemps de se faire conduire à Naples $[. . .]^{11}$. »

Il s'agit de prendre des nouvelles de chacun, de s'enquérir de ses affaires ou de sa famille. Un exemple révèle à quel point la solidarité au sein du lignage est forte ; il s'agit d'une lettre rédigée par Nicolò Acciaiuoli le 6 octobre 1355 :

« Je reconnais volontiers que la mort de Bartolomea t'a causé une grande douleur en soi et je ne doute pas que tu auras souhaité être rapidement des nôtres ; je ne doute pas non plus que tu seras plus consolé d'avoir eu une épouse si louable autant qu'une mère de tes si nombreux enfants - épouse qui a su vivre et mourir avec vertu et esprit catholique -

\footnotetext{
${ }^{9}$ I. Ortega, Les lignages nobiliaires dans la Morée latine (XIII'-XVe siècle), p. 125.

${ }^{10}$ J.-A. C. Buchon, Nouvelles recherches historiques, p. 49 et suiv.

${ }^{11}$ É.-G. Léonard, Histoire de Jeanne Iere, t. III, p. 507 : « Supono que da Napoli lo nostro mastro Zenobio ti scrive sovente e ogni cosa. Saluto messer Andrea e consilliolo que in questa primavera si faccia conduciere a Napoli [...]. »
} 
qu'affligé par la douleur que son heure soit venue trop tôt par rapport à tes souhaits alors que tu restes, toi, en vie. Cette douleur, nul homme sur Terre ne la pourrait négliger. [...] Tu sais que nous appartenons au groupe des chrétiens, dont la foi établit l'immortalité de l'âme et la grande miséricorde divine, surtout à ceux qui savent bien mourir. C'est pour cela que nous devons accepter sans aucun doute que Bartolomea est bien mieux aujourd'hui qu'elle ne l'a jamais été. Je suis sûr que jamais aucun roi n'a vécu dans un plus grand bonheur. Et s'il y a encore en toi une douleur liée à ton propre devenir à cause de sa mort, qu'elle soit expulsée afin que tu ne te retrouves pas parmi ceux qui pensent avec mépris qu'il n'existe pas d'autre vie ailleurs, afin que ta conscience ne $t^{\prime}$ accuse pas de ne pas avoir de vraie charité envers cette femme que tu as dû tant aimer pour toutes ces raisons, en souffrant plus de sa passion que de son bonheur. Il faut lui témoigner amour et gratitude par des cérémonies [religieuses] et non pas par des démonstrations d'affliction. Je voudrais aussi te dire que, n'étaient les considérations religieuses susmentionnées, je serais plus sensible à cette douleur si intense, tant Bartolomea, d'après moi, était digne de louanges. Mais tout est négligeable outre l'amour de Dieu $^{12} . »$

La peine provoquée par la perte d'un être cher est évoquée avec beaucoup de pudeur et de compassion dans ce pli adressé à Jacopo di Donato Acciaiuoli, un parent florentin qui

12 Ibid., p. 549 (traduction de l'auteur) : «Io conosco bene que dela morte Bartolonmea ai riceputo danno grande e intrinseco displacere, né dubito que averai considerato piccolo spatio di tempo dovere essere da noi a ipsa e que plu dei prendere di consolatione avere avuto una cosi laudabile mollie e matre di tanti tuoi filiuoli, laquale si virtuosamente e cattolicamente seppe vivere e morire, que aflictione per que, forse avanti la tua opinione sia, te vivente, venuta la sua hora, laquale per nullo homo mundano si pote preterite. Assai vive in questo mondo qui bene more e tutte le laude si prendono nelo fine. Non saria perfetto amore se homo plangesse plu lo suo proprio danno que non si alletasse dello bene di quella persona que dirittamente ama. Sai que noi semo dela setta deli cristiani, la cui fide aproba la immortalitate dell'anima e la amplia misericordia divina, massime ali bene morenti. Per laquale cosa dovemo indubiamente tenere que senza alcuna comparatione mellio istia la Bartolonmea que non istava; io per me credo a cierto que qualunque re plu beatamente vivente. E inpero se alcuna reliquia fusse in te restata di molestia per alcuna consideratione della sua morte riguardante alo tuo proprio bene, sia in tutto exulata accio que non ti ritrovi in quello grande numero di quelli que poco extimano que sia altra vita que questa, overo que la tua coscentia non te acusasse di non avere vera caritate verso quella fenmina laquale per tutte rasoni tanto dovevi amare, dolendoti plu della propria passione que aletandoti della sua beatitudine, alla quale si vole dimostrare amore e gratitudini con cerimonie e non con lamentose dimotrationi. Ne pertanto ti vollio tacere que se non fussono le sopraditte considerationi, io sarei multo plu partefice ala displicentia que levemente non si extimeria, inpero que ampliamente era la Bartolonmea dotata di laudabili condicioni gratissime allo moi judicio. Ma omnia pretereunt preter amare Deum. » 
vient de perdre son épouse. On y découvre un Nicolò Acciaiuoli proche des siens et partageant leur douleur ; un grand homme politique intéressé par la religion chrétienne, ses doctrines, sa conception du monde et de l'au-delà ; un croyant qui critique ceux qui n'ont pas la foi, et qui place l'amour de Dieu au-dessus de tout. On découvre en quelque sorte l'individu derrière le personnage politique.

D'autres exemples peuvent être évoqués, à l'instar d'une lettre de Sandro Altoviti travaillant pour la société Acciaiuoli, et qui est chargé par Donato Acciaiuoli de lui donner des nouvelles de son frère $\mathrm{Nerio}^{13}$. Celui-ci est au plus mal, il vient de perdre son épouse le mois précédent (juin 1394) et il a quelques problèmes à régler parmi ses successeurs légitimes et illégitimes.

$\mathrm{Au}$ XIVe siècle, la pratique épistolaire, permettant d'exprimer les sentiments et les tourments de chacun ${ }^{14}$, n'est pas l'apanage des Acciaiuoli. On retrouve les mêmes préoccupations chez les Tocco. C'est le cas de Leonardo Tocco, duc de Leucade et comte de Céphalonie, qui écrit à la mère de son épouse, Lapa Acciaiuoli, le 28 mai 1374, pour lui expliquer non seulement ses démarches politiques en Italie, mais également son inquiétude d'avoir laissé ses enfants et son épouse dans l'île ${ }^{15}$ :

«Lors de notre départ de Céphalonie, nous laissâmes la duchesse et nos enfants qui se portaient bien, et chaque jour nous attendons des nouvelles : nous vous prions de nous écrire de vos nouvelles, car nous sommes très désireux d'entendre souvent de bonnes nouvelles pour nous consoler ${ }^{16}$. »

La dépêche matérialise la relation entre l'auteur et le destinataire. Avec la distance, elle révèle en outre l'angoisse de chacun quant à la santé des siens. Un souci d'entraide et de

\footnotetext{
${ }^{13}$ J. Chrysostomidès, Monumenta Peloponnesiaca, p. 288-289.

${ }^{14} C^{\prime}$ est le cas d'une lettre de Nicolò Acciaiuoli qui, revenant de Sicile très endetté, écrit à sa sœur Lapa pour se plaindre de ses difficultés. Pourtant, il lui confie également sa volonté d'organiser une réception qu'il donnera pour la Cour dans son château de Nocera à l'automne 1357 (É.-G. Léonard, Histoire de Jeanne Ière, t. III, p. 295).

15 Il est surprenant de voir une relation épistolaire autre que protocolaire se nouer entre une dame et son gendre. Leurs lignages sont originaires d'une même région et leurs intérêts sont semblables, peut-être est-ce l'une des explications.

16 « A la partita nostra di Cifalonia lassammo la duchessa, e le nostre figlie star bene, et ogni giorno ne aspettiamo novelle: Preghemovi, che ne scriviate novelle di vostro stato, che noi semo assai desiderosi d'udirne spesso buone novelle a consolatione di noi ». Voir l'intégralité de la lettre dans A. Luttrell, "Aldobrando Baroncelli in Greece : 1378$1382 »$, p. 276-277.
} 
réconfort, non négligeable dans une période difficile, apparaît et concerne aussi bien les ascendants, les descendants que les collatéraux: on voit poindre là l'intérêt pour une vaste parentèle ${ }^{17}$.

De plus, pour les historiens, les lettres sont indispensables quand il s'agit d'étudier la mentalité des nobles moréotes. Leur quotidien, leurs angoisses, leurs sentiments ou encore leurs humeurs permettent d'éclairer différemment les structures familiales jusqu'alors évoquées en filigrane dans les sources narratives. Les lignages, déjà étroitement unis par des alliances matrimoniales, voient leur cohésion renforcée par la correspondance, qui sert de lien entre les différents groupes : à l'image des relations entre les Tocco et les Acciaiuoli, ou encore entre les Acciaiuoli et les Buondelmonti18. Malgré la dominante économique ou politique, les thèmes peuvent être parfois plus personnels, au détour d'une formule toute faite; et le plus souvent, il s'agit de prendre des nouvelles des proches restés en Occident, proches dont les lignagers moréotes sont éloignés depuis longtemps. Toutefois, le principal motif de ces relations épistolaires, en termes d'occurrences, reste les considérations politiques, qui sont au cœur des préoccupations de ces nobles moréotes.

\section{Dévoiler les ambitions politiques}

Il faut certainement voir dans l'intérêt grandissant pour les relations épistolaires au XIV e siècle la corrélation entre le développement de l'apprentissage de l'écrit et l'arrivée parmi les familles moréotes de souches marchandes ayant, bien avant la noblesse, développé un intérêt pour la lecture et l'écriture ${ }^{19}$. Le patriciat urbain italien, qui s'est inspiré des pratiques nobiliaires et qui est devenu noble en Morée, a toutefois conservé sa spécificité dans de nombreux domaines.

Mieux comprendre la place des échanges épistolaires dans le système politique du temps passe notamment par l'analyse des lieux de rédaction et des destinataires. En cela, on se rend compte que le lieu du pouvoir en cette fin du XIVe siècle est bien Corinthe, verrou du

\footnotetext{
17 I. Ortega, Les lignages nobiliaires dans la Morée latine (XIII'-XVe siècle), p. 118 et suiv.

${ }^{18}$ A. Luttrell, « Aldobrando Baroncelli in Greece : 1378-1382 » p. 275-276.

19 J. Favier, De l'or et des épices. Naissance de l'homme d'affaires moderne au Moyen Âge, p. 428-429.
} 
Péloponnèse, détenue par les Acciaiuoli, et non plus la capitale choisie par les conquérants occidentaux au XIII siècle, Andreville.

En ce qui concerne les destinataires, nous retrouvons les plus puissants des lignagers restés en Italie ou venus occasionnellement en Morée, informés ainsi de la situation politique complexe de cet État. Il en est ainsi de Donato Acciaiuoli, qui fut un temps gouverneur de Corinthe, avant de devenir gonfalonier de Florence. Il reste en quelque sorte au centre de ce réseau.

Autres actrices incontournables de ce réseau d'échanges épistolaires, les femmes, qui apprécient ce mode de correspondance. Elles servent d'intermédiaire familial pour dispenser ou recevoir des informations de leurs proches. C'est le cas de Maddalena Buondelmonti, dame de Céphalonie, qui entretient toujours des relations avec ses proches restés en Italie. Dans une lettre de 1388, la veuve du comte de Céphalonie et de Zante relate les activités de son frère, despote de Ioannina, à un cousin ${ }^{20}$. À travers une lettre datée du 25 mars 139321, son rôle de médiatrice auprès de son lignage apparaît : la régente s'emploie à décrire la situation des Acciaiuoli de Corinthe à leur parent Donato, resté à Florence ${ }^{22}$. C'est une tâche particulièrement difficile, car la situation politique de ce Nord-Est de la principauté est complexe, perturbée par le jeu politique des Serbes et Albanais.

Une autre dame épistolière est mentionnée dans les sources : Agnese Acciaiuoli, femme de Nerio Acciaiuoli (seigneur de Corinthe et duc d'Athènes) qui, dans une lettre datée de 1389, annonce à son beau-frère l'emprisonnement de son mari par des troupes mercenaires ${ }^{23}$. La concision du message (onze lignes), qui tranche avec les épanchements sentimentaux d'autres lettres, ne laisse pas de place au superflu : l'information principale est l'essence même du courrier.

Si ce n'est pour évoquer les difficultés sentimentales des uns et des autres, les sujets de ces missives sont ainsi souvent d'ordre politique. En cette fin de XIVe siècle, les querelles entre Latins (Vénitiens, seigneurs moréotes, Catalans) sont quelque peu éclipsées par

\footnotetext{
${ }^{20}$ J. Chrysostomidès, Monumenta Peloponnesiaca, p. 89.

${ }^{21}$ Ibid., p. 231.

22 J. Chrysostomidès, «Italian women in Greece », p. 122-127.

${ }^{23}$ Ibid., p. 119.
} 
l'avancée des Turcs dans les Balkans, thème développé dans plusieurs lettres échangées entre nobles au pouvoir. En 1394, Sismonda Acciaiuoli donne des nouvelles à son frère Donato de leur frère Nerio, aux prises avec les Turcs ${ }^{24}$. Le même jour, une autre lettre est adressée par Nerio à son frère Donato sur le même sujet ${ }^{25}$. Cela reflète bien l'angoisse générée par l'avancée turque. Le caractère bref des missives montre l'urgence de la situation : nul besoin de prendre les formes. La période pour laquelle nous avons le plus de documents épistolaires est la fin du XIVe siècle : une époque particulièrement troublée, durant laquelle trois forces sont en présence dans la péninsule du Péloponnèse : les Latins, les Grecs et les Turcs. Les lettres à motif politique s'enchaînent.

Outre la présence d'ennemis aux frontières, un autre sujet d'importance apparaît: le népotisme - car il n'y a pas d'autre mot pour qualifier l'acte par lequel les lignages nobiliaires placent leurs lignagers au faîte du pouvoir temporel et spirituel. Convoiter l'évêché de Patras, dont le tenant est le primat de Morée, relève de la stratégie, et on peut voir cela dans la lettre d'Angelo Acciaiuoli26, cardinal de Florence, adressée à son frère Donato : cette famille est très bien implantée de part et d'autre de l'Adriatique et réfléchit à de nouvelles possibilités d'accroître son pouvoir.

Les dirigeants croyaient en la vertu magique de la parole, dite ou écrite : d'où le recours permanent à la lettre et l'effort récurrent pour écrire et réécrire la loi, parce que trouver le mot juste permettait d'apaiser les tensions et les passions, et de rétablir la concorde. En cela, la lettre peut être vue comme un outil du pouvoir.

Le réseau épistolaire est également l'occasion de demander conseil aux proches, à l'image de Nerio Acciaiuoli, qui se confie à son frère Angelo à propos du mariage de sa fille en $1384^{27}$. Cette union a un objectif politique avant tout: il s'agit de se rapprocher $d u$ despotat grec de Morée en unissant Bartolomea, fille aînée de Nerio, à Théodore Paléologue, despote de Morée. D'ailleurs cette alliance, qui se veut fédératrice, sera davantage source de litiges ${ }^{28}$. Les stratégies matrimoniales sont des affaires éminemment

\footnotetext{
${ }^{24}$ J. Chrysostomides, Monumenta Peloponnesiaca, p. 255-256.

25 Ibid., p. 257.

${ }^{26}$ Ibid., p. 267-268.

${ }^{27}$ Ibid., p. 51.

${ }^{28}$ Le mariage est tout de même célébré au printemps ou à l'été 1384. Mais la confession orthodoxe du nouvel époux provoque les passions dans le lignage Acciaiuoli. Bartolomea est assez rapidement déshéritée par son
} 
politiques au sein de ces lignages nobles; nul besoin d'en douter quand on les étudie de près $^{29}$. L'approche officieuse et la démarche officielle se complètent de la sorte dans bien des domaines.

Si les unions interconfessionnelles sont amplement utilisées dans la principauté, il n'en est pas de même en Occident, où elles restent hors normes. À ce titre, elles sont révélatrices de l'état d'esprit des parents éloignés devant une action jugée négativement. Lorsque Nerio Acciaiuoli marie sa fille Bartolomea à Théodore Paléologue en 1388, le mariage mixte semble entré dans les mœurs, du moins en Morée. Pourtant, une lettre permet de souligner à quel point cette union soulève des critiques, tant dans le camp catholique que dans le camp orthodoxe. Le seigneur de Corinthe inscrit ce choix dans la lignée des unions de grands souverains précédents qui ont épousé des Grecques sans que cela soit considéré comme hérétique pour autant, que ce soit Louis Fadrique d'Aragon, marié à Hélène Cantacuzène; Anna de Savoie, mariée à l'empereur Andronic III ; Théodore Laskaris, marié à Marie de Courtenay; et enfin Guillaume de Villehardouin, marié à Anne d'Épire ${ }^{30} . .$. Bien qu'incomprises en Italie, ces unions indigènes sont tout à fait communes dans la principauté de Morée, et d'ailleurs les mariages grecs dans le lignage des Acciaiuoli se perpétuent au-delà du XIVe siècle. Certes, Nerio se marie avec une Italienne, Agnese de Saraceni ; mais Antonio, son fils naturel, est issu de sa liaison avec une Grecque, Maria Rendi. Antonio, quant à lui, se marie avec Maria Melissène, contractant une union grecque, comme sa demi-sœur Bartolomea Acciaiuoli. Il en est de même pour l'un de ses successeurs, Franco Acciaiuoli, qui épouse une fille de Démétrius Asan $^{31}$. Ainsi, le choix d'un conjoint grec ne constitue pas une exception dans le milieu nobiliaire moréote.

père pour éviter une progression grecque sur le sol moréote (J. Chrysostomidès, «An unpublished letter of Nerio », p. 120-122).

${ }^{29} \mathrm{I}$. Ortega, Les lignages nobiliaires dans la Morée latine (XIIIe-XVe siècle), p. 181 et suiv.

${ }^{30}$ J. Chrysostomidès, Monumenta Peloponnesiaca, p. 52-53 : «Ch'i'o udito che re di Ragona e conte di Savoia e conte di Franda e lo prenze di questa Morea ànno fatto parentado con issi e non li tenevano per eretici, a questo vi fo fine per vostra consolazione » : «J'ai entendu dire que le roi d'Aragon, le comte de Savoie, le comte de Flandre et le prince de Morée ont noué une telle parenté, et ils ne les tenaient pas pour hérétiques, si cela peut être votre consolation.» 31 I. Ortega, Les lignages nobiliaires dans la Morée latine (XIIIe-XVe siècle), p. 191. 
On le voit bien à travers ces quelques exemples, en rien exhaustifs, mais tout de même démonstratifs : le fait d'écrire est un acte de gouvernement. Demander conseil à ses proches, les informer, requérir leur soutien, sont autant d'actes qui renforcent la cohésion lignagère, mais qui au-delà assoient les ambitions politiques des plus déterminées.

Si les considérations politiques et stratégiques occupent une place importante dans les missives échangées par les nobles moréotes, c'est également l'occasion pour eux de revenir sur des sujets plus légers, au premier rang desquels les réjouissances, qu'ils affectionnent particulièrement.

\section{Partager le goût pour les divertissements}

En effet, les thèmes développés dans les lettres ne relèvent pas toujours du registre de la gravité. C'est plus rare, mais nous avons également la trace de considérations plus légères, comme par exemple la chasse, restée le divertissement martial par excellence. Sa pratique remonte à la nuit des temps et elle apparaît déjà chez les Francs comme un trait de culture réservé à l'aristocratie ${ }^{32}$; d'ailleurs, l'acte cynégétique lui-même est un véritable acte politique ${ }^{33}$. Dans la principauté de Morée, les plaisirs de la chasse sont connus et appréciés par le groupe nobiliaire, notamment durant les périodes de paix, qui sont l'occasion de mener une vie de distractions et de loisirs. Les chevauchées mentionnées dans les sources narratives peuvent être rapprochées de la chasse, car il est certain que les plaisirs qu'elle procure n'en sont pas exclus, la chasse étant devenue à l'époque féodale le seul grand rituel laïque permettant aux puissants de dominer l'espace par leurs déplacements ${ }^{34}$. C'est un moyen de distraction très prisé en outre par le baronnage, et la Chronique de Morée décrit cette pratique ${ }^{35}$.

L'art de la cynégétique s'est donc développé en Morée, et des constantes se dégagent visà-vis de l'Occident. La chasse se pratique tout d'abord en «bonne compaignie de gent » ainsi qu'avec une meute de chiens de chasse, parfois des lévriers, ou avec des faucons,

\footnotetext{
${ }^{32}$ F. Guizard-Duchamp, «L'Homme et les espaces du sauvage dans le monde franc », p. 441-444.

${ }^{33} \mathrm{Ibid} .$, p. 447 : la démonstration de bravoure confirme le souverain dans son rôle.

${ }^{34}$ A. Guerreau, «Chasse », dans J. Le Goff (éd.), Dictionnaire raisonné de l'Occident médiéval, p. 172.

${ }^{35} \mathrm{~J}$. Longnon, Le Livre de la conqueste de la princée de l'Amorée, p. 1002 : « [...] Et il s'aloit par le pays, deduisant en chasses et en rivieres, et se donnoit bon temps ».
} 
dont le dressage est un art particulièrement prisé, comme à Chypre ${ }^{36}$. Plusieurs échanges épistolaires permettent de mesurer l'attrait de certains seigneurs pour cette distraction : $c^{\prime}$ est le cas d'Antonio Acciaiuoli au début du XVe siècle ${ }^{37}$. On y apprend que l'engouement cynégétique est partagé par les plus grands seigneurs. C'est également un sujet prisé des Catalans qui, en dehors des thèmes politiques, évoquent cette activité. Ainsi, en 1382 des faucons et des lévriers de Turquie font partie des cadeaux diplomatiques échangés entre l'infant Jean et le vicomte Rocaberti ${ }^{38}$, mais la missive qui évoque cela est surtout intéressante car elle décrit de façon relativement précise les races de faucons. Sont donc transmis des faucons sacres, pèlerins et « munterins $^{39}$ ». La première catégorie regroupe des rapaces très appréciés par les Orientaux, et au contraire peu connus des Occidentaux, car il faut les importer, ce qui limite leur diffusion. Les pèlerins, quant à eux, sont les faucons de chasse par excellence, et ils sont plus familiers des Occidentaux. Enfin, le faucon désigné par le terme montanarius dans les sources, et décliné en de nombreuses variantes dans les langues romanes, est un rapace indigène d'Europe centrale, nichant dans les rochers, d'où son appellation ${ }^{40}$. Sont donc utilisés des oiseaux connus en Occident, d'autres qui sont indigènes, et enfin des rapaces venus d'Orient. À travers ce cas, on remarque que la Morée est une zone de contact entre différentes cultures, et la fauconnerie représente à sa manière le réceptacle où se mêlent des influences diverses.

Nous trouvons un autre témoignage de ce statut particulier de la Morée, entre Orient et Occident, dans un tout autre domaine. Dans une lettre datée du 13 décembre 1423, un certain Uberto prie Nerio Acciaiuoli de l'appuyer auprès de ses parents, le duc Carlo Tocco, de Leucade, et le duc Antonio, d'Athènes, pour qu'il puisse aller en Grèce donner des lectures de législation, de logique, de philosophie naturelle ou morale, ou de

${ }^{36}$ Ibid., p. 676 ; P. Edbury, « Franks », p. 83.

${ }^{37}$ J.-A. C. Buchon, Nouvelles recherches historiques, t. II, p. 271-273.

38 A. Rubió I Lluch, Dipomatari de l'Orient català, p. 564 : « Carta de l'infant Joan al vescomte de Rocaberti demanant-il noves sobre la seva estada a Grecia i que li trameti falcons i llebrers de Turquia » : « Charte de l'infant Joan au vicomte Rocaberti lui demandant des nouvelles de Grèce et de s'occuper des faucons et des lévriers de Turquie ».

${ }^{39} \mathrm{Ibid} .$, p. $564:$ : [...] que ns trametats falcons sacres palegrins e munterins » : «[...] que l'on s'occupe des faucons sacres, pèlerins et "montanarius" ».

${ }^{40}$ B. Van Den Abeele, La fauconnerie au Moyen Âge, p. 65-71. 
médecine dans leurs cours ${ }^{41}$. Ce témoignage reste exceptionnel, mais il démontre tout de même l'intérêt porté à la culture par certains seigneurs moréotes. Inspirés par l'humanisme en ce XVe siècle, ils souhaitent entretenir des cours à l'image de celles que l'on trouve en Italie ${ }^{42}$. Les lignages nobiliaires de Morée entretiennent donc les mêmes goûts que leurs contemporains en Occident, et les lettres symbolisent les liens qui sont tissés de part et d'autre de l'Adriatique.

On ne dispose pas pour le Moyen Âge de travaux d'ensemble sur le genre épistolaire ; en cela, cet ouvrage apporte de l'eau au moulin de la connaissance, même fragmentaire, de cette thématique ${ }^{43}$. En effet, les échanges épistolaires rythment la vie quotidienne des lignages moréotes peut-être dès le XIII siècle, et plus encore au XIVe siècle. Informer les siens, quels que soient les thèmes développés, est un acte qui apparaît anodin et qui, pourtant, permet à l'historien de prendre la mesure de la cohésion lignagère et d'enrichir toute une réflexion axée sur l'anthropologie historique. La structure du lignage, au plus près de la réalité quotidienne, y est évoquée, et cela permet d'appréhender le cadre de vie des nobles moréotes et leurs relations, car il s'agit bien de cela. La solidarité qui apparaît à travers les échanges de lettres semble être une continuité des pratiques italiennes en territoire moréote ; toutefois, elle ne suffit pas à effacer tous les contentieux. Loin s'en faut. Malgré une entente qui unit le plus souvent les lignagers, les différends peuvent prendre une tournure critique et la correspondance n'y changer rien.

La lettre apparaît ainsi comme une façon comme une autre d'asseoir son pouvoir et celui des siens. La noblesse moréote, à l'instar de la noblesse occidentale, semble intéressée par des thématiques récurrentes qui en font un relais de l'Occident dans les Balkans.

\footnotetext{
${ }^{41}$ J.-A. C. Buchon, Nouvelles recherches historiques, t. II, p. 276-277.

${ }^{42}$ I. Ortega, «L'évolution de la conception patrimoniale », p. 133-136.

${ }^{43}$ Cette absence de travaux d'envergure sur les relations épistolaire au Moyen Âge est démontrée par B. Dumézil, qui veut en faire son champ de recherche : B. Dumézil, L. Vissière (dir.), Épistolaire politique, vol. I : Gouverner par les lettres, p. 9.
} 


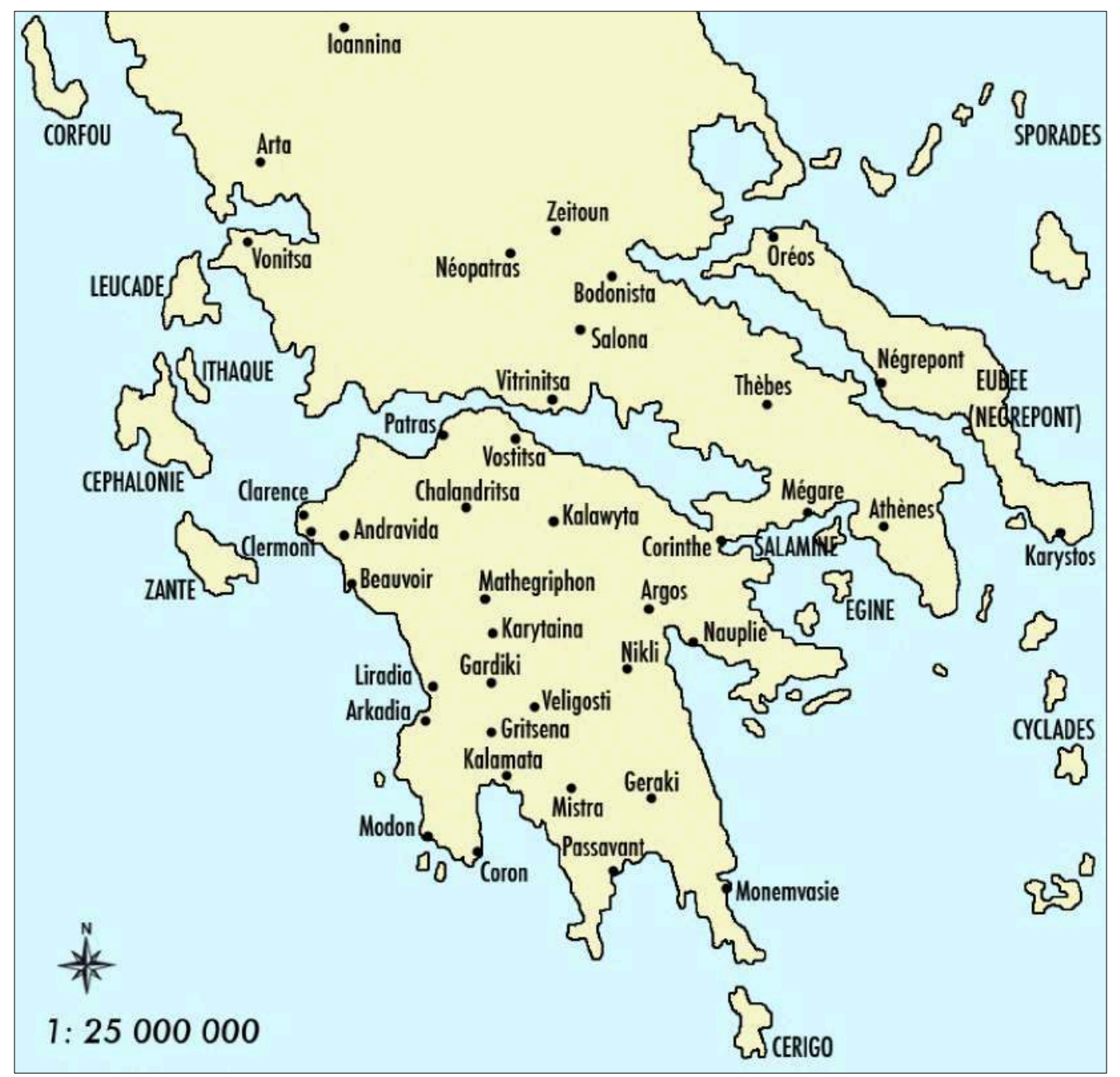

Fig. 1. - Les places fortes de la Morée latine (XII - XIVe siècle). Doc. I. Ortega. 


\section{Bibliographie}

ANGOLD Michael J., The fourth Crusade : event and context, Edimbourg, Routledge, 2003.

BoN Antoine, La Morée franque : recherches historiques, topographiques et archéologiques sur la principauté d'Achaïe (1205-1430), Paris, de Boccard, 1969, 2 vol.

BuCHON Jean-Alexandre C., Nouvelles recherches historiques sur la principauté de Morée et ses hautes baronnies, fondées à la suite de la quatrième croisade; t. I: Investigation des archives et bibliothèques de Toscane, Naples, Sicile, Malte, Corfou; t. II : Diplômes relatifs aux hautes baronnies franques extraits des archives et bibliothèques de Toscane, Naples, Sicile, Malte, Corfou, Paris, Renouart, 1843-1845.

Chantraine Pierre, Dictionnaire étymologique de la langue grecque : histoire des mots, Paris, Klincksieck, 1999 (1'̀re éd. 1968).

CHRYsostomidÈs Julian, "An unpublished letter of Nerio (30 october 1384) », Byzantina, t. VII, 1975, p. 111-123.

CHrYsostomidès Julian, «Italian women in Greece in the late fourteenth and early fifteenth centuries », Rivista di Studi Bizantini e Slavi, II, 1982, p. 119-132.

CHrYSOSTOMIDÈs Julian (éd.), Monumenta Peloponnesiaca: documents for the history of the Peloponnese in the $14^{\text {th }}$ and the $15^{\text {th }}$ centuries, Camberley, Porphyrogenitus, 1995.

DuMÉZIL Bruno et VISSIÈRE Laurent (dir.), Épistolaire politique, vol. I: Gouverner par les lettres, Paris, Presses universitaires Paris-Sorbonne, 2014.

EDbury Peter, «Franks», dans A. Nicolaou-Konnari et C. Schabel (éd.), Cyprus, society and culture : 1191-1374, Leiden, Brill, 2005, p. 63-102.

FAVIER Jean, De l'or et des épices. Naissance de l'homme d'affaires moderne au Moyen Âge, Paris, Fayard, 1987.

Guerreau Alain, "Chasse », dans Le Goff J. (éd.), Dictionnaire raisonné de l'Occident médiéval, Paris, Fayard, 1999, p. 166-177.

GUIZARD-DUCHAMP Fabrice, «L'homme et les espaces du sauvage dans le monde franc: Ve-IXe siècle », thèse de doctorat, université Paris I, Lille, ANRT, 2004. 
LÉONARD Émile-G., Histoire de Jeanne İ̀re, reine de Naples, comtesse de Provence (1343-1382),

t. III : Pièces justificatives, Paris, Presses universitaires de France, 1936.

LONGNON Jean (éd.), Le Livre de la conqueste de la princée de l'Amorée : chronique de Morée (1204-1305), Paris, Laurens, 1911.

LUTTRELl Anthony, «Aldobrando Baroncelli in Greece : 1378-1382 », Orientalia Christiana Periodica, XXXVI, Rome, 1966 ; repris dans A. Luttrell, Latin Greece, the Hospitallers and the Crusades : 1291-1440, Londres, Ashgate, 1982, p. 273-300.

Muntaner Ramon, Les Almogavres: l'expédition des Catalans en Orient, Toulouse, Anacharsis, 2002.

ORTEGA Isabelle, Les lignages nobiliaires dans la Morée latine (XIII-XVe siècle) : permanences et mutations, Turnhout, Brepols, 2012.

ORTEGA Isabelle, «L'évolution de la conception patrimoniale: l'exemple d'Athènes durant l'occupation latine », dans Ortega I. (éd.), Les villes antiques et médiévales: patrimoines matériels et immatériels, Paris, Léopard d'or, 2013, p. 121-137.

RuBió I LLUCH Antoni, Diplomatari de l'Orient català (1301-1409) : collecció de documents per a la història de l'expedició catalana a Orient i dels ducats d'Atenes i Neopàtria, Barcelone, Institut d'estudis catalans, fac-similé 2001 (1re éd. 1947).

VAN DEN ABEELE Baudoin, La fauconnerie au Moyen Âge. Connaissance, affaitage et médecine des oiseaux de chasse d'après les traités latins, Paris, Montbel, 1994.

\section{Résumé}

Quand on étudie la principauté de Morée, sorte de maillon entre l'Occident et l'Orient au Moyen Âge, ce ne sont certainement pas les lettres que l'on examine de prime abord. En effet, celles-ci sont rares au regard des autres types de sources historiques; elles sont pourtant riches en enseignements, notamment pour étudier le milieu nobiliaire. En effet, les écrits personnels traduisent la pensée d'une époque, d'où l'intérêt pour l'historien de retrouver là une trace de la vie quotidienne des nobles moréotes. Cependant, les lettres ne peuvent pas être l'unique source de réflexion historique, car l'analyse des discours peut révéler des contradictions. Ainsi, au-delà d'une simple conversation mise par écrit, nous étudierons le langage, notamment à travers l'adaptation du style au destinataire. Car 
finalement, la fonction de ces lettres n'est-elle pas de servir la cohésion des lignages, de consolider leur pouvoir? 



\section{TABLE DES MATIÈRES}

Introduction

Bernadette Cabouret.

D'hier à demain : la mise à jour du dictionnaire provençal-français de Frédéric Mistral

Pierrette Bérengier.

L'éclectisme du style dans le " canard » au XIXe siècle

Philippe Nieto.

Balzac et l'argot:

enjeux littéraires autour du roman populaire

Louis Bergès.

L'œuvre provençale de Castil-Blaze,

précurseur du mouvement félibréen

Roger Klotz

Les détails occultés : la correspondance de l'écrivain occitan

Jean-Baptiste Fabre et de son neveu Favre de Saint-Castor au prisme de l'honneur et de l'identité (1774-1782)

Danielle Bertrand-Fabre...

La correspondance diplomatique de la Renaissance comme document historique? Les lettres de Georges de Selve, ambassadeur à Rome (1537-1538)

Nicole Lemaitre.

Un Rouennais aux états généraux de 1789 :

Pierre Nicolas de Fontenay

Anne Mézin.

Les relations épistolaires au sein des lignages nobiliaires :

comment user de la plume pour consolider son pouvoir en Morée au Moyen Âge

Isabelle Ortega... 